\title{
The British Society of Gastroenterology
}

The Annual Meeting of the Society was held from 28 to 30 September 1983 at the University of York under the presidency of Professor J E Lennard-Jones. One hundred and twelve communications (including 43 posters) were selected for presentation in the scientific programme; the abstracts are printed below. Further details of the meeting appear on p. 966.
ENDOSCOPY

T1-5

T1

Pancreatic orifice sphincterotomy; experience from 15 centres

P B CotTon (Department of Gastroenterology, The Middlesex Hospital, London) Fifteen centres with experience of more than 15000 endoscopic sphincterotomies have pooled data on sphincterotomy of the pancreatic duct orifice, in patients with pancreatitis. Technical success was reported in 64 cases: extraction of pancreatic stones (18); main pancreatic orifice stennosis (23); accessory sphincterotomy in pancreas divisum (15); acute alcoholic pancreatitis (three); prostheses in chronic pancreatitis (four); before duct occlusion (one). Most groups used short diathermy wires, and usually also performed a biliary orifice sphincterotomy; few left splinting tubes in place. Eight patients developed pancreatitis after pancreatic sphincterotomy (including one pseudocyst which required percutaneous drainage), but there were no reported deaths. Clinical results were difficult to assess because many patients were alcoholic, and because follow up was relatively short. Attempts to extract pancreatic duct stones were successful in only $25 \%$ of attempts, and several of these patients developed further stones. Accessory sphincterotomy is technically difficult, but encouraging short term results justify further evaluation. Several groups are assessing the use of balloon dilatation at the main and accessory papilla. Five patients with pseudocysts have been treated successfully by endoscopic drainage into the stomach or duodenum.
$\mathrm{T} 2$

Controlled trial of Nd YAG laser photocoagulation in bleeding peptic ulcers

C P SWAIN, S G BROWN, P R SALMON, J S KIRKHAM, AND T C NORTHFIELD (Department of Gastroenterology, University College Hospital and Norman Tanner Gastroenterology Unit, St James' Hospital, London) The efficacy of Nd YAG laser photocoagulation in the endoscopic control of haemorrhage from peptic ulcers was tested in a controlled trial at two centres in London. Three hundred and ninety three unselected patients admitted consecutively with upper gastrointestinal haemorrhage underwent emergency endoscopy. Peptic ulcers were seen in 196. All 104 with stigma of recent haemorrhage (SRH) accessible to laser therapy were included in the trial $(20$ inaccessible, 72 had no SRH). Prospective stratification was in three groups - those with a visible vessel, those with other SRH and those in which the clot could not be washed off before therapy. Within each group, ulcers were randomised to conventional management with or without endoscopic laser therapy. Laser and control groups were well matched for other factors known to influence prognosis. Overall, 4/51 laser treated patients and $21 / 53$ control patients rebled $(p<0 \cdot 0005)$. Considering ulcers with a visible vessel, $4 / 9$ treated but $18 / 32$ controls rebled $(p<0.005)$. Considering other SRH, 0/13 treated and 1/11 controls rebled (NS) and with overlying clot, $0 / 9$ treated and $2 / 10$ controls rebled. Of those patients with active bleeding at endoscopy, $2 / 14$ treated rebled while $8 / 13$ controls rebled $(p<0.05)$. Four out of 51 treated but $17 / 53$ controls required emergency surgery $(p<0 \cdot 005)$. One treated patient but eight control patients died after an episode of rebleeding A967 $(p<0.05)$. These results suggest that the $\mathrm{Nd}$ YAG laser has significantly reduced the rebleeding rate and need for emergency surgery in patients with bleeding peptic ulceration and SRH accessible to laser therapy and confirm that endoscopic laser therapy can reduce mortality from this condition.

T3

Endoscopic control of peptic ulcer haemorrhage using the 'heater probe'

D W STOREY (Department of Surgery, University of Sydney, NSW, Australia)

The place of endoscopic control of peptic ulcer haemorrhage remains difficult to determine, even by controlled trial. In this study the author has taken the pragmatic approach of restricting the method to old or unfit patients who were already anaesthetised for an emergency operation which was warranted because of continued bleeding or rebleeding in hospital. The servocontrolled electrocautery probe was used via a large channel forward viewing endoscope.

Over a period of 20 months there were 15 patients with gastric ulcer, with a mean age of 60 years and mean pretreatment blood transfusion requirement of 6.6 litres. All but one of the 15 avoided immediate operation and only two of the rest had delayed bleeding. One of these two required operation. There were no deaths in this group. Over the same period there were 10 patients with duodenal ulcer with a mean age of 62 years and mean pretreatment blood transfusion requirement of 5 litres. Operation was avoided in only two patients, of whom one had a small delayed haemorrhage treated conservatively: Of 
the rest, the technique failed in three because access was impossible owing to bleeding, in three contact was possible but unsuccessful and there were two in whom initial success was followed by delayed haemorrhage necessitating operation. Three patients died during that admission.

One further patient with a large oesophageal ulcer was treated after 15 litres of blood transfusion. Treatment was successful and there was no further haemorrhage.

It would appear that this technique can usually replace emergency operation in patients with bleeding gastric ulcer, but only occasionally in those with duodenal ulcer.

\section{T4}

Preliminary clinical experience with an endoscopic Döppler ultrasound device in GI haemorrhage

D E BECKLY AND M P CASEBOW (Plymouth General Hospital, Devon) The equipment consists of a small cylindrical transducer connected by coaxial cable to a modified Sonicaid vascular flow detector producing continuous ultrasound emission at $8 \mathrm{MHz}$. The transducer can be passed down the biopsy channel of most standard endoscopes and the presence of an artery is detected by Döppler frequency shift. Sixtytwo ulcers have been examined in 60 patients. All patients presented with haemetemesis or melaena from peptic ulcer. In each case the presence or absence of a sharply localised arterial signal from the ulcer base was recorded. The type of visual stigmata present was also recorded and the patients subsequent course was followed to discharge or death.

Thirteen of 62 ulcers rebled sufficiently to require surgery and/or lead to death. Of these 11 were Döppler + ve $(85 \%)$. Fortynine ulcers did not rebleed. Thirty of these were Döppler - ve $(76 \%)$. The absence of a Döppler signal had good predictive value as only $5 \%(2 / 39)$ of Döppler - ve ulcers rebled. The relationship of visual stigmata to the risk of rebleeding is examined.

The Döppler device is clinically useful in predicting the risk of serious rebleeding from peptic ulcers the results in this preliminary study achieving significance at the $0.1 \%$ level. Used in conjunction with endoscopic haemostatic devices such as the laser or heater probe the Döppler shows promise in guiding the monitoring therapy.
T5

Balloon dilatation of papillae and ducts at ERCP

P B COTTON AND J W C LEUNG (Department of Gastroenterology, The Middlesex Hospital, London) This presentation illustrates the potential uses of angioplastytype balloon dilatation catheters, which are now available for endoscopic use. We have used balloons of 6 and $8 \mathrm{~mm}$ diameter (mainly $4 \mathrm{~cm}$ long), over 0.035 inch Teflon coated guide wires, through Olympus JF1T and JF3.7T endoscopes. Indications have included: biliary orifice stenosis (nine), removal of small stones without sphincterotomy (two), benign postoperative bile duct strictures (four), (of which two had stones above), cholangiocarcinoma (one), stenosed choledochoduodenostomy (two), pancreatitis with pancreatic orifice stenosis (six) (main papilla two, accessory four). Successful placement and dilatation was achieved in 18 of the 24 patients. There were no serious complications; both patients having balloon dilatation of the main pancreatic orifice had mild exacerbations of pancreatitis. Follow up is short but initial experience is encouraging in patients with definite strictures and stones.

\section{LIVER}

T6-19

T6

d-penicillamine in primary biliary cirrhosis: preliminary results of an international trial

J NEUBERGER, E CHRISTENSEN, H POPPER, B PORTMANN, J CABALLERI, J RODES, L RANEK, N TYGSTRUP AND ROGER WILLIAMS (Liver Unit, King's College Hospital, London and Rigshospitalet, Copenhagen, Denmark and Hospital Clinic $i$ Provencial, Barcelona, Spain) A multicentre, prospective randomised placebo controlled trial of d-penicillamine, $1200 \mathrm{mg}$ daily, in primary biliary cirrhosis (PBC) was set up in January 1978. One hundred and eighty nine patients were entered of whom 98 received the active drug. Patients were randomised separately, by sex, at each of the three centres, and were entered at all stages of the disease. There was no difference between the treated and placebo groups at entry in any of the clinical, serological or histological features and the proportion of asymptomatic patients was similar. Patients were followed up by six monthly assessments and annual liver biopsies.

Of the 98 patients taking d-penicillamine, 35 withdrew from the trial and 40 patients died during the follow up period, 18 of whom were taking d-penicillamine. The annual mortality rate was approximately $10 \%$ in each group. Cumulative mortality rates both in those who were allocated to receive d-penicillamine and in those who were not withdrawn were similar to the cumulative mortality rates in the placebo group. Although d-penicillamine did not prevent progression of early to late stages of the disease, those who received d-penicillamine in histological stage $1 / 11$ had a lower mortality rate compared with the comparable placebo group $(p=0 \cdot 21)$. There was no significant difference between those on placebo and active drug in any of the biochemical and investigation parameters measured, except the alanine transaminase levels were greater in those on d-penicillamine.

These results suggest that d-penicillamine is of little therapeutic benefit in $\mathrm{PBC}$ although longer study is required to determine its effect in early disease.

\section{T7}

\section{Survival in alcoholic liver disease}

W S HISLOP (Division of Medicine, Royal Alexandra Infirmary, Paisley, Scotland) Five hundred and ten patients with biopsy proven alcoholic liver disease were studied in eight centres in Scotland as a collaborative project by the Caledonian Society of Gastroenterology. One aspect studied was analysis of survival. Thirty patients died on initial admission, the initial mortality being higher in women than in men $(11 \%$ vs $5 \%$; $\mathrm{p}<0.05)$. Forty eight patients were lost to follow up. Using hospital records and death certificates returns survival data were collected on the remaining 432 patients (332 men and 100 women). The overall one year survival was $87 \%$ and five year survival $72 \%$. One year survival was not influenced by the patient's sex or the presenting liver histology. Five year survival was not influenced by the patient's sex. Five year survival, however, was better $(82 \%, \mathrm{p}<0.001)$ in the 196 patients with alcoholic fatty liver, and worse $(54 \%$, $\mathrm{p}<0.001)$ in the 67 patients with active 
cirrhosis. Patients with alcoholic hepatitis and those with inactive cirrhosis had a five year survival similar to the overall figures. Patients with decompensated liver disease at presentation had a higher initial mortality than those with compensated liver disease $(17 \%$ vs $2 \%$; $\mathrm{p}<0.001)$, a lower one year survival (76\% vs $92 \%$; $\mathrm{p}<0.001)$, and five year survival $(51 \%$ vs 83\%; $\mathrm{p}<0.001)$. Total abstention from alcohol had no influence on the survival rates.

\section{T8 \\ What determines the severity of alcoholic liver injury?}

J B SAUNDERS, A D WODAK, R D JOHNSON, A HAINES, $P$ DONALDSON, B R RICCIARDI, $M$ DAVIS, B PORTMANN AND ROGER WILLIAMS (Liver Unit, King's College Hospital, London) To determine what factors have an important influence on the severity of alcohol-related liver damage we have investigated, in a consecutive group of 462 patients with various grades of alcoholrelated liver damage admitted to a single unit, (1) measures of alcohol intake including duration of excessive drinking, mean daily intake, pattern of drinking and degree of alcohol dependence, (2) host factors such as sex, HLA phenotypes and phenotypes of the alcohol-metabolising enzymes ADH and ALDH, and (3) environmental factors including past infection with hepatitis viruses and exposure to hepatotoxic chemicals. The relative contribution of each risk factor was assessed by multiple regression analysis. The most powerful determinants of liver injury (degree of fibrosis and hepatocellular necrosis) were the number of drinking days (>40 $\mathrm{g}$ alcohol) per week $(B=0.27 ; p<0.01)$, the proportion of weeks in the year when consumption exceeded $40 \mathrm{~g} /$ day $(B=0.18 ; p<0.01)$ and duration of drinking $40 \mathrm{~g} /$ day $(B=0 \cdot 16$; $p<0.01$ ); and severity of liver damage was inversely related to the severity of alcohol dependence $(B=-0.18 ; p<0.01)$. Of the host factors, female sex was associated with more severe liver damage $(B=0.13$; $\mathrm{p}<0.05)$ as was the presence of HLA antigens $B 8$ or $B 40(B=0 \cdot 10 ; p<0 \cdot 10)$. Neither $\mathrm{ADH}$ an $\mathrm{ALDH}$ phenotypes nor exposure to hepatitis viruses and hepatotoxins were related to the severity of disease. The maximum multiple correlation coefficient incorporating these factors was $0 \cdot 52$. These results show the primary importance of continuous exposure to alcohol at relatively low levels of dependence in determining the severity of alcohol-related liver injury, with significant but lesser contributions from sex and HLA status.

\section{T9}

Alcoholic liver disease may be mediated by complement activation

R E BARRY AND J D MCGIVAN (Departments of Medicine and Biochemistry, University of Bristol, Bristol) Acetaldehyde is the primary metabolic product of ethanol in the liver and has been suggested as the injurious factor in alcoholic liver disease. We have recently shown that acetaldehyde binds to rat liver plasma membranes without affecting gross membrane function. This finding is compatible with the hypothesis that any acetaldehydeinduced hepatic damage is mediated via an immune response triggered by a change in surface membrane structure and not via direct metabolic toxicity. The present study investigates the binding of acetaldehyde to human liver plasma membranes and the effect of this binding on complement $\left(C_{3}\right)$ activation. Human liver plasma membrane vesicles were prepared by ultracentrifugation on discontinuous sucrose gradients. Binding of acetaldehyde to the membranes was studied by reductive methylation of intermediate Schiff base using $\mathrm{H}^{3}$-labelled sodium cyanoborohydride. Complement $\left(C_{3}\right)$ activation by plasma membranes preexposed to acetaldehyde was measured by immunofixation of $\mathrm{C}_{3}$ after electrophoretic separation of native and activated $\mathrm{C}_{3}$ components in $1 \%$ agarose gel then densitometric scanning. Human liver plasma membranes bound $212 \pm 18$ (SEM) nmols acetaldehyde/mg membrane protein. The binding constant was $439 \pm 81$ $\mu \mathrm{M}$. Incubation of normal human liver plasma membrane vesicles in serum caused $6.6 \pm 2.0 \%$ activation of $\mathrm{C}_{3}$. Pre-incubation of plasma membrane vesicles in $1 \mathrm{mM}$ acetaldehyde caused a $150 \%$ increase in $\mathrm{C}_{3}$ activation to $16 \cdot 4 \pm 1.8 \% \quad(\mathrm{t}=3.6196$, $p=0 \cdot 0037$ ).

Acetaldehyde binds to human liver plasma membranes via intermediate Schiff base formation. Adduction of acetaldehyde to human liver plasma membranes activates the complement sequence - a finding compatible with the known histological appearance in alcoholic liver disease.
$\mathrm{T} 10$

Functional immune regulation in alcoholic liver disease

UNA MCKEEVER, C O'MAHONY, C A WHELAN, D G WEIR, AND C FEIGHERY (Departments of Immunology and Clinical Medicine, Trinity College and St James's Hospital, Dublin 8, Ireland) A defect in immune regulation has been implicated in the hypergammaglobulinaemia of alcoholic liver disease (ALD). Imbalances in $\mathrm{T}$ lymphocytes which inhibit (suppressors) or augment (helpers) the immune response have been implicated in various liver diseases.

We have previously studied the relative distribution of peripheral blood $\mathrm{T}$ lymphocyte subpopulations using monoclonal antibodies directed at these subsets. This established that ALD subjects had a significantly increased ratio of helper: suppressor cells $(\mathrm{H}: \mathrm{S})$ compared with that of control subjects. The present study investigates the functional activity of peripheral blood $T$ lymphocytes and $B$ lymphocytes of ALD patients. Two separate assays looked at the function of suppressor $\mathrm{T}$ cells. One assay examined B cell function.

The effect of Con $\mathbf{A}$ induced suppressor $T$ cells in suppressing autologous responses to this mitogen was no different in a group of 15 patients with ALD [\% suppression = $15 \pm 14$ (mean \pm SD)] to that of 11 control subjects $[\%$ suppression $=15 \pm 18$ (mean \pm SD) $]$.

The second assay used involved the production of IgG by a pool of tonsillar B cells co-cultured with patient or control purified $\mathrm{T}$ cells. The results showed no significant difference between the effect of $\mathrm{T}$ cells from 6 patients with ALD [\% suppression $=71 \cdot 3 \pm 5 \cdot 6($ mean \pm SD) $]$ and that of four control subjects [\% suppression $=66 \cdot 3 \pm 11.4($ mean $\pm S D)]$

$B$ cell function was investigated using an assay which measured the spontaneous production of $\operatorname{IgG}, \operatorname{IgA}$, and $\operatorname{IgM}$ by peripheral blood mononuclear cells (PBMCs) of ALD patients, cultured over seven days, using a sensitive enzyme linked immunosorbent assay (ELISA). No significant difference was found between IgG produced by 10 ALD patient PBMCs $[2351 \pm 2370 \mathrm{ng} / \mathrm{ml}($ mean \pm SD)] and eight control subjects $[946 \pm 949 \mathrm{ng} / \mathrm{ml}$ (mean $\pm \mathrm{SD})]$ or IgM produced by nine ALD patient PBMCs [586 $4425 \mathrm{ng} / \mathrm{ml}$ (mean $\pm \mathrm{SD})]$ and nine control subjects $[532 \pm 275 \mathrm{ng} / \mathrm{ml}$ (mean $\pm \mathrm{SD}$ )]. There was, however, a highly significant increase in IgA synthesised by nine ALD PBMCs 
$[1336 \pm 958 \mathrm{ng} / \mathrm{ml}($ mean $\pm \mathrm{SD})]$ compared with that of eight normal healthy subjects $(355 \pm 243 \mathrm{ng} / \mathrm{ml}$ (mean $\pm \mathrm{SD})$ ]

We conclude that the altered $H: S$ ratio of ALD does not cause a defect in immune regulation and is therefore not responsible for the hypergammaglobulinaemia associated with this disease. We suggest that hyperstimulation of the B cells in vivo of ALD patients is responsible for the increased IgA production by ALD PBMCs in vitro.

\section{T11}

Sex differences in the metabolism of ethanol and acetaldehyde

M J P ARTHUR, A LEE, AND R WRIGHT (Department of Medicine, Southampton General Hospital, Southampton) Previous clinical studies suggest that women are more susceptible than men to the toxic effects of ethanol on the liver. The reason for this difference is not known. The aim of this study was to compare the metabolism of ethanol and acetaldehyde between normal male and female subjects after an ethanol load. Twenty healthy age-matched subjects were studied (10 men, mean age 21.9 years; 10 women, mean age 22 years); all had a regular ethanol intake of less than $80 \mathrm{~g} /$ week; each subject received $0.5 \mathrm{~g}$ ethanol/kg body weight intravenously over 75 minutes. Blood samples were taken every 20 minutes for four hours. Blood ethanol an acetaldehyde concentrations were assayed by gas liquid chromatography using a head space technique. Between two and four hours after the start of the infusion women had significantly higher mean concentrations of blood ethanol than men, but a significantly lower apparent volume of distribution of ethanol $(0.564 \pm 0.065 \mathrm{l} / \mathrm{kg}$ vs $0.689 \pm 0.170 \mathrm{l} / \mathrm{kg}$, $\mathrm{p}<0.05)$. There were no differences in ethanol elimination rate (women $0.082 \pm 0.014 \mathrm{~g} / \mathrm{kg} / \mathrm{h}$; men $0.086 \pm 0.019$ $\mathrm{g} / \mathrm{kg} / \mathrm{h})$. There were no significant differences in mean blood acetaldehyde concentrations, but the mean value of the areas under the acetaldehyde time curves (AUC) were significantly greater for men (3.99 $\pm 1.19 \mathrm{mg} / \mathrm{h} / \mathrm{l})$ than for women $(2.64 \pm 1.42 \mathrm{mg} / \mathrm{h} / \mathrm{l} \mathrm{p}<0.05)$. Differences in the apparent volume of distribution of ethanol between women and men may account for the higher concentrations of blood ethanol observed in women. As ethanol elimination rates were similar in both sexes, the observed difference in AUC for acetaldehyde may be due to sex differences in metabolism of acetaldehyde by the liver.

T12

Role of cytosolic aldehyde dehydrogenase in alcoholic liver disease

K MATTHEWSON AND C O RECORD (Gastroenterology Unit, Royal Victoria Infirmary, Newcastle-upon-Tyne) It is now established that hepatic cytosolic aldehyde dehydrogenase is reduced in patients with alcoholic liver disease. Some authors have suggested that this is a primary defect which predisposes towards alcoholic liver disease while others have suggested that it is simply a consequence of alcohol related liver injury.

In order to assess the specificity of this abnormality to alcoholic liver disease we have assayed hepatic cytosolic aldehyde dehydrogenase by a standard spectrophotometric technique in patients with a variety of acute and chronic liver disorders.

The patients studied included primary biliary cirrhosis (six); active chronic hepatitis (five); paracetamol poisoning (four); alcoholic liver disease (10); and normal controls (six). As expected, patients with alcoholic liver disease had significantly reduced enzyme levels $(p<0.001)$. Patients with active chronic hepatitis also had significantly reduced levels $(p<0.01)$ as did patients with paracetamol poisoning $(p<0.01)$. Levels in primary biliary cirrhosis were not significantly different from controls $(p>0 \cdot 1)$.

We conclude that low hepatic cytosolic aldehyde dehydrogenase levels are not specific to alcoholic liver disease, but are a consequence of liver damage from a variety of causes.

\section{T13}

Effect of cyclosporin $A$ on suppressor cell function in vivo and in vitro in primary biliary cirrhosis

M N A AL-AGHBar, G J M ALEXANDER, J NEUBERGER, $K$ T NOURI-ARIA, A $L$ W $F$ EDDLESTON, AND R WILLIAMS (Liver Unit, King's College Hospital, London) Defective $T$ cell mediated suppression of $B$ cell function is one of the abnormalities which may be involved in the pathogenesis of primary biliary cirrhosis (PBC). As Cyclosporin A (CyA) has been shown to modulate suppressor cell activity in animals, we have investigated its use in vitro and in vivo in these patients. The number of IgG producing cells was measured using an haemolytic plaque assay in the presence or absence of pokeweed mitogen (PWM). T suppressor cell function was assessed by Concanavalin $A$ (Con A) activated inhibition of PWM stimulated IgG or IgM producing B cells. Lymphocytes, isolated from 13 patients with PBC, after incubation with CyA $(300$ $\mathrm{ng} / \mathrm{ml}$ ) for 30 minutes at $37^{\circ} \mathrm{C}$ showed a significant improvement in Con $\mathrm{A}$ induced suppression of IgG producing plaques $[74.0 \% \pm 12.0$ (mean \pm SD)] compared with controls $[36.0 \pm 14.0(p<0.01)]$. Preincubation with CyA had no effect on the spontaneous or PWM induced production of IgG plaques. Comparable effects were seen with respect to IgM. Ten untreated patients with PBC were given CyA (150$300 \mathrm{mg} /$ day). Con $A$ induced suppression of IgG producing plaques improved from $33.0 \% \pm 22.0$ (mean \pm SD) to $68.1 \% \pm 8.6$ $(\mathrm{p}<0.01)$ after six month's treatment, reaching levels similar to normal $(70.0 \% \pm 5 \cdot 5)$. No changes were observed in the spontaneous or PWM induced production of IgG plaques. Similar results were obtained for the suppression of IgM. There was a modest biochemical improvement with relief of pruritus in 5/7 and of symptoms of sicca in $3 / 3$. These preliminary results show that $\mathrm{CyA}$ has a selective effect on Con $A$ induced suppressor cells both in vivo and in vitro. The correction of this defect in association with clinical and biochemical improvement in patients with $\mathrm{PBC}$ receiving $\mathrm{CyA}$ suggests that the drug may have a therapeutic role.

\section{T14}

Pulmonary vascular bed as a site for implantation of isolated cells in inbred rats

C SELDEN, S GUPTA, $K$ WEINBREN AND H J F HODGSON (Gastrointestinal Unit, and Dept Experimental Pathology, Royal Postgraduate Medical School, Hammersmith Hospital, London) In experimental animals the potential value of isolated hepatic parenchymal cells as a means of providing liver cell function has been explored. Others have shown survival of such cells implanted directly in splenic pulp, or into the liver by portal vein infusion. Using inbred August rats, we have implanted isolated hepatic parenchymal cells, obtained by in situ collagenase perfusion of donor liver, into liver and spleen, and also into the pulmonary vascular bed by infusion into 
the jugular vein.

Experimental infusion of hepatocytes into the portal vein proved to be limited by development of acute portal hypertension, and the capacity of the splenic bed is also limited. Over $24 \times 10^{6}$ viable hepatic parenchymal cells, however, can be infused into the pulmonary circulation of $180 \mathrm{~g}$ August rats without significant haemodynamic or respiratory effects. Short and medium term survival in this site has been assessed by light microscopic and ultrastructural techniques, and function by assessment of specific hepatic enzyme activity in homogenates of recipient lungs. Liver cells are detectable within vascular spaces in recipient lungs, never within alveolar spaces, and the presence of occasional liver cell mitoses indicates proliferation in these sites. Cells have been identified so far up to eight weeks after infusion. The pulmonary vascular bed thus offers a convenient and accessible site for experimental study of the survival, function, and proliferation of ectopically implanted hepatic parenchymal cells.

\section{T15}

Effects of vasodilators on portal pressure in patients with portal hypertension

J G FREEMAN, J R BARTON AND C O RECORD (Gastroenterology Unit, Royal Victoria Infirmary, Newcastle-upon-Tyne) In patients with portal hypertension, propranolol lowers portal pressure by reducing cardiac output. An alternative pharmacological approach to reducing portal pressure is to increase the capacitance of the portal vasculature by vasodilatation. A study has been conducted to assess the acute effect of three vasodilator drugs, verapamil, labetalol and isosorbide dinitrate, upon raised portal pressure in patients with known oesophageal varices. Wedged hepatic vein pressure, measured by a standard technique, was used as an index of portal pressure. All drugs were given intravenously through a peripheral vein.

Isosorbide $(n=10)$ produced a significant fall in portal pressure with a mean reduction in pressure of $9.3 \pm 3.2 \mathrm{mmHg}$ $(p<0.01)$. There was no correlation between the fall in portal pressure and fall in arterial blood pressure after the administration of isosorbide. Neither verapamil $(n=5)$ nor labetalol $(n=5)$ produced a significant reduction in portal pressure. Six patients were given oral isosorbide for one month and all subjects had a significant fall in portal pressure at the end of the study period, (mean fall in pressure $11 \cdot 3 \pm 4.9 \mathrm{mmHg} p<0 \cdot 01$ ). Studies to assess the incidence of variceal bleeding after long term isosorbide are being undertaken.

\section{T16}

Endoscopic variceal pressure measurements: response to isosorbide dinitrate

J DAWSON, R WEST, P GERTSCH, F MOSIMANN AND E ElIAS (Queen Elizabeth Hospital, Birmingham and Centre Hospitalier Universitaire Vaudois, Lausanne, Switzerland) Recent reports have cast doubt on the value of B-blockers in preventing rebleeding from oesophageal varices and there is now a need to assess other drugs. Traditional methods of estimating portal venous pressure are invasive and unsuitable for evaluation of such agents. In this study we have used an endoscopic pneumatic pressure gauge to assess the response of portal pressure to intraduodenal isosorbide dinitrate.

In five patients with alcoholic cirrhosis who had bled from oesophageal varices simultaneous measurements of endoscopic variceal pressure and hepatic venous wedge pressure were made before and after instillation of $5 \mathrm{mg}$ isosorbide dinitrate. Good correlation of endoscopic pressure with wedge pressure was observed in each patient. Isosorbide dinitrate produced a profound fall in arterial systolic pressure (mean $48 \mathrm{mmHg}$; range 30 to 75 ) in all patients. Despite this there was no significant change in either endoscopic (mean $-1.5 \mathrm{~cm} \mathrm{H}_{2} \mathrm{O}$; range +1 to -3 ) or hepatic wedge (mean $+1.2 \mathrm{~cm} \mathrm{H}_{2} \mathrm{O}$; range 0 to +2 ) pressures.

Thus endoscopic pressure measurements give a reliable estimate of portal pressure, correlating well with conventional wedge pressure measurements. These measurements are suitable for rapid evaluation of drugs of potential value in portal pressure at the site where patients bleed. The current data indicate that isosorbide dinitrate is unsuitable as a therapeutic agent for reducing portal pressure to prevent repeat variceal haemorrhage.

\section{T17}

Does continued alcohol abuse or binge drinking influence variceal rebleeding in alcoholic cirrhotics?

T P YIN, A K BURROUGHS, M Y MORGAN AND S
SHERLOCK (Department of Medicine, Royal Free Hospital School of Medicine, London) The influence of continued or binge drinking on variceal rebleeding in alcoholic cirrhotics was studied using 78 consecutive patients abusing alcohol who were admitted for variceal bleeding between 1974 and 1983. Mortality in hospital at index bleed was $39 \%$. Only five had any previous gastrointestinal bleeding.

Forty eight patients survived but only 22 $(46 \%)$ rebled from varices (38 admissions for rebleeding) and 14 had only one rebleed. In this rebleeder group followed up for 520 months (1-83 months - mean 25 months) $14(64 \%)$ continued to drink alcohol or had binge drinking (10-250 $\mathrm{g}$ median 122.5 - five abusing). Eight of this group died from variceal rebleeding, four from other causes and two survived. Eight rebleeders abstained completely (three died from rebleeding - others survived).

In the non-rebleeding group (26 patients) followed up for 884 months (2101 , mean 34 months) eight patients (31\%) continued to drink (8-80 $\mathrm{g}$ alcohol, median $45 \mathrm{~g}$ - one abusing) with two dying. Eighteen have abstained completely with three dying.

This study suggests that in alcoholic cirrhotics who survive variceal bleeding, abstinence or reduction in alcohol intake increases survival. It also shows that complete or relative abstinence greatly diminishes the risk of variceal rebleeding, and improves the chances of survival if rebleeding occurs. Continued alcohol abuse in alcoholic cirrhotics is thus an extremely important factor in identifying the risk of rebleeding and in designing trials in variceal rebleeding.

\section{T18}

Improvement in long term survival with injection sclerotherapy - final analysis of a controlled trial

D WESTABY, B R D MACDOUGALL AND ROGER williams (Liver Unit, King's College Hospital, London) In 1981 the analysis of the controlled trial of injection sclerotherapy of oesophageal varices, initiated in 1977, had shown that patient survival at two years was significantly improved as compared with those medically treated and on this basis no further patients were included in the trial. The present report describes the final analysis of the results in the 116 patients in the study at its termination. Variceal obliteration was achieved in 45 of $56(80 \%)$ patients with a 
mean of 4.5 courses of injections (range 3-13); 11 patients having died before successful obliteration. In $18(40 \%)$ of these 45 patients there has been no recurrence of varices since initial obliteration despite a mean follow up of over two years. In the remaining 27 patients $(60 \%)$ oesophageal varices recurred with a mean time from initial obliteration of 12 months although in 10 patients these were observed within the first six months. In 12 of these 27 patients the reappearance of varices was associated with bleeding but was a cause of death in only one. In 19 of the 27 patients, one or two courses of injections were necessary to eradicate the new varices, while in a further six, three or four courses were required; two patients died before obliteration was again achieved. With respect to long term survival, 18 deaths have occurred in the sclerotherapy group of which five were from variceal haemorrhage and this is in marked contrast to the 32 deaths in those managed conservatively of which 25 were from haemorrhage. As assessed by cumulative life analysis, the survival in the sclerotherapy group was significantly better than in the medically treated group $(p<0.001)$, this difference being more marked in comparison to the previous analysis and applied equally to Child's grade A, B, and $\mathrm{C}$ category cases.

\section{T19}

Can endoscopic sclerotherapy infiuence significantly the course of cirrhotics who survive variceal bleeding?

A $K$ BURROUGHS, A SANCHEZ, $N$ M BASS, G SMITH-LAING, D COOK AND S SHERLOCK (Depts of Medicine and Clinical Epidemiology and General Practice, Royal Free Hospital School of Medicine, London) Repeated endoscopic sclerotherapy is a popular current therapy to prevent variceal rebleeding in cirrhotics. The hope is that survival will be improved. It has been recently questioned whether the present day 'natural' history of these patients is favourably influenced by sclerotherapy, as the degree of hepatic decompensation seems to outweigh any other prognostic factor. Therefore we analysed the course of 186 consecutive cirrhotics presenting with active variceal bleeding over a five year period with a minimum of one year follow up (3237 patient months). During this time no measures to prevent rebleeding were used. Hepatic reserve was categorised using Pugh's criteria. Mortality in hospital was $27 \%$, uninfluenced by prior bleeding or diagnostic grouping: grade A 5\% (65), B $18 \%$ (68), C 68\% (53). Emergency procedures (95\% non-surgical) were needed in $55 \%$ of 'C's, $38 \%$ of 'B's, and $17 \%$ of 'A's. No variceal rebleeding occurred in $31 \%$ of all survivors (follow up mean 23 months) and in $50 \%$ of alcoholics. More grade A cirrhotics never rebled than B or $\mathbf{C}$ despite longer mean follow up. (32 vs 17 months). Fifty per cent of rebleeders (follow up mean 24 months) had only one admission for rebleeding. Interval to first rebleed correlated with initial grading. Only 27 of $124(22 \%)$ survivors (11 lost to follow up) died following 156 admissions for rebleeding.

This population shows the influence of hepatic reserve in variceal bleeding and rebleeding. As half of the rebleeders only had one rebled and few patients died following admission for rebleeding it would seem a priori that sclerotherapy used universally would yield little clinical benefit. Secondly a very large patient population would be needed to prove statistically any benefit in prospective trials.

GASTRO-DUODENAL

T20-33

T20

Four week study of the rate of duodenal ulcer healing with omeprazole

A WALAN, J BERGSÅKER-ASPÖY, P FARUP, R GILLBERG, L HALVORSEN, A KILANDER, T LIND, J NAESDAL AND S OFFERGAARD INTRODUCED BY J H BARON (Regional Hospital, Linköping, Sweden; Central Hospital of Rogaland, Stavanger, Norway; District Hospital, Gjøvik, Norway, Sahlgrenska Hospital, Gothenburg, Sweden) Omeprazole is known to be an effective inhibitor of both basal and stimulated gastric acid secretion in man. As the incidence of duodenal ulcer healing after four weeks was high in a preliminary study, this trial was undertaken in order to study the rate of duodenal ulcer healing during omeprazole treatment. Forty four patients with ulcers $\geqslant 5 \mathrm{~mm}$ in diameter were treated with omeprazole, $40 \mathrm{mg}$ once daily for 4 weeks, with or without an $80 \mathrm{mg}$ loading dose on day 1 . They were also given antacid tablets to use in case of pain. Healing was assessed endoscopically after one week and, if the ulcer had not already healed, again after two and four weeks.

Fourteen'patients $(32 \%)$ healed within one week and $41(93 \%)$ within two weeks. The remaining three healed within four weeks. Symptoms resolved within one week in 22 patients, within two weeks in 32 and within four weeks in 42 patients. They also improved within four weeks in the remaining two patients. After the first week, only four patients used any antacids. The $80 \mathrm{mg}$ loading dose did not appear to influence healing rate or symptomatic relief.

There were few adverse events, and none necessitated any change in dose. No clinically significant changes in laboratory variables were observed.

Omeprazole thus appears to be an effective drug in the treatment of duodenal ulcer, giving very rapid healing and relief of symptoms.

T21

Efiect of oral omeprazole on fasting and meal stimulated serum gastrin and serum pepsinogen levels in healthy volunteers

H FESTEN, J THUS, C LAMERS, J JANSEN, G PALS, R FRANTS AND S MEUWISSEN (Depts of Gastroenterology and Human Genetics, Free University Hospital, Amsterdam, and Dept of Gastroenterology, St Radboud Hospital Nijmegen, The Netherlands) Omeprazole is a potent, long acting inhibitor of gastric acid secretion. It acts by blocking the $\mathrm{H}^{+}-\mathrm{K}^{+}$ATP-ase in the parietal cells. The effects and after-effects of oral omeprazole on fasting and mealstimulated serum gastrin and serum pepsinogen levels were studied in eight healthy male volunteers. Tests were performed on six different occasions: one week before omeprazole, after one, seven and 14 days omeprazole, and one and two weeks after stopping omeprazole. At each test blood samples were drawn 10, 5 and 0 minutes before and $15,30,45,60,90$, and 120 minutes after a standard test breakfast. In addition two and four days after discontinuing omeprazole a single fasting blood sample was taken. Omeprazole was given as a $\mathbf{3 0} \mathrm{mg}$ oral dose ec granules once daily in the morning. Serum gastrin levels were determined by RIA (normal fasting range $10-80 \mathrm{pg} / \mathrm{ml}$ ). The mean of the three basal samples and the integrated increment of serum gastrin (IGR) were calculated. Serum pepsinogen levels were determined by ELISA (normal range $25-80 \mathrm{ng} / \mathrm{ml}$ ) and calculated similarly. 
Fasting serum gastrin levels were $27 \pm 10$ $\mathrm{pg} / \mathrm{ml}$ (mean $\pm \mathrm{SD}$ ) before, 25 \pm 7 after one day omeprazole, $44 \pm 27$ after one week $(\mathrm{p}<0.01)$ and $42 \pm 13$ after two weeks omeprazole $(p<0.01)$. Two days after stopping omeprazole fasting serum gastrin levels were $32 \pm 21 \mathrm{pg} / \mathrm{ml}$ (NS), after four days $31 \pm 16$, one week after stopping omeprazole $20 \pm 8$ and after two weeks $23 \pm 10$. The increment of serum gastrin increased from $4 \cdot 7 \pm 1 \cdot 3 \mathrm{ng} / \mathrm{min} / \mathrm{ml}$ (mean $\pm \mathrm{SD}$ ) before to $6 \cdot 1 \pm 1 \cdot 2$ (NS), $9.5 \pm 3.6 \quad(\mathrm{p}<0.001)$ and $11.2 \pm 4.6$ $(p<0.001)$ after one, seven and 14 days omeprazole respectively. One week after stopping omeprazole the increment of serum gastrin was $5 \cdot 2 \pm 2 \cdot 7$ (NS) and after two weeks $4.5 \pm 1 \cdot 7 \mathrm{ng} / \mathrm{min} / \mathrm{ml}$.

Basal serum pepsinogen levels increased significantly from $52 \pm 15 \mathrm{ng} / \mathrm{ml}$ (mean \pm SD) to $95 \pm 29$ after one day, $104 \pm 37$ after seven days and $>120(120=$ upper limit of detection) after 14 days omeprazole. One week after stopping levels were $70 \pm 35 \mathrm{ng} / \mathrm{ml}$ and after two weeks $56 \pm 22$ (NS). Serum pepsinogen did not change significantly after the test meal.

We conclude that omeprazole in a dose of $30 \mathrm{mg}$ daily induced an increase of fasting serum gastrin levels and postprandial serum gastrin response. After stopping omeprazole, however, fasting serum gastrin levels fell in a few days and the gastrin response to a test meal normalised in one week. Serum pepsinogen levels rose during omeprazole and normalised after stopping the drug, but the clinical importance of this phenomenon is not yet established.

\section{T22}

Intragastric acidity after treatment with omeprazole

B K SHARMA, I A SANTANA, R P WALT AND. R E POUNDER (Academic Department of Medicine, Royal Free Hospital, London) Omeprazole, the $\mathrm{H}^{+} \mathrm{K}^{+}$ATPase inhibitor, is a potent inhibitor of gastric acid secretion. Omeprazole $30 \mathrm{mg}$ daily causes a 95\% decrease of 24 hour intragastric acidity, with a significant increase of fasting and postprandial plasma gastrin concentration. One week after a fortnight's course of omeprazole a continuing decrease of 24 hour intragastric acidity has been observed. The object of the present study was to observe changes of nocturnal intragastric acidity in the days after cessation of omeprazole treatment.

Ten healthy male volunteers were studied before and after 14 daily $30 \mathrm{mg}$ doses of oral omeprazol. They were also studied three, six, nine, 12,15 and 29 days after cessation of treatment. Each study was identical: they were given a standard meal at 1730 hours, intubated, and the $\mathrm{pH}$ of hourly aspirates of gastric contents was measured from 2100 to 0700 hours. Fasting plasma gastrin concentration was measured in three samples at $\mathbf{0 7 0 0}$ hours.

After 14 days of omeprazole $30 \mathrm{mg}$ daily there was a significant $76 \%$ decrease of nocturnal acidity (mean $\mathrm{H}^{+}$activity), when compared with before treatment. Three, six and nine days after treatment there was no change of nocturnal acidity compared with before treatment, but 12,15 and 29 days after treatment there was significant hyperacidity $(+32 \%,+29 \%$, and $+35 \%$ respectively). Fasting plasma gastrin concentration was significantly raised at the end of treatment, three and six days later $(+339 \%,+197 \%$ and $+190 \%)$, but always remained in the normal range.

Omeprazole is a potent inhibitor of gastric acid secretion and has a long lasting antisecretory effect. The results of this study suggest that this combination may be associated with a degree of post-treatment intragastric hyperacidity.

\section{$\mathrm{T} 23$}

Duration of action of misoprostol, an orally active synthetic E1 analogue prostaglandin

J $K$ RAMAGE, A DENTON, AND J G WILliams (Royal Naval Hospital, Plymouth, Devon) Misoprostol (SC 29333) is an orally active synthetic $\mathrm{E} 1$ analogue prostaglandin which has been shown in man to inhibit gastric acid secretion, both basal and when stimulated by histamine and food.

We have investigated the duration of action of $200 \mathrm{mcg}$ oral misoprostol on food stimulated acid secretion in 16 normal volunteers, in a double blind placebo controlled study. The test tablets were given at 0900 hours. At 0930 a clinifeed and Oxo meal ( $\mathrm{pH} \mathrm{5.5)} \mathrm{was} \mathrm{given} \mathrm{via} \mathrm{an}$ indwelling nasogastric tube. Over the next 90 minutes mixing was continuous while the $\mathrm{pH}$ of the gastric contents was measured at five minute intervals. At $\mathbf{9 0}$ minutes the stomach was emptied. The meal procedure was repeated at 1300 and 1700 hours.

All 16 subjects completed the study uneventfully except one who vomited during his final meal. He has been excluded from the analysis of the data for the third meal. Ninety minutes after the first meal the decrease in $\mathrm{pH}$ with misoprostol (4.38 $\pm 0.71 \mathrm{SD})$ was markedly less than with placebo (3.42 $\pm 0.74 \mathrm{SD})$. At the end of the second meal the difference was smaller $(3.42 \pm 0.75$ for misoprostol, $3 \cdot 18 \pm 0.65$ for placebo), and after the third meal there was minimal difference between the two treatments $(3.30 \pm 0.79$ for misoprostol, $3 \cdot 34 \pm 0 \cdot 66$ for placebo). After the first meal mean $\mathrm{pH}$ on misoprostol (4.94) was significantly greater than on placebo $(4.53, p<0.001)$, but the differences for the second and third meals were not statistically significant.

We conclude that inhibition of food stimulated acid secretion after misoprostol is unlikely to be prolonged significantly beyond four hours after dosing.

\section{T24}

Prostaglandin metabolism in human gastric mucosa

C J HAWKey AND M J S LANGMan (Department of Therapeutics, University Hospital, Nottingham) Exogenous prostaglandins (PGs) can enhance gastric mucosal integrity but the importance of endogenous PGs in protecting against gastric ulceration is unclear. Because the high $P G$ metabolising capacity of gastric mucosa may be an important determinant of tissue levels we have compared PG metabolism by normal and abnormal gastric mucosa.

Endoscopic gastric mucosal biopsy specimens were homogenised $(20 \mathrm{mg} / \mathrm{ml})$ in Tris $\mathrm{HCl} 0.05 \mathrm{M}, \mathrm{pH} 7.4$, and $0.5 \mathrm{ml}$ aliquots incubated with $1 \mu \mathrm{g} \mathrm{PGF}_{2} \alpha(25 \mathrm{nC}$ as $\left.9 \beta \mathrm{H}^{3}-\mathrm{PGF}_{2} \alpha\right)$ in the presence of NAD 1 $\mathrm{mM}$ for 15 minutes. $\mathrm{PGF}_{2} \alpha$ and its metabolites were extracted into chloroform and separated by TLC. Metabolites were characterised by co-chromatography with 15 keto $\mathrm{PGF}_{2} \alpha, 13 \cdot 14$ dihydro $\mathrm{PGF}_{2} \alpha$ and $13 \cdot 14$ dihydro 15 keto $\mathrm{PGF}_{2} \alpha$ and quantitated as per cent total cpm on the plate.

Biopsy specimens from lesser curve metabolised $46.7 \pm 2.5 \%$ (mean \pm SEM) of added $\mathrm{PGF}_{2} \alpha(\mathrm{n}=60)$. In paired studies metabolism by the antrum was significantly higher $(129 \pm 12 \%$ of lesser curve values $\mathrm{n}=11, \mathrm{p}<0.05)$. Carbenoxolone inhibited PG metabolism by $29.2 \pm 8.8 \%$ at $10^{-5} \mathrm{M}$ $(n=8, p<0.01)$ and by $79.1 \pm 4.5 \%$ at $10^{-4} M(n=6, p<0 \cdot 001)$. Metabolism by mucosa from the rim of gastric ulcers was lower than by intact mucosa $5 \mathrm{~cm}$ away (58.9 $\pm 11.9 \%$ control, $n=7, p<0.05)$.

These data support the notion that carbenoxolone may assist ulcer healing by 
inhibiting PG metabolism. Increased PG metabolism by antral mucosa could lead to antral localisation of gastric ulcers. The significance of the unexpected finding of reduced PG metabolism by the ulcer rim requires further elucidation.

\section{T25}

Interactions of pirenzepine and ranitidine pharmacodynamic secretory studies in man

W LONDONG, $V$ LONDONG, H EBERL, G PÖCH, G BOZLER AND R GUGLER (Medizinische Klinik Innenstadt, University of Munich; Institut für Pharmakodynamik, University of Graz; Medizinische Klinik, University of Bonn, FRG) As was shown in previous investigations, combined application of the H2-receptor antagonists cimetidine or ranitidine and the antimuscarinic drug pirenzepine suppresses meal-stimulated gastric acid secretion and prevents rebleeding from gastroduodenal ulcers significantly more effectively than single drug treatment. Whether these effects are additive or synergistic, is not known. Therefore, we investigated the mode of interaction using a new method which is more advantageous compared with the traditional method described by Loewe and Muischnek.

Peptone-stimulated acid secretion of healthy subjects $(n=10)$ monitored by continuous intragastric titration for three hours was studied in two randomised and double-blind series. Pirenzepine and ranitidine were given orally and measured in plasma by radioimmunoassay or HPLC, respectively. The data were statistically evaluated using Wilcoxon's test.

In the first series of experiments, $50 \mathrm{mg}$ pirenzepine reduced acid output by $45 \%$, $100 \mathrm{mg}$ pirenzepine by $71 \%, 50 \mathrm{mg}$ ranitidine by $78 \%$, and $100 \mathrm{mg}$ ranitidine by $98 \%$. From these data it was calculated that $100 \mathrm{mg}$ pirenzepine and $50 \mathrm{mg}$ ranitidine are equally effective. There was a good correlation between percentage inhibition and drug plasma concentrations. In the second series, reduced dose combinations suppressed acid from $50 \pm 6 \mathrm{mmol}$ $\mathrm{H}^{+} / 3$ h (placebo; mean $\pm \mathrm{SEM}$ ) to $3.9 \pm 2.0$ ( $92 \%$ by $25 \mathrm{mg}$ pirenzepine +37.5 mg ranitidine), to $3 \cdot 2 \pm 1.8(94 \%$ by $50 \mathrm{mg}$ pirezepine $+25 \mathrm{mg}$ ranitidine), and to $4.4 \pm 2.3 \mathrm{mmol} \mathrm{H}^{+} / 3 \mathrm{~h}(91 \%$ by $75 \mathrm{mg}$ pirenzepine $+12.5 \mathrm{mg}$ ranitidine). These effects of reduced dose combinations were significantly stronger than those of equieffective doses alone.

Our results support the concept that the interaction of ranitidine and pirenzepine can be characterised as a potentiating effect which should be used clinically in definable indications.

T26

Does speed of DU healing on cimetidine have any predictive value?

C J OLIIHANT AND $\mathrm{c}$ w VENABLES (Freeman Hospital, Freeman Road, Newcastle-uponTyne) Currently we have no way of predicting the likely outcome of long term medical treatment for DU

In long term studies (1-7 yr: $\overline{\mathrm{x}}=2.5 \mathrm{yrs})$ of 'rapid relapsing' ulcers (those recurring in less than three months) treated with continuous maintenance therapy with cimetidine (400 $\mathrm{mg}$ nocte) we have examined whether the speed of initial ulcer healing has any predictive value. One hundred patients are included in this study ( 80 men): 84 healed their ulcer in less than six weeks (Group A) and 16 took more than six weeks (Group B).

In Group A $60 \%$ developed a relapse at some stage (40\% asymptomatic) with a median time to relapse of six months. In $44 \%$ these relapses took more than six weeks to heal and 14/22 of these recurred a third time.

In Group B $88 \%$ relapsed $(12 \%$ asymptomatic) in a median time of seven months. Of these relapses $88 \%$ again required more than six weeks to heal and $6 / 14$ recurred a third time.

It is concluded that those patients whose ulcers are slow to heal represent a special group. We suggest that such patients probably require prolonged hospital follow up rather than referral back to the general practitioner.

\section{$\mathrm{T} 27$}

$\mathrm{N}$-Nitrosocompounds in cimetidine-treated duodenal ulcer patients

J BARNARD, D W DARKIN, O M HOWARD, N F LIGHTFOOT, G J MILTON-THOMPSON AND N J vINEY (Smith Kline \& French Research, Welwyn and the Royal Naval Hospital, Haslar, Portsmouth) Suggestions that rises in intragastric $\mathrm{pH}$ by anti-secretory drugs may increase the risk of gastric cancer are controversial, the postulated mechanism being that increased growth of nitrate reducing baceria may occur, leading to increased concentrations of nitrite and $\mathrm{N}$-nitrosocompounds which may produce gastric cancer. Sixteen duodenal ulcer patients were studied over four 24-hour periods: before, on the last day of both two weeks' cimetidine $1 \mathrm{~g} /$ day and two weeks' cimetidine $400 \mathrm{mg}$ nocte and after a five week cimetidine free period. Patients ate a normal, standardised diet, and gastric juice was sampled half-hourly by day and hourly overnight for measurement of $\mathrm{pH}$, bacterial counts (total and NRB), nitrite and total $\mathrm{N}$-nitrosocompounds (TNC).

Mean 24-hour hydrogen ion concentration was significantly reduced by both cimetidine treatments (by $56 \%$ and $39 \%$, $\mathrm{p}<0.01$ ). Isolated counts of NRB of $10^{5}$ $10^{9}$ occurred in association with $\mathrm{pH}>3.5$, more frequently during cimetidine treatment, but colonisation did not occur and enteric organisms were not detected. Nitrite concentrations were variable, rose with $\mathrm{pH}$ and were higher during therapy $(p<0.01)$. TNC concentrations were variable, but neither correlated with $\mathrm{pH}$ nor increased during cimetidine treatment.

These results are similar to those in healthy subjects, showing no increase in intragastric $\mathrm{N}$-nitrosocompound concentrations during cimetidine treatment.

\section{T28}

Intestinal metaplasia subtypes in the assessment of gastric cancer risk. A multicentre prospective study

M I FILIPE, W BOGOMOLETZ, P DAWSON, B FABIANI AND F POTET (Dept of Histopathology, Guy's Hospital, London; Institute Jean Godinot, Reims and Dept of Histopathology, Hospital Beaujon, Clichy, France) The heterogeneity of intestinal metaplasia is now recognised and it has been suggested that some variants secreting sulphomucins may have a higher malignant potential. If so, the identification of intestinal metaplasia subtypes in gastric biopsies could be a useful marker for detection and surveillance of cancer risk patients.

We present preliminary data of a prospective study on gastric biopsies from three centres. A common protocol for endoscopy and histological criteria was prepared. The intestinal metaplasia subtypes identified are: type I complete cell differentiation and sialomucin secretion; type II and III incomplete cell differentiation with secretion of neutral and sialomucin in II and sulphomucins in III.

One thousand, four hundred and sixty biopsies were examined: 'normal' (30\%), chronic gastritis $(47 \%)$, gastric ulcer $(14 \%)$, carcinoma $(2 \%)$, stoma $(3 \%)$ and 
miscellaneous (5\%). Two hundred and seventy two biopsies (19\%) show intestinal metaplasia. It was common in carcinomas $(65 \%)$, less so in gastric ulcer $(36 \%)$, chronic gastritis $(22 \%)$, stoma $(23 \%)$, rare in 'normal' (3\%). Type I showed the highest incidence $(73 \%)$, type III the lowest $(8.7 \%)$. Type I was most common in benign conditions $(93 \%, 76 \%$ and $72 \%$ respectively) in 'normal', gastric ulcer and chronic gastritis. Type III showed a higher incidence in carcinoma $(35 \%)$ than in gastric ulcer and chronic gastritis (11 and $6.4 \%$ respectively) and none in 'normal'. These data show: (1) intestinal metaplasia is more common in carcinoma; (2) type I is the most common and related to benign lesions; (3) type III less common and more associated with carcinoma. Differences were noted among the centres regarding incidence of intestinal metaplasia (lowest in Reims), type III intestinal metaplasia (similar London and Paris, absent in Reims) and gastric cancer (2\% London and Paris; $0.3 \%$ Reims). These findings further suggest that subtypes of intestinal metaplasia may have different malignant potential and type III should be regarded as a form of dysplasia in the screening for gastric cancer.

\section{T29}

Long term gastric mucosal changes in medically and surgically treated duodenal ulcer

P C H WATT, J M SLOAN, AND T L KENNEDY (Departments of Surgery and Pathology, The Queen's University of Belfast, Royal Victoria Hospital, Belfast) Gastric mucosal abnormalities have been reported in late postgastrectomy patients. It is not clear if these abnormalities are any more common than in non-operated patients or if they merely represent progression of the underlying disease, independent of surgery. Resection of the antrum may in fact reduce the area of gastric mucosa at risk.

We therefore studied 82 postvagotomy and gastrojejunostomy (V+GJ) patients who had had surgery between 15 and 25 years (mean 20.1 years) previously for duodenal ulcer. In addition we studied 59 patients of similar ages who had a long history (minimum 15 years) of duodenal ulcer treated medically and now inactive (control group). Each had endoscopy and seven biopsies taken from equivalent sites. Biopsies were assessed without knowledge of patient group.

No carcinoma was found in either group. Severe dysplasia occurred in two $(2.3 \%)$ and moderate dysplasia occurred in 13 $(15.8 \%)$ of the $V \pm G J$ group - neither change was seen in the control group, $(p<0.01)$. There was no significant difference between groups for mild dysplasia. Intestinal metaplasia occurred in $44(53 \%)$ of the $V \pm G J$ group and $16(27 \%)$ of the control group $(\mathrm{p}<0.01)$. Atrophy and gastritis were assessed separately and each biopsy was scored between 0 and 6 for both. The atrophy and gastritis score for each patient was taken as the mean score of all biopsies in that patient. Using this system, atrophy was more severe in the $\mathrm{V}+\mathrm{GJ}$ group $(\mathrm{p}<0.01)$ as was gastritis $(p<0.05)$.

Although we found no case of carcinoma, we conclude that mucosal abnormality is more common in surgically treated duodenal ulcer patients. We fear that a high incidence of gastric carcinoma in $\mathrm{V}+\mathrm{GJ}$ patients may emerge after 25 post-operative years.

\section{T30}

Are the mucosal abnormalities of the postoperative stomach reversible?

P C H WATT, J M SLOAN, ANN SPENCER, AND T L KENNEDY (Departments of Surgery and Pathology, The Queen's University of Belfast, Royal Victoria Hospital, Belfast) Enterogastric reflux of bile has been suggested as a cause of mucosal abnormality in the postoperative stomach. It is unclear whether or not these abnormalities are reversible.

Thirty three patients had gastric biopsies taken before and a minimum of 10 months after a bile diversion procedure. Twelve had a closure of gastrojejunostomy and 17 had a roux loop. A total of 283 biopsies was taken of which 122 were preoperative and 161 postoperative. Individual biopsies were assessed without knowledge of whether they were pre or postoperative or from which patient they came. Each biopsy was scored between 0 and 6 for gastritis, atrophy, intestinal metaplasia and dysplasia and patients were given a mean pre and postoperative score for each of these.

Using a paired statistical test (Wilcoxon's) to compare pre and postoperative bile division scores we found no significant difference for gastritis, atrophy, or intestinal metaplasia.
In 13 patients the dysplasia score was the same before and after bile diversion. In three patients the dysplasia was worse after bile diversion and in 17 patients it was improved. Comparison of pre and postoperative dysplasia scores for all patients showed a significant improvement $(p=0.002)$. Significant improvement $(p=0.006)$ was also found in roux loop patients considered separately but in closure of gastrojejunostomy patients, although some improvement occurred, it did not reach significance.

It was concluded that diversion of bile from the postoperative stomach leads to an improvement of dysplasia but not other histological abnormalities.

T31

\section{Serotonin and dumping?}

FIONNA MOORE, MARIE COOPER AND J H WYLLIE (Departments of Gastroenterology and Surgery, and the Whittington Academic Unit of Surgery, University College, London) Serotonin has been suspected of implication in the pathophysiology of the dumping syndrome. To test the hypothesis that platelet serotonin levels alter during attacks of dumping we counted platelets and measured platelet serotonin in platelet-rich plasma obtained one to two minutes before, and 30 minutes after an oral dose of 90 grams of sucrose. In 10 experiments on eight patients with symptoms of dumping after gastric surgery, blood was obtained from an antecubital vein by indwelling siliconised cannula.

Administration of sucrose provoked, at 30 minutes, a median Sigstad dumping score of 7 (range 3-11) but did not affect the mean platelet count $\left(10^{9} \mathrm{ml}, 0.77\right.$ before sucrose, 0.73 after). Nor was severity of dumping symptoms related to change in these parameters.

Analysis of variance, however, showed that the level of serotonin in platelet rich plasma changed during experiments $(p<0.01)$ - either rising or falling by an average of $0.47 \mu \mathrm{g} / \mathrm{ml}$. Similar changes occurred in volunteers.

These results do not suggest that platelet serotonin is implicated in dumping, but they do show that platelet serotonin varies greatly, and apparently spontaneously, over 30 minutes. This may indicate a physiological role of platelet serotonin.

T32

Resting but not stimulated gastric mucosal 
blood flow is higher in duodenal ulcer patients compared with the normal population

B J JOHNSTON, K HAINES, R L MCISAAC, P I REED, AND H A F DUDLEY (Gastroenterology Unit, Wexham Park Hospital, Slough and Academic Surgical Unit, St Mary's Hospital Medical School, London) It has been reported that changes in gastric mucosal blood flow may play a role in peptic ulcer disease. There is undoubtedly some basis in fact for a pathophysiological role of mucosal blood flow in stress ulceration, but its role in duodenal ulcer pathophysiology is more controversial. Previous studies in man using neutral red clearance to estimate blood flow found that duodenal ulcer patients had a lower stimulated level of mucosal blood flow compared with normal volunteers. We wished to investigate whether this was due to a change in resting blood flow or to stimulated mucosal blood flow. The studies were divided into two groups: (1) A study of resting mucosal blood flow and acid secretion over four hours in a group of $\mathbf{1 0}$ normal volunteers to assess variability of mucosal blood flow; (2) A comparison of resting and stimulated mucosal blood flow and acid secretion in 10 duodenal ulcer patients and six volunteers. Maximal acid secretion was stimulated by pentagastrin 1 $\mu \mathrm{g} / \mathrm{kg} / \mathrm{h}$ iv for 1.5 hours after collecting resting secretion for two hours. Gastric secretions were collected via a nasogastric tube in 10 or 20 minute epochs by continuous aspiration. Mucosal blood flow was estimated by neutral red clearance and acid secretion by titration to $\mathrm{pH} 7$ with $0.1 \mathrm{~N}$ $\mathrm{NaOH}$. The Mann-Whitney $U$ test was used to assess differences in resting and stimulated mucosal blood flow or acid secretion. Data are given as mean and standard deviation.

In group 1 mucosal blood flow during the first hour was $23 \pm 15.7 \mathrm{ml} / \mathrm{min}$ and was not significantly changed at the fourth hour $(26 \pm \cdot 4 ; p>0 \cdot 1)$. Acid secretion was also not significantly changed from the first hour to the fourth hour $(2.9 \pm 1.06 \mathrm{vs}$ $3.0 \pm 2.54 \mathrm{mEq} / \mathrm{h} ; \mathrm{p}>0.1)$. In group 2 resting mucosal blood flow was significantly higher in duodenal ulcer than in normals $(34 \pm 17.9 \mathrm{ml} / \mathrm{min}$ vs $18 \pm 4.9 \mathrm{ml} / \mathrm{min}$; $\mathrm{p}<0 \cdot 01)$. Acid output was also significantly higher in duodenal ulcer $(7.4 \pm 4.47 \mathrm{mEq} / \mathrm{h}$ vs $1.5 \pm 0.26 \mathrm{mEq} / \mathrm{h} ; \mathrm{p}<0.05)$. Stimulated mucosal blood flow, however, was lower in duodenal ulcer than in normals; $67 \pm 32.0$ $\mathrm{ml} / \mathrm{min}$ vs $84 \pm 21.6 \mathrm{ml} / \mathrm{min}$ but this did not reach statistical significance. Acid output was higher in the duodenal ulcer group than in volunteers $(38 \pm 14.1 \mathrm{mEq} / \mathrm{h}$ and $29 \pm 10.6 \mathrm{mEq} / \mathrm{h}$ respectively; $\mathrm{p}<0.05)$. We conclude that in duodenal ulcer the higher resting mucosal blood flow is due to an increased resting acid secretion but that this higher level of mucosal blood flow is less sensitive to stimulation than in the normal population.

\section{T33}

Gastric acid and gastrin production in the short bowel syndrome

N S WILLIAMS, P F EVANS, AND R F G J KING INTRODUCED BY D JOHNSTON (University Department of Surgery, The General Infirmary, Leeds) Excess gastric acid secretion and gastrin production may occur in patients with the short bowel syndrome and may be important in both its aetiology and treatment. Although rises in each have been recorded after extensive small bowel resection, these parameters have never been measured simultaneously in man. We have used the technique of intragastric titration to do this in patients $(n=8)$ after extensive small bowel resection resulting from vascular occlusion $(2.3 \pm \mathrm{SE} \quad 0.6$ metres resected) and normal control subjects $(n=8)$ matched for age, sex, and body weight.

Basal acid output (BAO) and peak acid output in response to pentagastrin $\left(\mathrm{PAO}^{\mathrm{PG}}\right)$ were determined by the standard aspiration technique. On a separate day maximal acid output in response to a $\mathbf{5 0 0}$ ml Oxo 'meal' (MAO ${ }^{\circ 0}$ ) was determined by intragastric titration while serum gastrin was measured at regular intervals by radioimmunoassay.

Basal, peak and integrated gastrin responses were significantly increased after extensive small bowel resection (ESBR $107 \pm 59,450 \pm 109 \mathrm{pg} / \mathrm{ml}, 11,280 \pm 2,961 \mathrm{pg}-$ min: Controls $30 \pm 24,111 \pm 67 \mathrm{pg} / \mathrm{ml}$, $3,158 \pm 1,977$ pg-min: $p<0 \cdot 05)$. BAO, $\mathrm{PAO}^{\mathrm{PG}}$ and $\mathrm{MAO}^{\text {OxO }}(4 \cdot 1 \pm 1.4$; $18 \cdot 9 \pm 4 \cdot 8 ; 10 \cdot 7 \pm 2.4 \mathrm{mmol} / \mathrm{h})$ were, however, not significantly different compared with normal controls $(3 \cdot 4 \pm 1 \cdot 5$; $19.9 \pm 5 \cdot 5 ; 12 \cdot 3 \pm 7 \cdot 8 \mathrm{mmol} / \mathrm{h})$.

Although serum gastrin is raised in patients with the short bowel syndrome the parietal cell mass seems insensitive to its effect. Thus, there is no rationale for treating these patients with longer term $\mathrm{H}_{2}$ antagonists.

\section{PAEDIATRICS}

T34-39

T34

Hirschsprung's disease in Birmingham

C M E MCKEOWN AND R PROOPS - INTRODUCED BY PROFESSOR A MCNEISH (Department of Clinical Genetics, Infant Development Unit, Birmingham Maternity Hospital, Birmingham) One hundred and one of 109 children with histologically confirmed Hirschsprung's disease born between 19681980 , treated in Birmingham and followed up for two to 14 years, were reviewed retrospectively to confirm previously reported recurrence risks and to look at the outcome of treatment. Information was obtained by interview, questionnaire and from the notes. Twenty per cent had long segment disease and in $12 \%$ there was ileal involvement. One in $\mathbf{1 0}$ of the siblings of the 20 long segment patients were also affected. In short segment patients the risk to brothers was $<1 / 13$ and to sisters $<1 / 58$. The sex ratio was M:F $4 \cdot 8: 1$ for short segment patients and 1.9:1 for long segment patients. Eleven per cent had significant associated abnormalities. There were 13 deaths (three in children with very extensive ileal involvement, one with Down's Syndrome, one with severe congenital heart disease) giving a corrected mortality of $8 \%$. The mean age at diagnosis fell significantly over the period of review.

The growth of patients with short segment disease followed a normal distribution but that of long segment patients showed a significant reduction in the mean height and weight. Bowel function was scored on a scale $0-12$. The mean score for short segment patients was $1.7 \pm 1.9$ and differed significantly from that for long segment patients $3 \cdot 8 \pm 1 \cdot 6$ $(p<0.01)$. Three short segment patients had colostomies and two long segment patients had ileostomies. A significant improvement in score was shown with time but the younger children scored better than older ones at comparable ages. This study is in close agreement with earlier data on recurrence risks and shows a continued improvement in outcome of treatment.

\section{T35}

Clinical evaluation of histochemical acetylcholinesterase estimation in the diagnosis of Hirschsprung's disease

L C BARR, S J BOOTH, M I FILIPE, AND J O N 
LAwSON (Department of Surgery, Westminster Children's Hospital and Department of Histopathology, Guy's Hospital, London) Acetylcholinesterase activity (AChE) was estimated histochemically on suction biopsies from 115 consecutive patients presenting with symptoms and signs of colonic dysfunction, usually chronic constipation or intestinal obstruction. Clinical tests included barium enema and anorectal physiological studies. Suction biopsies were performed according to strict principles: $1-2 \mathrm{~cm}$ above anal margin; minimum of two to three taken at various distances; to consist of mucosa, muscularis mucosae, and preferably submucosa; properly orientated and fresh frozen in liquid nitrogen. The histochemical criteria for the diagnosis of Hirschsprung's Disease (HD) was: presence of increased number of AChE positive thick tortuous nerve fibres in the lamina propria and muscularis mucosae; also the finding of thick nerve trunks in the submucosa.

In our series, a definite diagnosis of HD was obtained in 22 patients; AChE activity was equivocal in three and atypical in four. There was one case of colonic neuronal dysplasia. The material was insufficient or unsatisfactory in four instances. No false positives were reported. In two neonate patients no AChE activity was shown; subsequent tests revealed total aganglionosis in one and HD in the other.

We also compared the relative success of histochemistry and clinical studies in predicting the final diagnosis of these patients.

Our data show that histochemical AChE estimation on suction biopsies provides a highly accurate diagnosis of $\mathrm{HD}$ and we suggest that this new approach may soon replace full thickness and deep mucosal rectal biopsy in the diagnosis of, and screening for, disorders of large bowel parasympathetic innervation.

\section{T36 \\ Slow vs rapid introduction of milk in infant gastroenteritis}

D P MAUDGAL, M H WANSBROUGH-JONES, AND H P LAMBERT (Communicable Diseases Unit, St George's Hospital, London) The standard treatment of infant gastroenteritis is rehydration followed by gradual reintroduction of milk. This requires several days hospitalisation which might be unnecessary for treating mild gastroenteritis as seen in the UK today. We have studied the effect of slow and rapid refeeding (milk) in $1 \div 2$ children with gastroenteritis. After oral rehydration with Dextrolyte (24 h), each patient was reassessed and randomly allocated to (A) slow ( $\left(1, \frac{1}{2}\right.$ and full strength milk given for 24 h each), or (B) immediate re-introduction of full strength milk. Clinical assessment was repeated every 24 hours. Eighty three patients received regimen $A$ and 79 received regimen $B$. Patients on the two regimens were matched for age, sex, and length or severity of illness before admission. Pathogenic organisms were detected in $57 \%$ of patients on regimen $A$ and $46 \%$ on regimen $B$. Percent change in admission weight (mean) on $\mathbf{A}$ and $B$ respectively was $0.66 \%(n=82)$ and $0.41 \%$ $(n=77)$ at $24 h ; 0.12 \%(n=82)$ and $0.35 \%$ $(n=70)$ at $48 \mathrm{~h} ;-0.53 \%(n=73)$ and $0.84 \%$ $(n=48)$ at $72 h$; and $0.21 \%(n=56)$ and $1.41 \%(n=32)$ at $96 \mathrm{~h}$. The mean $( \pm$ SEM) stay in hospital on regimen $A$ and $B$ was $3.57 \pm 0.07$ and $2.93 \pm 0.12$ days respectively $(p<0.001)$. We conclude that rapid reintroduction of full strength milk after adequate rehydration is well tolerated and is associated with a shorter stay in hospital.

\section{T37}

Development of colonic transport in early childhood: implications for diarrhoeal disease

A HEATH AND P J MILla (Institute of Child Health, Guilford Street, London) The adequacy of colonic salvage often determines, whether diarrhoea occurs. We have previously suggested that in severe protracted diarrhoea in infancy (SPDI) the diarrhoea is due to overwhelming small intestinal secretion. Studies of colonic function in SPDI, however, are few and nothing is known of the development of colonic transport in the infant.

We have modified the technique of non-equilibrium dialysis of the rectum to simultaneously measure electrolyte transport and transmural potential difference (PD) in control children and those with SPDI. There were three groups of controls, neonates (N) $0-1 / 12(n=8)$, infants (I) $1 / 12-1$ year $(n=6)$, Children $(C) 1-4$ years $(n=8)$, and SPDI ( $n=3 I$ and $2 \mathrm{C})$. In $\mathrm{C}, \mathrm{Na}^{+}$was absorbed electrogenetically and was less than $\mathrm{Cl}^{-}\left(\mathrm{Na}^{+} 211 \pm 7.8 \mathrm{SEM} \mathrm{nmol} / \mathrm{min}\right.$ $\mathrm{cm}^{2}$. $\mathrm{Cl}^{-}$225 \pm 9.8$) ; \mathrm{HCO}_{3}^{-}$secretion accounted for the difference between $\mathrm{Na}^{+}$ and $\mathrm{Cl}^{-} . \mathrm{K}^{+}$movement was passive. In $\mathrm{N}$ and $\mathrm{I}, \mathrm{Na}^{+}$absorption $(\mathrm{N} 115 \pm 9$, I $158 \pm 16)$ was greater than $\mathrm{Cl}^{-}(\mathrm{N} 108 \pm 12$,
I 127 \pm 13$)$ and there was a marked reduction of $\mathrm{HCO}_{3}^{-}$secretion in $\mathrm{N}(\mathrm{N}$ $11 \cdot 3 \pm 2$ vs I $33 \pm 10 \quad \mathrm{p}<0.02$ ) implying reduced anion exchange. In SPDI all had reduction of $\mathrm{Na}^{+}$absorption (SPDI $87.6 \pm 8.2$ vs $158 \pm 16 \mathrm{p}<0.02$ ) and $P D$ (SPDI 13.2 \pm 2 vs $34.4 \pm 5 \mathrm{mV} \mathrm{p}<0.02$ ) with reduction of anion exchange in the three infants $\left(\mathrm{HCO}_{3}{ }^{-}\right.$secretion $\mathrm{I} 33 \pm 10 \cdot 2$ vs SPDI (1) $5 \pm 17 \mathrm{p}<0 \cdot 02$ ).

These data show that impaired colonic function may play a role in the production of diarrhoea in SPDI. In the neonate anion exchange is poorly developed, with increasing age this and electrogenic $\mathrm{Na}^{+}$ absorption improves. The different pattern of electrolyte movement suggests that the neonate has reduced ability to conserve water and electrolytes and emphasises a particular susceptibility to dehydration from diarrhoea.

\section{T38}

Gastro-oesophageal refiux (GOR) in newborn infants: a problem?

C A HUGHES, P. K SARKAR, G M DURBIN, A MAYNE, A $S$ MCNEISH, AND $P$ WILLIAMS (Institute of Child Health, Birmingham, and Birmingham Maternity Hospital, Birmingham) Gastro-oesophageal reflux may be associated with severe complications in children - for example, vomiting and apnoea but there is no information on the natural history of reflux, nor whether GOR is common in the newborn. Eight asymptomatic and six symptomatic newborn infants (gestational age 33-41 weeks) were studied up to six weeks postnatally, while being fed and nursed normally, using a $\mathrm{pH}$ micro-electrode placed in the distal oesophagus having located the sphincter (distal high pressure zone) by manometry. The number, duration, and clearance time of refluxes ( $\mathrm{pH}<4.0)$ were recorded in each infant for 12-26 hours and standardised per 1000 minutes.

There was no difference between asymptomatic and symptomatic infants for number $(4 \cdot 16 \pm 2 \cdot 68 ; 5 \cdot 55 \pm 4 \cdot 24)$, duration $(16.44 \pm 15.7 ; 30.03 \pm 0.38 \mathrm{sec})$, clearance time $(32 \cdot 21 \pm 27 \cdot 71 ; 55 \cdot 62 \pm 54 \cdot 16 \mathrm{sec})$ of refluxes which were highest when the infant was nursed on the right side and least in the prone position. There was no significant correlation between episodes of reflux and the distal oesophageal sphincter pressure. The volume of feed given did not affect the results $(p>0.5)$.

Gastro-oesophageal reflux commonly 
occurs in newborn infants and symptoms for example, apnoea are not necessarily associated with reflux. It is necessary to obtain longitudinal data to determine the natural history of GOR

T39

Influence of long term cimetidine as an adjuvant to pancreatic enzyme therapy in cystic fibrosis

D M CHALMERS, R C BROWN, M G MILLER, P C N CLARKE, J KELLEHER, J M LITTLEWOOD, AND M S LOSOWSKY (Depts of Medicine and Paediatrics, St James's University Hospital, Leeds, and District Hospital, Harrogate, Yorks) Seventeen children with cystic fibrosis on pancreatic enzyme therapy and with continuing steatorrhoea were randomised to receive either cimetidine (25 $\mathrm{mg} / \mathrm{kg} /$ day, 30 minutes before meals) or placebo for either of two successive six month periods. The patients were assessed anthropometrically and nutritionally, and absorptive function measured at the beginning and end of each six month period. Dietary intake was similar during each period while faecal collections were performed. Liver function tests, serum electrolytes, and haematological screening were not influenced by placebo or cimetidine treatment. Standard deviation scores for height, weight, subscapular and skinfold thicknesses were not altered by cimetidine treatment. Faecal fat and nitrogen decreased on cimetidine compared with placebo, 40.6 to $27.8 \mathrm{~g}$ /day and 3.1 to $2.62 \mathrm{~g} /$ day respectively. The response in individual patients was extremely variable and the mean reduction did not reach statistical significance. The mean faecal bile acid output was significantly reduced $(p<0.01)$ by cimetidine, falling from 84.5 to $49.8 \mu \mathrm{mol}$ $\mathrm{kg}$ body weight/day. Long term cimetidine does produce some improvements in intestinal absorption in cystic fibrosis but during six months this improved absorptive function was not reflected in the nutritional state of the patient.

GENERAL CLINICAL

T40-47

T40

Oral microfiora afiect postprandial exhaled breath hydrogen concentrations

\section{T41}

Endoanal anastomosis without proximal faecal diverting stoma

D G THOMPSON, J O'BRIEN, M MCCARTHY, AND J HARDIE (Department of Gastroenterology and Oral Microbiology, The London Hospital Medical College, London) An early transient rise in exhaled hydrogen $\left(\mathrm{H}_{2}\right)$ concentration is often seen in normal subjects after a carbohydrate meal. The reason for this phenomenon remains uncertain but is not due to arrival of meal at the colon. We have tested the hypothesis that fermentation by the anaerobic bacteria of the oropharynx might be a contributing factor.

Ten healthy adults performed four studies each, in random order, on separate days. Serial exhaled $\mathrm{H}_{2}$ samples were collected and measured using an $\mathrm{H}_{2}$ monitor (GMI Ltd) after at least 12 hours overnight fast. In one study a standard meal (150 $\mathrm{g}$ baked beans) was eaten. In another, the meal was eaten after oral hygiene (toothbrushing and chlorhexidine mouth wash) to reduce oral microbial activity. The other two studies involved sham feeding the meal with and without preceding oral hygiene.

Meal ingestion was followed within 45 minutes by an $\mathrm{H}_{2}$ rise in $8 / 10$ subjects (mean 45 minute rise $v s$ baseline $4 \mathrm{ppm}$ SD5) plus a later prolonged rise in all. Oral hygiene greatly reduced the early peak (mean rise -3 ppm SD5 $\mathrm{p}<0 \cdot 01$ vs meal), but not the delayed peak. Sham feeding produced a similar early peak (mean rise 2 ppm SD5) which was again greatly reduced by oral hygiene (mean rise -3 ppm SD5 $\mathrm{p}<0.01$ vs sham feed). No delayed rise was seen.

Fasting oral contents from seven subjects, cultured anaerobically with added carbohydrate all produced $\mathrm{H}_{2}$. Chlorhexidine inhibited the $\mathrm{H}_{2}$ production. The oropharyngeal microflora thus make a major contribution to the early $\mathrm{H}_{2}$ peak. Suppression of oral anaerobes should therefore be undertaken before breath $\mathrm{H}_{2}$ studies, particularly when a premature peak is suspected - for example, bacterial overgrowth or rapid transit.

E M BARKER - INTRODUCED BY M R B KEIGHLEY (Department of Surgery, University of Natal Medical School, Durban, S Africa)

It appears to be universal practice to protect endoanal anastomoses by ileostomy or colostomy, to minimise the risks of anastomotic breakdown and pelvic and cuff abscesses, despite the absence of published evidence to support the need for such a stoma. This practice imposes on all patients a period of morbidity and an additional operation for closure.

Nineteen patients (ages 26-62 years) were treated by endoanal anastomosis without proximal stoma. Ileo-anal with S-pouch (7), ulcerative colitis (on steroids) (4), multiple polyposis (3). Colo-anal sleeve anastomosis (12), radiation rectovaginal fistula (3), radiation proctitis and bleeding (5), rectal malignancy (3), birthtrauma recto-vaginal fistula (1).

No patient suffered any local complication, nor any other complication attributable to omission of a proximal stoma. One patient died of myocardial failure. Fifteen of the 18 survivors were fully continent two weeks after operation, and all but one by four weeks.

T42

Influence of single dose penicillins and cephalosporins on emergence of $\mathrm{C} 1$ difficile in volunteers

N S AMBROSE, MARGARET JOHNSON, D W BURDON, AND M R B KEIGHLEY (Departments of Surgery and Microbiology, General Hospital, Birmingham) Single dose intravenous antibiotic prophylaxis is now regarded as safe and adequate cover for elective intestinal operations. Although antibiotic associated pseudomembranous colitis (AAPC) is rare, it may occur even after single dose antibiotic prophylaxis. We have examined the influence of a single intravenous dose of six different cephalosporins and five different penicillins on the faecal flora of six volunteer subjects in each antibiotic group. The antibiotics studied included: cephaloridine $1 \mathrm{~g}$, cephazolin $1 \mathrm{~g}$, cefuroxime $1.5 \mathrm{~g}$, cefoxitin $2 \mathrm{~g}$, cefotaxmie $1 \mathrm{~g}$, moxalactam $2 \mathrm{~g}$, penicillin $1 \mathrm{meg}$ unit, ampicillin $1 \mathrm{~g}$, piperacillin $2 \mathrm{~g}$, mezlocillin 2 $\mathrm{g}$ and ticarcillin $2 \mathrm{~g}$. Faecal material was collected before and 1, 3, 7 and 14 days after injection of antibiotic. We report the emergence of $C 1$ difficile after antibiotic exposure. None of the 66 volunteers had C1 difficile in the stool before treatment. C1 difficile did not appear in any of the patients receiving the penicillins (penicillin, ampicillin, piperacillin, mezlocillin, and ticarcillin) or after single dose cephaloridine. C1 difficile (no toxin) was identified in one subject after cephazolin. $C 1$ difficile with toxin emerged in one volunteer after cefuroxime. $\mathrm{Cl}$ difficile (no toxin) was detected in two 
subjects after cefoxitin and in two after cefotaxime. C1 difficile (one with toxin) appeared in three subjects after moxalactam. These data indicate that even single dose broad spectrum cephalosporins may be responsible for emergence of $C 1$ difficile whereas the penicillins are free from this potentially serious complication.

\section{T43}

Initial experience with a free floating intragastric balloon in the treatment of morbid obesity

T V TAYLOR AND B R PULLAN (Departments of Surgical Gastroenterology, Manchester Royal Infirmary and Medical Biophysics, University of Manchester, Manchester), The treatment of the patient with morbid obesity remains a major problem. Surgery offers the only realistic hope of long term weight reduction but it is associated with considerable hazards. Jejuno-ileal bypass has been largely replaced by gastric partitioning; the latter procedure producing weight loss by reducing the reservoir capacity of the stomach. It occurred to us that the introduction of a free floating intragastric balloon might achieve the same result.

Seven patients with morbid obesity had intragastric balloons inserted. The initial prototype always became deflated within one month of insertion, but three patients achieved weight loss of up to $6 \mathrm{~kg}$. An improved silicone balloon has been inserted in four patients. Three sustained weight loss within the initial six week period of between 7 and $12 \mathrm{~kg}$; in one the balloon deflated. All patients vomited during the first 24 to 72 hours but then settled. A feeling of early satiety was achieved and associated with reduced food intake.

Our intitial experience with a free floating intragastric balloon in patients with morbid obesity has shown the device to be capable of producing weight loss, at least in the short term.

\section{T44}

Value of a defined policy for surgical management in the treatment of acute upper gastrointestinal haemorrhage due to peptic ulceration

S A RAIMES, M B CLAGUE, C W VENABLES, AND R G WILSON (Department of Surgery, Newcastle General Hospital, Westgate Road, Newcastle-upon-Tyne) Con- troversy continues over the role of early surgery in the management of acute upper gastrointestinal haemorrhage due to peptic ulceration. It has been suggested that early surgical intervention does not improve overall survival. A study of the impact of a defined management policy, in one surgical unit, has been performed. During a 54 month period (A) no defined policy was followed, surgery being advocated when uncontrolled or recurrent haemorrhage occurred. During a subsequent 36 month period (B) a strict policy was followed based upon the nature of the lesion, the endoscopic stigmata of bleeding, the age of the patient and the presence of severe coincident disease. Early consultation from the admitting medical unit was encouraged and early endoscopy used to define the management plan.

A total of seventy-eight operations were performed (period $A \mathrm{n}=40$, period $B$ $n=38$ ). Comparison of groups $A$ and $B$ showed a very close correlation for age, sex, presence of coincident disease, and the site of bleeding. In period B there was a significant increase in the proportion of patients operated upon within 24 hours of admission and the overall operative rate increased from 0.74 operations/month to 1.06 operations/month. Overall operative mortality fell from $25 \%$ in group A to $13.2 \%$ in group $B$ and was halved in the over 60 age group. In group $B$, in those operated upon before evidence of further haemorrhage, mortality was only $\mathbf{7 . 7 \%}$. This improvement was most noticeable in duodenal ulcer patients.

These findings support the concept that a management policy, including early surgery when indicated, can reduce mortality.

\section{T45}

Simultaneous combined barium meal and cholecystogram - an analysis of 1444 investigations

R A J SPENCE, P C H WATT, R C CAMPBELL, J J MCGURK, AND D G C WHYTE - INTRODUCED BY T G PARKS (Departments of Surgery and Medical Statistics, The Queen's University of Belfast and Department of Radiology, Altnagelvin Hospital, Londonderry, N Ireland) As many dyspeptic patients are still investigated by radiology in the first instance, a policy was initiated whereby all such patients were directly referred for combined simultaneous double contrast barium meal and cholecystogram.

The results of 1444 combined procedures are presented. Of these, $310(25.5 \%)$ had a positive finding on barium meal only; 275 (19\%) were positive for cholecystogram only; $117(8.1 \%)$ were positive for both examinations; $742(51.4 \%)$ were negative for both examinations. Of all the patients (427) who had a positive finding on barium meal, $27.4 \%$ (117) also had a positive finding on cholecystogram. Of all the patients (392) with positive cholecystogram, $29.8 \%$ (117) also had a positive barium meal. In those patients presenting with typical peptic ulcer symptoms a positive cholecystogram was found in $13.4 \%$. The clinical diagnosis of peptic ulcer was correct in $38.7 \%$. Patients presenting with typical gall-bladder disease symptoms had a positive barium meal in $21.3 \%$ and gall-bladder disease was found in $50.9 \%$. The incidence of dual pathology increased considerably with age.

It was concluded that in patients over $\mathbf{4 0}$ years old, this policy improved diagnostic yield. In all other patients this policy markedly reduced the number of hospital visits. Combined simultaneous double contrast barium meal and cholecystogram is therefore recommended for hospitals which use radiology for the first line investigations of dyspepsia.

\section{T46}

Gastric and gall-bladder emptying relationships - pertubation by truncal vagotomy and pyloroplasty

J N BAXTER, J S GRIME, M CRITCHLEY, AND R SHIELDS (Departments of Nuclear Medicine and Surgery, Royal Liverpool Hospital and University of Liverpool, Liverpool) The normal relationship between gastric emptying (GE) and gallbladder emptying (GBE) have been previously reported to this society, however, whether they are maintained following truncal vagotomy and pyloroplasty (V \& P) is unknown. Using a reproducible non-invasive dual isotope technique, we studied 28 patients after $\mathrm{V} \& \mathrm{P}$ and compared them with 22 healthy control subjects. Tracers used were ${ }^{99} \mathrm{Tc}^{\mathrm{m}} \mathrm{EHIDA}$ for gall-bladder bile and bran labelled with ${ }^{113}$ In $^{\mathrm{m}}$ for gastric contents.

Gastric emptying in healthy subjects was monoexponential while after $\mathrm{V} \& \mathrm{P}$ it was double exponential. Gall-bladder emptying occurred only in relation to eating in $26 \mathrm{~V}$ $\& P$ patients and 15 normal subjects. These 15 normal subjects emptied $15 \cdot 0 \pm 1 \cdot 6 \%$ of gall bladder contents before gastric emptying while the $26 \mathrm{~V} \& \mathrm{P}$ patients emptied 
only $1.9 \pm 0.6 \%$ of gall bladder contents before gastric emptying $(p<0.001)$. This difference was due to delay in onset of GBE $(p<0.001)$ and earlier onset of gastric emptying $(p<0.001)$ when compared with healthy controls. Gall-bladder emptying unrelated to eating occurred in seven normal subjects and two $V \& P$ patients. This difference was almost significant $(p=0.059$ Fisher's exact test). There were considerable variations in GBE patterns after V \& P when compared with healthy controls.

We conclude that $V$ \& $P$ causes (a) delay in onset of GBE, (b) earlier onset of gastric-emptying, (c) considerable variation in GBE patterns and (d) probable reduced interdigestive GBE.

T47

Measurement of gastric emptying (GE) in dyspeptic patients; effect of a new gastrokinetic agent (cisapride)

R JLAN, F DUCROT, Y NAJEAN, AND J J BERNIER (Inserm U54 - Hôpital Saint-Lazare and Department of Nuclear Medicine Hopital Saint-Louis, Paris, France) Symptoms suggesting gastroparesis in patients without organic disease (idiopathic dyspepsia) are very common but their relation with an objective delay of gastric emptying has been poorly investigated. A dual isotopic technique was used (a) to evaluate patients with non-obstructive gastric stasis (idiopathic vs secondary) and (b) to assess the effects of a new gastrokinetic agent (cisapride) on gastric emptying in these patients.

Sixty patients with symptoms suggesting gastric stasis (vomiting, bloating, early satiety) and without lesions at endoscopy were studied. They were separated in three groups: idiopathic (group 1, $n=31$ ), post vagotomy (group $2, n=16$ ) and miscellaneous (diabetes, sclerodermia . . ., group $3, n=13$ ). All patients ingested the same solid-liquid meal $(500 \mathrm{cal}, 500 \mathrm{ml})$; ${ }^{99 m}$ Tc sulphur colloid tagged egg white was the solid phase marker and ${ }^{11}$ In chloride mixed with water the liquid phase marker.

Solid and liquid gastric emptying was delayed in these patients taken as a whole $(n=60)$ as compared with normal subjects. Percentages of patients with a delayed gastric emptying rate $(<m+2$ SD from normal subjects) of at least one phase of the meal were $48 \%$ in group 1 vs $87 \%$ in group 2 and $75 \%$ in group 3 . In the 10 last consecutive patients of the group a doubleblind cross over study of cisapride $(8 \mathrm{mg}$
IV) vs placebo was done. A significant ( $p<0.05$, analysis of covariance) enhancement of solid gastric emptying was induced by the drug: $23 \pm 3$ vs $18 \pm 3$ (\% emptied/h, mean \pm SEM), whereas no significant effect was evidenced on liquids. The effect on solids was more pronounced in patients with a delayed gastric emptying (six out of 10): $19 \pm 3$ vs $12 \pm 3$.

This study emphasises the importance of an objective evaluation of gastric emptying in the presence of symptoms of gastric stasis and suggests that specific local acting therapy can be useful in patients when an abnormal gastric emptying is identified.

PLENARY

T48-52

T48

Angelchik prosthesis in refiux oeophagitis

J R BENNET, C M S ROYSTON, A S MAKAR, AND G BUCKTON (Departments of Medicine and Surgery, Hull Royal Infirmary, Kingston upon Hull) The Angelchik prosthesis is a silicone ring which, when tied around the lower oeosophagus subdiaphragmatically, is said to prevent reflux oesophagitis.

Of a series of 31 patients with heartburn because of reflux oesophagitis, in whom Angelchik prostheses were inserted, 20 were asymptomatic or had very mild dysphagia, six had moderate dysphagia, four severe dysphagia. One had to be removed. Concomitant procedures were performed in nine patients: five vagotomy and pyloroplasty, four cholecystectomy. No patient suffered from intra-abdominal sepsis.

Fifteen hour intra-oesophageal $\mathrm{pH}$ measurements were done before and six months after the procedure in 15 patients. All but two showed a reduction in frequency and duration of acid reflux episodes and a diminution of percentage time below pH 5 and $\mathrm{pH} 4$. Two patients showed a worsening of $\mathrm{pH}$ figures despite a good symptomatic result. Oeosphageal manometry by a standard station-pullthrough technique under radiological control was done before and six months after the procedure in eight patients. All showed a rise in barrier pressure at the level of the prosthesis from $7 \cdot 3 \pm 2.9$ to $25 \cdot 8 \pm 6.72 \mathrm{~cm}_{2} \mathrm{O}$. The pressure rise was different from a normal gastrooesophageal sphincter in failing to relax completely on swallowing (residual pressure $8 \cdot 5-15 \mathrm{~cm} \mathrm{H}_{2} \mathrm{O}$ ). The patient with severe dysphagia had the highest residual pressure of $15 \mathrm{~cm}$. Although the sphincter length after the prosthesis was greater than pre-operatively the difference was not significant. The Angelchik prosthesis appears to raise gastro-oesophageal sphincter pressure but relaxation is incomplete and may cause dysphagia. The dysphagia usually lasts from three to six months only.

\section{T49}

Can the preliminary screening of patients with dyspepsia allow better use of investigational resources?

A G MORGAN, P DAVENPORT, AND A DARNBOROUGH (Endoscopy Unit, Airedale General Hospital, Steeton, Keighley, West Yorkshire) In this project a non-medically trained research assistant interviewed patients with dyspepsia who presented either to a dyspeptic clinic, to a Department of Radiology, or to a general practitioner's surgery. Having taken a structured case history, the data were put on a specially devised proforma, coded and then entered in to a Apple II desk top microcomputer. This compared the clinical features of the patients with several hundred similar patients in its memory stores and from this produced a risk prediction.

One thousand and forty five patients have been studied, and the results show that the medium and high risk groups contain all but $12.5 \%$ of the diagnosed ulcers (31/247) and all but $3 \%$ of the cancers (1/34). A patient over the age of 50 years and placed in the high risk group has a $12.6 \%$ chance of having cancer $(29 / 230)$.

In the low risk group if the patients with a hiatus hernia are excluded (52/306), $85.5 \%$ of the remainder had either a normal barium meal or endoscopy. If these low risk patients were referred for investigation only if their dyspeptic symptoms failed to settle with simple measures, the demand for radiology or endoscopy could be reduced by almost a third. In contrast, all high risk patients over the age of 50 years, require urgent hospital consultation and investigation.

\section{T50}

Is cigarette smoking associated with Crohn's disease?

R F A LOGAN, K W SOMERVILLE, M EDMOND, AND M J S LANGMAN (University Department 
of Therapeutics, City Hospital, Nottingham) The association of nonsmoking and ulcerative colitis has been recently recognised. The only previous study of smoking in Crohn's disease reported a small but not significant excess of current or ex-smokers among Crohn's patients. As in our earlier study of smoking and ulcerative colitis, questionnaires including an enquiry about smoking habits were posted to 48 unselected patients with Crohn's disease and to 96 randomly chosen controls matched for age, sex and general practice. Response rate to the first letter has been $88 \%$ for cases and $63 \%$ for controls.

Forty five percent of 42 Crohn's patients currently smoke cigarettes compared with $25 \%$ of 60 controls and $8 \%$ of 119 colitics attending the same practices. Eighty one percent of Crohn's patients reported they had previously smoked at least five cigarettes/day for a year (controls $47 \%$; colitics $56 \%$ ). At symptom onset $70 \%$ of Crohn's patients smoked cigarettes compared with $31 \%$ of controls at the same age, and $16 \%$ of colitics. Of 15 who had stopped smoking four (29\%) stopped six months or more before symptom onset, compared with $78 \%$ of 55 colitics. Crohn's patients tended to have started smoking younger (mean 16.6 years) than the controls (mean 19.0 years). The estimated relative risk of smokers developing Crohn's disease was $6.4\left(X_{2}=10.4, p<0.002\right.$; Miettinen's method for matched triplets) based on reported smoking habit at disease onset. These results show that patients with Crohn's disease are more likely to be smokers than their age, sex, and general practice-matched controls. The association antedates symptom onset and is in striking contrast with the association of nonsmoking with ulcerative colitis in colitics from the same practices. This raises the possibility that smoking may influence which type of inflammatory bowel disease develops.

\section{T51}

Peptic ulcer in childhood - how many do we miss?

E J EASTHAM, M Z JIMINEZ, R H JACKSON, AND R NELSON (Department of Child Health, Royal Victoria Infirmary, Newcastle-uponTyne) The prevalence of peptic ulcer disease in childhood is uncertain. Recurrent abdominal pain is common $(10 \%)$ and it is well known that peptic ulcer disease does not conform to standard adult symptomatology. The wide variation in prevalence of ulcer disease in different centres possibly reflects the criteria for which investigations are instigated. Other than haematemesis and melaena, we regard nocturnal pain and/or a positive family history as an indication for endoscopy. Using these criteria, analysis of 173 consecutive patients undergoing endoscopy reveals 39 peptic ulcers $(22.5 \%)$ mean age 12 years (range $4-16$ years). The male:female ratio was $3: 1$. There were 31 primary duodenal ulcers, two secondary, three pre-pyloric and three gastric ulcers. Of the primary duodenal ulcers only $40 \%$ presented with haematemesis and/or melaena. Excluding these $80 \%$ had a positive family history and $90 \%$ had nocturnal pain. At endoscopy more than one ulcer was found in $15 \%$, associated duodenal deformity in $70 \%$ and duodenitis in $50 \%$.

Compared with other European centres, our prevalence of duodenal ulceration in childhood is high. Unless peculiar regional factors prevail, we feel that underdiagnosis of this condition may be considerable and suggest that any child presenting with recurrent abdmonial pain in whom there is a positive immediate family history or the presence of nocturnal pain, should be subjected to upper gastrointestinal endoscopy irrespective of whether the pain is classically 'dyspeptic'.

\section{T52}

\section{Alcohol and colo-rectal cancer}

K WARD, K J MORIARTY, S O'NEILL, M L CLARK, AND G DEAN (Medico-socio Research Board, Dublin, Department of Gastroenterology, St Bartholomew's Hospital, London) An association between beer consumption and colorectal carcinoma has been suggested. One retrospective study of Dublin brewery workers, known to have a high intake of beer, predominantly stout, showed a two-fold increase in the expected mortality from rectal cancer. A case control study was therefore performed in Dublin and London. In each centre, male patients with colonic $(n=100)$ and rectal $(n=100)$ cancer, together with appropriate controls $(n=200)$, were interviewed in detail, with particular reference to their lifetime drinking habits.

In men with colonic tumours, regular beer drinking was more common than in controls (137 vs $115, \mathrm{p}>0.05)$ and a greater number of cancer patients had consumed beer for longer than 10 years (150 vs 126 , $\mathrm{p}<0.01)$. In long term beer drinkers, the relative risk of developing cancer of the colon was $1 \cdot 77$. There was no statistical difference in ale or stout consumption between patients with rectal cancer and controls. Regular consumption of spirits was more common both in men with carcinoma of the colon (116 vs 65, $\mathrm{p}<0.001)$ and rectum $(110$ vs $66, \mathrm{p}<0.001)$. Similarly, a regular intake of spirits for longer than 10 years was more prevalent both in patients with colonic (110 vs 69, $\mathrm{p}<0.001)$ and rectal $(92$ vs $65, \mathrm{p}<0.01)$ malignancies. The relative risks of developing cancer of the colon and rectum in long term spirit drinkers were 2.32 and 2.48 respectively.

In this study, the presence of carcinoma of the large bowel in men was associated with regular, long standing consumption of alcohol.

INFLAMMATORY BOWEL

F1-8

F1

Fibronectin level predicts the occurrence of stenosis in patients with Crohn's disease

C ANDRE, $L$ DESCOS, AND $F$ ANDRE INTRODUCED BY $\mathrm{R}$ N ALLAN (Service d'Hepato Gastroenterologie et Groupe d'Immunopathologie Digestive, $U \mathbf{4 5}$ INSERM, Centre Hospitalier, Lyon Sud, Pierre Benite, France) A prospective study was conducted over a two year period on 58 patients with Crohn's disease. The site of the disease was the colon alone in 15 , the small bowel alone in 14 and both areas in 29 patients. At the beginning of the study, the activity of the disease was classified according to a clinical scoring method. The disease was considered to be quiescent in 16, mild in 14, moderate in 12 and severe in 16 patients. Each patient had a colonoscopy or a sigmoidoscopy. Radiological studies carried out on all patients included examination with barium of the upper gastrointestinal tract, small bowel and colon. When the clinical index was determined, blood was taken for the measurement of plasmatic fibronectin by radial immunodiffusion. Patients were then studied regularly. During the course of the study, and at least at the end of the two year period, the patients were submitted to a new complete morphologic examination.

There was no relation between initial fibronectin level and activity of Crohn's disease. The prospective study was 
completed in 52 patients. Completion was not possible in six for reasons of refusal of further investigation in three, death from leukaemia in one, and departure to a foreign country in two. Eleven patients had a stenosis at the beginning of the study. The mean fibronectin level in those patients was $16.6 \mathrm{mg} / 100 \mathrm{ml}$. No stenosis was present or developed in 29 patients; their mean fibronectin level was $19.4 \mathrm{mg} /$ $100 \mathrm{ml}$. Twelve patients with no stenosis at the beginning of this prospective study had a mean fibronectin level of $26.0 \mathrm{mg} / 100 \mathrm{ml}$. This value is significantly higher $(p<0.001$ and $\mathrm{p}<0.02$, Student's $t$ test) than that observed in the two other groups. They developed a stenosis of large or small bowel during the two years of the study. In tissues, fibronectin is usually associated with the early but not the later fibrotic reaction - that is, it is codistributed with immature collagen but is not related in distribution to mature collagen.

Fibronectin monitoring is advisable in the care of patients with Crohn's disease in order to detect those developing a stenosis.

F2

Interferon and the pathogenesis of inflammatory bowel disease: low interferon induced oligo $\alpha$ synthetase activity in peripheral blood mononuclear cells of ulcerative colitis patients

R STALNIKOWICZ, K GODER, D WALLACH, M REVEL AND D RACHMILEWITZ (Dept of Gastroenterology, Hadassah University Hospital, Jerusalem and Dept of Virology, Weizmann Institute of Science, Rehovoth, Israel) Interferon is produced in response to viral infections and has immunoregulatory effects. Raised plasma interferon (IFN) was reported in active inflammatory bowel disease (IBD). $\left(2^{\prime}-5^{\prime}\right)$ oligo A synthetase activity in peripheral blood mononuclear cells (PBM) is induced by IFN and shown to be increased in viral and autoimmune disease. We found, however, reduction of the enzyme activity in PBM of patients with active ulcerative colitis (UC). The average enzyme activity in PBM isolated from patients with active UC was significantly lower $(\mathrm{p}<0 \cdot 01)$ than in PBM isolated from UC patients in remission or controls - normal subjects and colon cancer patients. Oligo A synthetase activity in PBM isolated from Crohn's disease (CD) patients was similar to controls:

\begin{tabular}{lrr}
\hline & Activity & No \\
\hline UC Act & & \\
UC Rem & $1 \cdot 3 \pm 0 \cdot 4$ & \\
Normal subjects & $2 \cdot 7 \pm 2 \cdot 2$ & 12 \\
Colon cancer & $2 \cdot 3 \pm 0 \cdot 6$ & 14 \\
CD Act & $2 \cdot 2 \pm 0 \cdot 8$ & 7 \\
CD Rem & $2 \cdot 3 \pm 0 \cdot 7$ & 4 \\
& $2 \cdot 5 \pm 0 \cdot 7$ & 5 \\
& & 6 \\
\hline
\end{tabular}

ATP polymerised to $\left(\mathrm{A}_{2}{ }^{\prime} \mathrm{p}\right) \mathrm{nA} / 10^{5}$ cells $/ 21 \mathrm{~h}(\mathrm{~nm}$, $\overline{\mathbf{x}} \pm \mathrm{SD}$ )

When determined in the same UC patients, the enzyme activity significantly increased with clinical improvement.

These results suggest that: (a) oligo A synthetase activity in PBM may serve as an indicator of disease activity in UC; (b) the raised IFN in active IBD is probably of the $\gamma$ type which is not an important inducer of oligo A synthetase; (c) the decreased oligo A synthetase activity in UC might be also interpreted as reflecting decreased response of PBM to IFN effect in this disease.

F3

Rectal spirochaetosis: a sexually transmitted disease?

H M GILMOUR AND A MCMILlAN (University of Edinburgh and Royal Infirmary, Edinburgh) In a study of 255 male homosexuals, which included rectal biopsy, $70(27.5 \%)$ were shown to have rectal spirochaetosis on the first biopsy and a further six patients were shown to have spirochaetosis on a subsequent biopsy. This compares with an incidence of $4 \%$ in a control sample of consecutive rectal biopsies and a reported incidence of $2-7 \%$ in unselected series of rectal biopsies.

The homosexual patients with spirochaetosis did not show an increased incidence of diarrhoea, anal discharge, pruritus ani, or rectal bleeding when compared with those homosexuals without spirochaetosis nor was there any evidence of an increased incidence of histological abnormality in the rectal mucosa in the group with spirochaetosis.

In 19 patients, multiple biopsies were obtained over periods ranging from a few weeks to three years. No consistent pattern of infection emerged within this group and the presence of spirochaetosis could not be related to increased symptoms or to inflammatory changes in the rectal mucosa.

This increased incidence of spirochaetosis in homosexual males suggests sexual transmission of the organism but in our study there is no evidence to support the contention that rectal spirochaetosis by itself is a cause of significant alimentary symptoms.

\section{F4}

Adhesion of $\mathbf{E}$ coli to cultured colonoscopic biopsies from patients with ulcerative colitis

I F PINDER, R J LEE, M F DIXON, E M COOKE, AND A T R AXON (Gastroenterology Unit, The General Infirmary, Leeds, Department of Pathology, University of Leeds, an Departent of Microbiology, University of Leeds, Leeds) $E$ Coli isolated from patients with ulcerative colitis more often possess the ability to adhere to or invade Hela cell monolayers than those isolated from controls but these invasive and adhesive properties which are thought to confer pathogenicity have not been studied in cultured colonic mucosa.

We have studied the adhesion of $E$ coli to cultured colonic mucosa obtained at colonoscopy. Biopsies were taken, carefully orientated mucosal surface uppermost, and aliquots of radio-labelled $E$ coli of known characteristics added. After incubation for four hours the biopsies were fixed, washed thoroughly, and sectioned with careful orientation. The sections were then applied to photographic emulsion and autoradiographs obtained to show the location of the $E$ coli.

Biopsies were taken from patients without inflammatory bowel disease and in colitics from areas of normal mucosa and inflamed mucosa. Using $E$ coli shown by Hela cell studies to be non-adhesive mean counts of $12 \pm 3.5,14 \cdot 2 \pm 4 \cdot 5$ and $18 \pm 5 \cdot 4$ were obtained for normals, 'normal colitic' and 'inflamed colitic' mucosa respectively. There was no significant difference in this group. In the biopsies to which adhesive or invasive $E$ coli were added, however, the mean counts were $24 \pm 6 \cdot 1,40 \pm 7$, and $61 \pm 10$ respectively. There is significant difference $(p<0.01)$ between the two groups and also within the adhesive bacteria group.

$E$ coli shown to be adhesive by other methods have been shown by this technique to adhere to cultured colon and they appear to have an increased adhesion to mucosa from colitics especially when inflamed.

F5

Comparison of ${ }^{111}$ Indium granulocyte scanning with colonoscopy for assessing 
disease severity and extent of colonic involvement in inflammatory bowel disease

$S$ H SAVERYMUTTU, M CAMILLERI, H REES, J P LAVENDER, H J $F$ HODGSON, AND $V$ S CHADWICK (Departments of Medicine and Radiology, Royal Postgraduate Medical School, DuCane Road, London) ${ }^{111}$ Indium leucocyte scanning has recently been introduced as a new method for imaging inflammatory bowel disease. Its accuracy in assessing disease extent and severity, however, has yet to be established. We have recently reported that the technique can be improved and made more specific for acute inflammation by isolating and labelling a pure granulocyte fraction instead of the conventional mixed leucocyte preparation. Using this technique we have prospectively compared ${ }^{11}$ Indium granulocyte scanning with colonoscopy for assessing disease extent and disease severity.

Studies were performed in 52 patients with Crohn's disease or ulcerative colitis representing a wide spectrum of clinical disease activity (CDAI median + range 226; 30-436). Disease extent and severity at colonoscopy were estimated both macroscopically and histologically (multiple mucosal biopsies) using a numerical grading system. Similarly disease extent and severity scores were assessed from the early ${ }^{111}$ Indium granulocyte scan (at two to three hours).

Excellent correlations were found between both macroscopic and histological assessment at colonoscopy and the ${ }^{111}$ Indium scans: $\mathrm{r}=0.91, \mathrm{p}<0.001$ and $r=0.84 p<0.001$ for extent; and $r=0.80$ $\mathrm{p}<0.001$ and $\mathrm{r}=0.80 \mathrm{p}<0.001$ for disease activity. Correlations between macroscopic and histological assessments at colonoscopy were: $r=0.83$ for extent and $r=0.72$ for disease activity.

These results show that ${ }^{111}$ Indium granulocyte scanning is an accurate noninvasive technique for assessing both disease extent and severity of colonic involvement in inflammatory bowe disease.

F6

Maintenance of remission in ulcerative colitis with an oral preparation of 5-amino salicylic acid in high doses

M J DEW, A D HARRIES, N EVANS, B K EVANS, AND J RHODES (Departments of Gastroenterolgy and Pharmacy, University Hospital of Wales, Cardiff) Oral acrylic coated 5-amino salicylic acid which is released in the colon has a similar effect to sulphasalazine in the maintenance of remission in ulcerative colitis. In this study we test whether high doses of this preparation are more effective than salazopyrin at preventing relapse, and measure serum levels of 5-ASA and its metabolites. Sixty seven patients, 36 men, 31 women, mean age 45.4 years with ulcerative colitis on at least $2 \mathrm{~g}$ sulphasalazine (SLP) per day, in remission (< three stools/day without blood or slime) were entered into a double-blind trial. Each patient received two sets of tablets either active 5-ASA or placebo SLP, or active SLP and placebo 5-ASA. Patients on 2 g SLP were given 2.4 g 5-ASA (equivalent to $6 \mathrm{~g}$ SLP) and for each gram of SLP above $2 \mathrm{~g}$ they received $800 \mathrm{mg}$ of 5-ASA. Tablets of 5-ASA contained 400 mg of 5-ASA and were coated with Eudragit-S, 120 microns in thickness. Patients were seen during the six-month trial at 12 and 24 weeks and completed diary cards recording stool frequency and blood loss. Patients were sigmoidoscoped at entry and the time of relapse or completion of the trial. Ten patients withdrew, four because of headache related to SLP. Twelve of 57 patients relapsed; seven relapses out of 32 patients taking 5-ASA $(22 \%)$, five out of 25 patients taking SLP $(20 \%)$. Serum levels of metabolites were higher in patients taking the high dose of 5-ASA compared with those on smaller doses of SLP. With 5-ASA median serum acetyl 5-ASA level was $1.8 \mu \mathrm{g} / \mathrm{ml}$ (range $0.2-12$ ) and with SLP, median value was $0.3 \mu \mathrm{g} / \mathrm{ml}$ (range $0 \cdot 2-1 \cdot 4)$. The study confirms that coated 5-ASA and SLP are equally effective but the high dose of 5-ASA has no added benefit.

\section{F7}

Screening for colonic epithelial dysplasia in longstanding extensive ulcerative colitis

A P MANNING, $\mathbf{N}$ WOOD, I PINDER, $\mathbf{R} \mathbf{J}$ DICKINSON, M F DIXON, AND A T R AXON (Gastroenterology Unit, The General Infirmary, Leeds) In 1979, we described a series of patients with longstanding extensive ulcerative colitis who entered a prospective study of regular colonoscopic screening for mucosal dysplastic change. This paper details four years of further follow up. Patients have had colonoscopy annually, biopsies being taken from multiple sites processed for histology by standard techniques, and examined by one pathologist. Dysplasia diagnosed according to published criteria was graded mild, moderate or severe. The original group included 43 patients (median age 43 years, range 18-70 years; median duration of disease 14 years, range 8-35 years). At initial colonoscopy two patients had severe dysplasia in association with carcinoma, both after 30 years of disease; the diagnosis was revised to Crohn's disease in one patient. Of the remaining 40 patients dysplasia was seen in 16 at some time during up to five years' follow up. No further examples of severe dysplasia or carcinoma have been found; one patient had moderate dysplasia at three sites on one occasion but only mild dysplasia at each of three subsequent examinations. The other 15 had mild dysplasia. Of these, five have had consistent mild dysplasia on at least three successive examinations; eight have had mild dysplasia on at least one occasion, but no dysplasia on subsequent examination. No progression of dysplasia has been observed. This continuing study illustrates that severe or moderate dysplasia is infrequently seen, but that mild dysplasia is common and may be transient. Possible implications for the surveillance of patients with extensive longstanding colitis will be discussed.

\section{F8}

Survival from colorectal cancer in ulcerative colitis - implications for surveillance programmes

S N GYDE, R N ALLAN, P PRIOR, AND J A H WATERHOUSE (Gastroenterology Unit, General Hospital, Birmingham) Early studies reported a poor prognosis for colorectal cancer complicating ulcerative colitis. Recent studies after matching for Duke's staging at diagnosis of colorectal cancer, however, suggest that survival does not differ from cancer arising de novo in the general population which has encouraged surveillance programmes of ulcerative colitis patients at risk from developing cancer. This study examines the survival of patients with colorectal cancer complicating ulcerative colitis before screening for dysplasia as a baseline for determining the success of surveillance programmes. Thirty five patients developing colorectal cancer complicating ulcerative colitis were identified in a large hospital series under long term review. The crude five year survival was compared with 
the survival from colorectal cancer in the relevant general population from which the patients were drawn. The median age at diagnosis of cancer was 47.5 years and the actuarial five year survival $33.5 \%$ A comparison was made with colorectal cancers registered in the West Midlands region between 1962-1967. In this period 462 cancers were observed. The median age at diagnosis of cancer was 45-49 years and the actuarial five year survival $34.6 \%$. The five year survival is similar - only one-third of the patients in both groups surviving for five years.

Surveillance programmes can be justified if they can improve the current outcome.

HEPATO - BILIARY AND PANCREATIC

F9-F18

\section{F9}

Hepatocellular carcinoma in Thailand characterisation by monoclonal antibody

C J HAWKEY, C H HOLMES, T CHAINUVATTI, P G SMITH, V VIRANUVATTI, R W BALDWIN, AND P J TOGHILl (Department of Medicine and Cancer Research Campaign Laboratories, Nottingham, and Siriraj Hospital, Bangkok, Thailand) The monoclonal antibody RL23/36/Ab detects an hepatocyte associated determinant (RL23/36/Ag) expressed in both the rat and human. In the rat expression is reduced or lost in most primary hepatocellular carcinomas (HCCs) and some putative premalignant lesions such as neoplastic nodules. We have therefore studied expression of RL23/36/ $\mathrm{Ag}$ in 34 liver biopsies from Thailand, a high incidence area for $\mathrm{HCC}$, and compared them with liver biopsies from 74 British patients. Expression of RL23/36/Ag was defined by reactivity with RL23/36/Ab detected using an indirect immunoperoxidase technique. The diagnosis of HCC was made on the basis of histology and raising of serum $\alpha$ fetoprotein.

Hepatocytes of all 10 Thai liver biopsies without evidence of parenchymal liver disease expressed RL23/36/Ag as did hepatocytes from 28/29 comparable British liver biopsies and from Thai patients with non-malignant liver diseases $(n=19)$. Six cases of HCC were studied: in all, expression of RL23/36/Ag was abnormal or absent but the pattern varied: (1) nonexpression of RL23/36/Ag in both HCC and non-malignant hepatocytes, (2) nonexpression in HCC hepatocytes but normal expression in non-malignant hepatocytes,
(3) non-expression in a sub-population of both HCC and non-malignant hepatocytes, (4) non-expresion in a sub-population of HCC hepatocytes with normal expression in all non-malignant hepatocytes. In the rat the pattern of RL23/36 reactivity shows some correlation with morphological tumour differentiation. Our results show that HCC hepatocytes are not uniform antigenetically and that expression of RL23/36/Ag may be absent before the development of malignancy. The pattern of expression of RL23/36/Ag in HCC may be related to the degree of differentiation.

F10

Successful treatment of human primary liver cancer xenograft by new quinazoline antifolate agent CB 3717

M F BASSENDINE, N J CURTIN, $K$ WOODHOUSE, A L HARRIS, AND O F W JAMES (Departments of Medicine and Clinical Oncology, University of Newcastle upon Tyne) We investigated two new approaches to the treatment of primary liver cancer (PLC). (1) Because levels of thymidylate synthetase are high in PLC cells we studied a new quinazoline antifolate (CB 3717) which inhibits this enzyme. (2) Following the report suggesting benefit of reduced glutathione (GSH) treatment in aflatoxin B1-induced PLC in rats we also examined this agent.

We used the human PLC xenograft model derived from the PLC/PRF/5 ('Alexander') cell line heterotransplanted into athymic mice. In this model alphafetoprotein (AFP) levels reflect tumour mass. Twenty four mice bearing visible subcutaneous tumours were studied: (a) six control animals; (b) six animal receiving

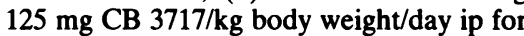
five days; (c) six animals receiving $200 \mathrm{mg}$ CB $3717 / \mathrm{kg}$ body weight/day ip for five days; (d) six animals receiving $200 \mathrm{mg}$ $\mathrm{GSH} / \mathrm{kg}$ body weight-day until death (minimum 21 days). Tumour growth was measured by following serial serum AFP levels and by direct tumour volume estimation (Vernier callipers).

There were no significant differences in serum AFP or tumour volume between controls and those treated with GSH or low dose CB 3717. The short course of high dose CB 3717 produced highly significant reduction in serum AFP levels compared with controls at seven $(p<0.05), 14$ $(p=0.02)$, and $21(p<0.02)$ days from the start of treatment. This reduction in a measure of viable tumour mass was followed by significantly decreased tumour volume after $14(\mathrm{p}<0.02)$ and $21(\mathrm{p}<0.02)$ days compared with controls.

CB 3717, unlike existing drugs of this group - for example, $5 \mathrm{FU}$ - preserves de novo purine synthesis leading to low toxicity. Out study shows that it is a potent inhibitor of human PLC growth and its high therapeutic efficacy is reflected in a promising early clinical evaluation.

\section{F11}

New somatostatin analogue for home treatment of endocrine tumours

S M WOOD, M E KRAENZLIN, AND S R BLOOM (Department of Medicine, Hammersmith Hospital, and Royal Postgraduate Medical School, Du Cane Road, London) Somatostatin, a neuropeptide in the brain, gut, and pancreas, inhibits hormone secretion and may be of value for treating peptide hypersecretion from endocrine tumours as these are slow growing but life threatening as a result of their hormonal sequelae. The use of somatostatin is limited by its short half life which necessitates iv administration. A very long acting analogue of somatostatin (Sandoz, SMS 201-995) has been recently developed for subcutaneous use. We have investigated its effect on nine patients with peptide secreting tumours: two glucagonomas (both also secreting gastrin), two VIPomas (both also secreting neurotensin and peptide histidine isoleucine), three gastrinomas, one insulinoma, and one carcinoid syndrome. Patients were given SMS 201-995 $\mu \mathrm{g} \mathrm{sc}$ bd for three days which produced at least a $50 \%$ fall in basal concentrations of all secreted peptide except glucagon which fell by only 15$20 \%$. There was an associated improvement in symptoms: complete resolution of profuse diarrhoea in the patients with VIPomas and carcinoid syndrome, in the latter flushing was also diminished. Epigastric pain and diarrhoea resolved in all three gastrinomas. Fasting hypoglycaemia was prevented in the insulinoma patient. Two patients had side effects, one with diabetic autonomic neuropathy had worsening of postural hypotension, another developed anorexia and mild nausea. In almost all cases there was a noticeable exacerbation of symptoms 3648 hours after stopping treatment with an overswing of the respective plasma peptides. SMS 201-995 effectively suppresses peptide secretion from tumours resulting in dramatic remission of 
symptoms. It can provide a life saving adjunct to surgery or chemotherapy, with the advantage that it can be given on an outpatient basis.

F12

Copper retention in the fetus and neonate possible relationship to Wilson's disease

A $K$ BURROUGHS, S K S SRAI, B WOOD, T L DORMANDY, AND O EPSTEIN (Department of Medicine, Royal Free Hospital School of Medicine, Hampstead, and Department of Biochemistry, Whittington Hospital, London) Liver copper retention in Wilson's disease is related to failure of biliary copper excretion and an abnormality of caeruloplasmin synthesis. The mammalian fetus has a copper profile indistinguishable from Wilson's disease. Failure to switch from fetal to adult copper metabolism has been proposed as leading to Wilson's disease. To determine causes of liver retention in the normal fetus and neonate and to study effects of further copper loading fetal liver, we used a guinea-pig model to copper stress the fetus. Control pregnant dams drinking normal water and their litters were compared with a matched group drinking $0.185 \%$ $\mathrm{CuSO}_{4} .5 \mathrm{H}_{2} \mathrm{O}$, between 45 days' gestation and 30 days after birth. Dams fed $\mathrm{CuSO}_{4}$ and similar liver copper concentrations (LCC), serum copper and caeruloplasmin to time matched controls. At 45, 54, and 60 days' gestation LCC values were higher in copper fed dams' litters than in controls $(p<0 \cdot 01)$. Despite increased LCC, serum copper and caeruloplasmin were similarly reduced below adult levels in all litters. Liver copper concentrations peaked at 60 days in copper fed litters compared with the peak at birth in controls. At birth, however, LCC and total liver copper content were lower $(p<0.01)$ in copper fed dams' litters. Biliary copper excretion peaked at birth in both experimental groups but despite lower LCC, was higher in copper fed dams' litters $(p<0 \cdot 05)$ Despite similar LCC at 65 days' gestation (near term) and at four days after birth, biliary copper excretion was increased in litters from copper fed dams $(p<0.05)$. This suggests that the physiological liver copper retention before birth is related to poor biliary copper excretion and the latter can be induced by copper stress. Failure to switch on this pathway might perpetuate fetal copper metabolism and lead to Wilson's disease.
F13

Albendazole in hydatid disease. Results of treatment in 22 patients

D L MORRIS AND P W DYKES (Department of Surgery, General Hospital, Birmingham) We reported the early results of treating our first four patients with albendazole a year ago. We have now treated 22 patients with albendazole $10 \mathrm{mg} / \mathrm{kg} /$ day in divided dosage for one month. There were multiple cysts in eight cases, six had recurrent disease and three had previously undergone mebendazole therapy. All patient have been monitored by serial computerised tomography and/or real time ultrasound.

Two patients developed adnormalities of liver function tests during therapy but recovered uneventfully on withdrawal of therapy. One patient probably leaked from a large hepatic cyst two weeks after withdrawal of therapy. Of the 22 patients treated, one did not have hydatid, two were treated pre- and two postoperatively - results in these patients cannot yet be assessed. In the remaining 14 patients the radiographic change can be classified thus: (1) virtually complete disappearance of cysts in five cases; (2) partial reponse in an additional six cases; (3) no response in three cases.

Two specific features have been noted: the appearance of a transonic halo around the cysts during therapy and the apparent disappearance of daughter cysts. No patient as yet has developed evidence of recurrence (the first having been treated 18 months ago). The results of the use of albendazole in hydatid disease continue to be promising.

HEPATO - BILIARY AND PANCREATIC

F9-F18

\section{F14}

High fat-protein diet and pancreatic carcinogenesis

A G HOWATSON AND D C CARTER (University Department of Surgery, Royal Infirmary, Glasgow) The aetiology and pathogenesis of pancreatic cancer is unknown. The influence of high fat-protein diet (cooked soya flour) on pancreatic susceptibility to carcinogens was examined in the hamster/nitrosamine model.

The high fat-protein diet comprised $19 \%$ fat and $40 \%$ protein as compared with $3 \%$ fat and $16 \%$ protein for the standard diet.
High fat-protein diet (HF-P) fed ad libitum for 15 weeks caused modest pancreatic hypertrophy as evidenced by increased pancreatic wet weight when compared with a control group fed on standard diet (SD) (HF-P 229 $\pm 31 \mathrm{mg} / 100$ g; SD $256 \pm 32 \mathrm{mg} / 100 \mathrm{~g} ; \mathrm{p}<0.05)$. There was no increase in pancreatic DNA content to suggest hyperplasia.

Two groups of hamsters received nitrosamine by weekly subcutaneous injection and either high fat-protein diet or standard diet for up to 15 weeks. Histological assessment after the batch was killed at periods from five to 15 weeks revealed that premalignant and malignant pancreatic lesions occurred earlier and with greater frequency in the high fat-protein diet group $(\mathrm{p}<0.02)$.

High fat-protein diet shortens the tumour latency period, increases induction rate, and is a co-carcinogen in pancreatic carcinogenesis. The observation has important implications for our understanding of the pathogenesis of pancreatic carcinoma.

\section{F15}

Protective effect of dietary protein in bypass induced liver disease: an experimental study

J G C ARAUJO, R A HARRISON, TINA BARTON, M R LEWIN, AND C G CLARK (Department of Surgery, The Rayne Institute, University College, London) The role of protein malnutrition in the pathogenesis of jejunoileal bypass induced liver disease was investigated in the rat model. Twenty five female Wistar rats (mean weight $225 \mathrm{~g}$ ) were used in the study. In 20 rats, a $90 \%$ jejuno-ileal bypass was perfomed and the rats randomly allocated on the second postoperative day into two groups: group $A$ received normal laboratory diet and group B an isocaloric diet containing $25 \%$ more protein. Five rats had an enterostomy and reanastomosis performed and served as controls (group C), fed on a normal laboratory diet. All animals were weighed weekly. At eight weeks blood was collected for liver function tests, the animals were killed, total liver weight was recorded and full necropsy performed.

The results showed that the liver weight expressed as percentage of body weight was significantly reduced in group A animals $(p<0.02)$ when compared with groups $\mathbf{B}$ and $\mathbf{C}$, which did not differ. Compared with controls, albumin was 
significantly reduced in all bypassed animals $(p<0.01)$, the reduction being significantly less $(p<0.01)$ in the high protein fed animals (group B). Further, alkaline phosphatase was significantly raised in the normal diet fed bypassed animals (group A), compared with groups $B$ and $C(p<0.05)$. There was no difference in alanine or aspartate transaminases between the three groups.

This study supports the hypothesis that the liver dysfunction caused by jejuno-ileal bypass is the result of protein malnutrition and has shown the protective action of a high protein diet.

\section{F16}

Permanent non-operative access to the chronically diseased biliary tract

E M BARKER (introduced by $M \quad R \quad B$ Keighley) AND M WINKLER (Department of Surgery, University of Natal Medical School, Durban, $S$ Africa) No completely effective surgical solutions have yet been devised to meet the problems posed by recurrent benign strictures of the bile ducts, sclerosing cholangitis, and intrahepatic duct ectasia, with their complications of stasis, stone formation, recurrent attacks of acute cholangitis and secondary biliary cirrhosis.

A technique is described which permits permanent non-operative access to the biliary tree for purposes of repeated dilatation of anastomotic and intrahepatic duct strictures, placement and removal of tube-stents, removal of stones and debris, and lavage of intrahepatic ducts.

A biliary-intestinal anastomosis is constructed using a Roux-en-y loop of jejunum, the proximal 10 to $15 \mathrm{~cm}$ of this loop being brought to the surface, where an access jejunostomy-stoma is constructed. An anti-reflux valve is incorporated in the loop between the stoma and the biliary-intestinal anastomosis to limit external loss of bile.

Subsequent access to the biliary tree is gained by intruments introduced through the stoma, either using radiological control or by direct vision through a paediatric sigmoidoscope. When no longer needed, the stoma is closed and left in a subcutaneous position. It is easily reestablished should delayed biliary problems become evident. The successful use of this technique in three patients with complex biliary problems is reported.
F17

Epidemiological and clinical aspects of delta infection in Britain

P FARCL, A S F LOK, H C THOMAS, AND S SHERLOCK (Academic Department of Medicine, Royal Free Hospital, London) To investigate the epidemiology of delta infection in Britain, sera from $332 \mathrm{HBsAg}$ positive British patients consecutively collected from 1976-1982 were tested for delta antigen $(\delta \mathrm{Ag})$ and antibody (anti- $\delta$ ) and the characteristics of $\delta$ positive patients were analysed. Two hundred and nineteen patients had acute viral hepatitis (AH), 86 chronic liver disease (CLD), and 27 were asymptomatic carriers. Delta antigen and anti- $\delta$ were measured by RIA (reagent kindly provided by Dr $M$ Rizzetto), $\mathrm{HBsAg}, \mathrm{HBeAg}$ and anti-HBe by Abbott, RIA and IgM, and anti-HBc by IgM capture assay (Colindale).

Serum markers of $\delta$ infection were detected in 40 patients (33 men and seven women). Mean age was $27 \cdot 3$ years. Nineteen were drug addicts, five had contacts with drug addicts, and two were haemophiliacs. Thirty out of $219(13.7 \%)$ patients with $\mathrm{AH}$ had $\delta \mathrm{Ag}$ or low titre anti- $\delta$ in serum. Fifteen of these patients had simultaneous infection with hepatitis $B$ virus (HBV) and $\delta$ agent; three had a fulminant course, four recovered, two progressed to CLD (one had cirrhosis on biopsy nine months after the acute infection), and six were lost to follow-up. The other 15 patients had acute $\delta$ superimposed on chronic $\mathrm{HBV}$ infection: one had a fulminant course, four recovered and cleared both HBV and $\delta$ markers, two had deterioration of liver disease, and eight were lost to follow-up. Ten out of 86 (11.6\%) patients with CLD had high titre anti- $\delta$ in serum. Eight of these had liver biopsies: two with chronic active hepatitis and six cirrhosis. None of the asymptomatic carriers had any markers of $\delta$ infection.

In summary, our findings confirm that delta infection in Britain is predominantly found among addicts and haemophiliacs and is associated with more severe and rapidly progressive liver disease.

F18

Effect of cimetidine on hepatic cytochrome P450 turnover

K E L MCCOLL, M A CORREIA, G G THOMPSON, AND R SCHMID (Liver Centre, University of
California, San Francisco, USA, and University Department of Medicine, Western Infirmary, Glasgow) Cimetidine binds to the haem moiety of cytochrome (Cyt) P450 and thus inhibits hepatic mixed function oxidative metabolism. We provide evidence that this ligand binding also inhibits the oxidative degradation of the haemoprotein itself.

Induction of Cyt P450 by phenobarbitone (PB) requires increased haem synthesis which is reflected by increased activity of the rate controlling enzyme of haem biosynthesis delta-aminolaevulinic acid (ALA) synthase. We have observed in rats that cimetidine ( $50 \mathrm{mg} / \mathrm{kg}$ ip) administered 45 minutes before PB (40 mg/kg ip) diminishes the ALA synthase rise while enhancing the Cyt P450 rise. The combination of increased haemoprotein concentration with reduced rate of haem synthesis indicates reduced rate of Cyt P450 degradation. Confirmatory evidence was obtained by examining the effect of cimetidine $(50 \mathrm{mg} / \mathrm{kg} \mathrm{ip} / 8 \mathrm{~h})$ on the turnover of [ ${ }^{3} \mathrm{H}$-haem] Cyt $\mathrm{P} 450$. Twenty four hours after commencing cimetidine both the specific radioactivity (cimetidine $=11518 \mathrm{dpm} \times 10^{3} \mathrm{nmol}$ haem; placebo $=5595, \mathrm{p}<0.001)$ and concentration (cimetidine $=1.79 \mathrm{nmol} / \mathrm{mg}$ protein; placebo $=1.61, \mathrm{p}<0.05)$ of hepatic Cyt P450 were increased. Cimetidine did not affect hepatic microsomal haem oxygenase which catalyses the oxidative degradation of haem to bilirubin.

This ability of cimetidine to inhibit the in vivo degradation of the major hepatic haemoprotein Cyt $\mathrm{P} 450$ and thus reduce the demand for hepatic haem synthesis suggests that it may be beneficial in patients with acute porphyria who have hereditary impairment of hepatic haem synthesis.

CLINICAL GASTROENTEROLOGY AND BILIARY F19-F28

\section{F19}

Obscure gastrointestinal bleeding of small bowel origin

J $\mathbf{N}$ THOMPSON, A P HEMINGWAY, G A D MCPHERSON, H REES, D J ALLISON, AND J SPENCER (Departments of Surgery, Histopathology, Radiology, Hammersmith Hospital, Royal Postgraduate Medical School, London) The cause of gastrointestinal haemorrhage is identified in 
approximately $95 \%$ of cases by routine upper or lower gastrointestinal investigations. In the remainder the cause may be considered obscure. The majority of these patients have colonic angiodysplasia. The small bowel is a less common source of haemorrhage. We have investigated 34 patients with obscure gastrointestinal bleeding from the small bowel.

They had a median age of 52 years (range 13-71 years) and an equal sex ratio. Patients presented with melaena (30 cases), chronic anaemia (three) and haematemesis (one). The median length of history was 49 weeks (range one day-36 years), with a median four previous blood transfusions (range 0-40) and median four previous gastrointestinal investigations (range 0-9).

The small bowel lesions identified were: vascular anomalies (12 cases), Meckel's diverticula (eight), leiomyomas (seven), ulcerated diverticula (two) and five other single lesions. All but one of the patients with vascular lesions were over 50 years old. Selective visceral angiography identified $50 \%$ of lesions, and additionally two cases of colonic angiodysplasia, the remainder were found at operation.

Our results suggest that when selective angiography for obscure bleeding from the small bowel is negative, or unavailable, laparotomy should be considered earlier as a diagnostic procedure.

\section{F20}

Steroid responsive veno-obliterative syndrome: survival after combined SVC and IVC obstruction with 'downhill' oesophageal varices

P N MATON, H J F HODGSON, D J ALLISON, AND v S CHADWICK (Departments of Medicine and Radiology, Royal Postgraduate Medical School, DuCane Road, London) Oesophageal varices are usually associated with intrinsic liver disease or occlusion of hepatic portal or splenic veins. In all these cases the blood flow in the varices is cephalad. We describe a patient with an inflammatory veno-obliterative disorder leading to 'downhill' varices. The patient presented with bleeding oesophageal varices but gave a 16 year history of skin nodules, arthralgias, anaemia, pericarditis menorrhagia requiring hysterectomy and episodes of spontaneous thrombosis of an axillary vein, and the superior vena cava. Venography showed an occluded superior vena cava, innominate vein, and axillary veins with venous return from the arms occurring via intercostal vessels to the azygous system. Venous return from the head occurred via mediastinal vessels including the varices and the portal vein to the liver. Both iliac veins and the inferior vena cava were also thrombosed, but direct splenoportography showed normal portal pressures, portal vein, and hepatic veins. Extensive haematological, immunological, biochemical and bacteriological investigations revealed no predisposing cause for the thrombosis but the patient had an ESR of $85 \mathrm{~mm}$, and an IgG of $26 \mathrm{~g} / \mathrm{l}$ (polyclonal). The patient was given steroids and anticoagulants but bled from oesophageal and colonic veins necessitating cessation of anticoagulants. On prednisolone the ESR is $<15 \mathrm{~mm}$, the patient has had no further episodes of bleeding and, as evidenced by reduction in the size of the azygous vein further venous anastomoses have developed. We suggest that patients with episodes of venous thrombosis and evidence of an inflammatory disorder warrant a trial of steroids.

\section{F21}

\section{Unselected variceal haemorrhage}

P C HAWKER, D I MORRIS, P FABRICIUS, M R B KEIGHLEY, AND P W DYKES (Department of Gastroenterology, and Department of Surgery, General Hospital, Birmingham) The results obtained by specialist units in the management of variceal haemorrhage may not be widely applicable to unselected patients presenting to a general hospital. We have, therefore, carried out a three and a half year audit in our unit. There were 45 admissions in 37 patients, 29 men, mean age 57 years (range 16-78 years), the underlying liver disease was alcoholic in 21, chronic active hepatitis $\mathrm{B}$-ve three, $\mathrm{B}+\mathrm{ve}$ two, primary biliary cirrhosis two and schistosomiasis one. Eight were idiopathic.

Mortality per admission was $40 \%$ (18 patients). Treatment had been withdrawn in six of the patients who died (three hepatoma, three physicians request). Of the remaining deaths three were from uncontrolled haemorrhage, four from liver failure and one each due to CVA, myocardial infarction, septicaemia, postoperative sepsis and a clotted shunt. Of those who died four were Childs group B and the remaining 14 were group C. Seven patients underwent operation - oesophageal transection in five (three deaths) and portacaval shunt in two (one death).

During the period of the study we have carried out injection sclerotherapy in 29 admissions (25 patients) bleeding was controlled in $19(65 \%)$ admissions. All patients in whom bleeding was not controlled died.

In an unselected series of patients such as our own a higher mortality is to be expected but the acute results of sclerotherapy in terms of control of haemorrhage suggest this technique is also likely to be a useful technique outside specialised units.

F22

Stresses of vomiting. A study of the pathophysiology of the Mallory Weiss tear

C P SWAIN, T N MILLS, JULIA M DARK, J O'SULLIVAN, $P$ R SALMON AND $T$ C NORTHFIELD (The Norman Tanner Gastroenterology Unit, St James' Hospital and Departments of Gastroenterology and Medical Physics, University College Hospital, London) This study seeks to elucidate the pathophysiology of the Mallory Weiss tear and the mucosal stresses of vomiting. From data of 100 Mallory Weiss tears in 79 of 724 patients admitted with UGI bleeding, new endoscopic data on retching and direct observations of experimental tears in post mortem gastric specimens, a reconstruction of the probable events in the production of the Mallory Weiss tear is presented as a new model. This model should account for the following features: $100 / 100$ tears occurred within $2 \mathrm{~cm}$ of the cardiooesophageal mucosal junction (COMJ), $99 \%$ ran in luminal axis, most $(71 \%)$ were in gastric mucosa alone and most $(\mathbf{7 1 \%})$ lay posterior to the mid point of the lesser curve. A striking endoscopic observation during retching is of forceful prolapse of a tongue-like process of gastric mucosa into thoracic oesophagus seen in $40 / 45$ endoscopies interrupted by retching. Prolapse measured $7.5 \mathrm{~cm} \pm 3.5$, arising from left anterior wall of stomach in $75 \%$. Experimental tears were observed in 14 water filled stomachs with an endoscope or mucosal side out. Pressures of $110 \pm 35$ $\mathrm{mm} \mathrm{Hg}$ initiated a tear. Maximum dilatation under pressure always occurred just below COMJ on lesser curve posteriorly. Measurement of tenting distance during biopsy clinically and in stretched specimens show that mucosalmuscle attachments are firmer at the COMJ than in body. A new model of the pathogenesis of the Mallory Weiss tear was constructed from these observations. Pressure greater than $100 \mathrm{~mm} \mathrm{Hg}$ forces stomach contents and anterior aspect of 
fundus into oesophagus dilating COMJ. Forcible prolapse of gastric mucosa causes extra hoop stress at COMJ. Inelasticity of mucosa at COMJ on stretched muscle contributes. Site of the tear is determined by site of maximally stretched muscle.

\section{F23}

Differential diagnosis of dyspepsia: peptic ulcer or not?

G P CREAN, W I CARD, A D BEATTIE, $R$ J HOLDEN, R P KNILL-JONES, R W LUCAS, AND D SPIEGELHALTER (Diagnostic Methodology Research Unit, Southern General Hospital, Glasgow) Our group is attempting to develop a diagnostic decision system for dyspepsia. In this presentation the symptoms that discriminate peptic ulcer $(n=230)$ from other causes of dyspepsia $(n=537)$, and DU from GU are described. The data have been analysed by the method of logistic discrimination by which a 'score' can be attached to a symptom (indicant) signifying the amount of evidence conveyed towards the diagnosis of peptic ulcer when it is present; the negative score against ulcer when the symptom is absent has been calculated also. Some indicants which are uncommon in peptic ulcer (less than $20 \%$ of cases) for example, previous perforation, symptoms worse in winter etc., convey powerful evidence in favour of ulcer (scores $>100$ ) when present, but much less evidence against ulcer when absent (scores about 50). The 'classical' symptoms of ulcer (pain relieved by food or antacids, family history) occur in $40-70 \%$ of patients with ulcer, and convey modest evidence in favour of ulcer when present (scores about 50). Their 'negative' scores or scores against ulcer when they are absent are roughly the same. The commonest symptoms of ulcer (abdominal pain, epigastric pain, episodic pain) occur in over $70 \%$. When present they convey little evidence in favour of ulcer (scores about 20); when absent, however, they convey almost twice as much evidence against peptic ulcer (scores more than 50).

The data exemplify the value of symptoms in distinguishing peptic ulcer from other causes of dyspepsia and illustrate the relationship between the frequency of a symptom or an indicant, and its evidential value in diagnosis.

F24

Tumours and pseudotumours of the duodenal papilla - cases of mistaken identity

D L CARR-LOCKE, J MATHER, D FOSSARD, AND A W HALL (Leicester Royal Infirmary and Leicester General Hospital, Leicester) From a consecutive series of 44 tumours of the papilla of Vater diagnosed at ERCP during a six year period, 32 were adenocarcinomas, two were adenomas, one was a non-secreting apudoma and nine were considered to be pseudotumours an entity not well documented. Fifteen of the cancers and all nine pseudotumours underwent endoscopic sphincterotomy to relieve biliary obstruction as a preoperative measure in seven and as sole therapy in 17. All cancers were confirmed by endoscopic biopsy, surgery, or autopsy.

All pseudotumours had normal endoscopic biopsies, one a normal surgical biopsy and all have been followed for three months to three years with repeat endoscopy or ERCP in six. These patients had all had previous evidence of gallbladder or common bile duct calculi and all presented with jaundice clearing after sphincterotomy. In all nine patients the endoscopic appearances at ERCP were intially thought to be typical of cancer and the recognition of this entity of pseudotumour of the papilla is important to avoid unnecessary surgical intervention.

\section{F25}

Ultrasonic detection of common bile duct stones: prospective comparison with ERCP in the postcholecystectomy patient

H J O'CONNOR, I HAMILTON, J K WATTERS, D J LINTOTT, AND A T R AXON (The Gastroenterology Unit and Department of Radiology, The General Infirmary, Leeds) Though of proven diagnostic value in jaundice and suspected cholelithiasis, the place of ultrasound in the evaluation of postcholecystectomy patients with suspected common bile duct (CBD) stones is not clear. To clarify its role in this impórtant clinical problem we have performed ultrasound in 52 symptomatic postcholecystectomy patients before ERCP. Sonography was performed with a static scanner in the early examinations later superseded by a real-time sector scanner and the size of the intra- and extra-hepatic bile ducts and the presence or absence of CBD stones were noted. Endoscopic cholangiography failed in seven patients (success rate, $87 \%$ ); one patient subsequently had PTC leaving 46 in whom uitrasound and direct cholangiography were compared.

In total, 22 of 46 patients had CBD stones and ultrasound detected 10 of these (sensitivity, $45 \%$ ). The absence of a stone was correctly diagnosed by ultrasound in 23 of 24 patients (specificity, 96\%). There was no significant learning effect with similar results in the first 23 examinations and the last 23. Stones were seen in 19 of 28 patients with dilated ducts $(>6 \mathrm{~mm}$ at ultrasound) and in two of 17 with nondilated ducts $(<6 \mathrm{~mm})$; the predictive value for CBD stones of a diagnosis of duct dilatation was thus $68 \%$, the value of a negative diagnosis was $88 \%$. Endoscopic sphincterotomy was performed in 19 patients with extraction or spontaneous passage of stones in 15 (success rate, 79\%). We conclude that ultrasound cannot reliably diagnose or exclude $\mathrm{CBD}$ stones and that ERCP should be the initial diagnostic modality in the symptomatic postcholecystectomy patient.

\section{F26}

Gall-stone migration and early diagnosis of cholelithiasis in acute pancreatitis

A D MAYER AND M J MCMAHON (University Department of Surgery, The General Infirmary, Leeds) In acute pancreatitis (AP), an early rise in plasma aspartate transaminase (AST) above $60 \mathrm{IU} / \mathrm{l}$ is characteristic of gall-stone aetiology, probably due to transient biliary tract obstruction by a migrating gall stone. Some patients may benefit from urgent removal of an impacted stone, making early diagnosis increasingly important. This study was designed to compare AST with ultrasound in the early diagnosis of gall stones and to establish the incidence of migrating stones in patients with AP.

Thirty five attacks of AP were studied prospectively. Aspartate transaminase was estimated on admission, grey scale ultrasound was performed during the first week, and faeces passed during the admission were sieved for stones. Biliary radiology was performed after recovery from the attack.

Gall stones were found in 20 patients, 15 $(75 \%)$ of whom were correctly diagnosed by AST and $11(55 \%)$ by ultrasound. Four patients without gall stones $(27 \%)$ were wrongly diagnosed by AST and two had false positive ultrasound scans. Stones were retrieved from the faeces in 16 patients, 13 of whom had an AST $>60$ IU/1 
including three patients who had normal ultrasound and radiological investigations.

This study confirms that most patients with gall-stone pancreatitis pass stones in their faeces and suggests that, while ultrasound has a higher specificity, AST estimation may be more sensitive in the early detection of gall stones.

\section{F27}

How should gall stones be detected after an attack of acute pancreatitis?

A J GOOdMan, J NeOPTOLEmos, D L CARRLOCKE, AND D P FOSSARD (Departments of Medicine and Surgery, Leicester Royal Infirmary, Leicester) After an attack of acute pancreatitis gall stone detection is important as early surgical or endoscopic intervention may prevent recurrent attacks. Routine radiological investigations will miss gall stones in some patients. In this study 128 consecutive patients with acute pancreatitis underwent biochemical analysis (BA), ultrasonography (US) and/ or oral cholecystography (OCG) except in six patients who died within 24 hours of admission and in three with postcholecystectomy calculi.

Ultrasonography and OCG detected 74 out of 85 patients who had gall stones. Thirty four patients who had normal US and OCG underwent ERCP and nine further cases with gall stones were detected including two alcoholics. ERCP also revealed patients with chronic pancreatitis (four), pancreas divisum (three) and pancreatic carcinoma (one). Ultrasonography, OCG, and ERCP failed to detect two other patients with gall stones. Biochemical analysis predicted 45 patients with gall stones including six detected by ERCP but not by US or OCG. Only 13 patients were finally classified as idiopathic.

Endoscopic sphincterotomy and stone extraction were performed soon after clinical improvement in $\mathbf{1 0}$ patients, four before cholecystectomy. Three other patients had sphincterotomy for retained stones.

In conclusion, it is recommended that ERCP be performed after normal OCG and US if gall stones are predicted by biochemical analysis.

\section{F28}

Improved method of endoscopic endoprosthesis insertion in patients with malignant obstructive jaundice
A $R$ W HATFIELD, $R$ S MURRAY, AND J E LENNARD-JONES (Academic Department of Gastroenterology and Department of Radiology, The London Hospital, London) Patients with malignant obstructive jaundice can be palliated by inserting a biliary endoprothsesis via the endoscopic route. Conventional duodenoscopes (Olympus JF-IT) allow a 7 or 8 FG pigtail stent to be inserted through a biliary stricture but a prototype large channel instrument (Olympus JF-3.7T) allows a larger 10 FG stent to be used.

The initial experience with small 8 FG pigtail stents and the later experience with straight, barbed large 10 FG stents is reported in 30 patients with malignant biliary obstruction in whom surgery was considered unsuitable. A small stent (8 FG) was inserted in 14 patients and a large stent (10 FG) in 12 . The age, level of serum bilirubin, and clinical state were similar in each group. Stenting failed in four patients as it was impossible to pass a guide wire through the stricture and in two patients the stricture was too narrow to pass a large 10 FG stent so a smaller 8 FG was used. Antibiotics were given intravenously before, and for at least $\mathbf{4 8}$ hours after each procedure.

A substantial fall in serum bilirubin at seven to 10 days was achieved in $65 \%$ of patients with small stents and in $85 \%$ of patients with large stents. The degree of fall in bilirubin was greater in the 10 FG group. The incidence of sepsis $(>48 \mathrm{~h})$ was $79 \%$ in the small stent group but only $25 \%$ in the large stent group. Two of the 8 FG stents slipped out, stopped draining and had to be re-inserted, whereas none of the 10 FG stents slipped.

A satisfactory outcome in relieving jaundice and discharging patients was achieved in $50 \%$ of the 8 FG group and in $75 \%$ of the $10 \mathrm{FG}$ group. The insertion of a single barbed $10 \mathrm{FG}$ stent using a prototype $3.7 \mathrm{~mm}$ duodenoscope relieves jaundice more effectively and with less complications than conventional instruments with smaller stents.

SMALL BOWEL

F29-F38

\section{F29}

Influence of food and digestive secretions on metoprolol jejunal absorption

N VIDON, D EVARD, J GODBILLON, J HERTZ, AND J J BERNIER (INSERM U54 - Hôpital
Saint-Lazare, Paris, France. Laboratoires Ciba-Geigy, Rueil Malmaison, France) Previous investigations have established that food enhances the bioavailability of metoprolol, a cardioselective betaadrenergic antagonist. Several mechanisms have been proposed: an increase of drug gastric emptying, changes in hepatic blood flow or in the metabolism of the drug during the first passage through the liver; but an enhancement of the intestinal transport of the drug has never been proposed. The present work examines, in six healthy male volunteers by a direct method the role of nutrients and digestive secretions on the intestinal absorption of metoprolol and the relation between this absorption and the bioavailability of the drug. The intestinal perfusion technique was used, an occluding balloon allowing to isolate, when desired, a $30 \mathrm{~cm}$ study segment of jejunum. Two solutions containing $60 \mathrm{mg} / \mathrm{l}$ of metoprolol was perfused at the rate of $10 \mathrm{ml} / \mathrm{min}$ during 150 minutes: (a) a saline which has been tested twice: once with balloon deflated and once with balloon inflated in order to disregard the role of pancreatic and biliary secretions in the test segment; (b) a nutrient solution, at $300 \mathrm{mOsm} / \mathrm{kg}$, bringing $2.6 \mathrm{Kcal} / 10 \mathrm{ml}$, balloon being deflated. Intestinal and blood samples were collected.

The results indicate that (1) with the nutrient solution, metoprolol absorption was four fold $(93 \%)$ as high as that with saline (23\%); (2) bile salts did not increase the drug absorption; (3) with or without nutrients, the drug and its major metabolite appeared in plasma at the same rate when the same quantity of drug reached the portal circulation; (4) in conclusion this study suggests that the increased bioavailability of metoprolol induced by nutrients is related to the higher absorption rate of this drug in the first part of the small bowel. Nutrients did not modify the metabolism of the drug.

\section{F30}

$E$ coli enterotoxin and anti-bacterial drug absorption

J LYNCH AND M L LUCAS (Institute of Physiology, University of Glasgow, Glasgow) An intestinal derangement is induced in vivo on exposure of rat jejunum to $E$ coli (ST) enterotoxin. This derangement has two components; a reduction of fluid absorption, and consequently solvent drag, and an alkalinisation of the luminal 
contents causing a change in concentration of the undissociated lipophilic species. This typically leads to malabsorption of the weakly acidic drugs such as salicylate. The effect of toxin on the absorption of the anti-bacterials cephalexin, pyrimethamine and trimethoprim was investigated.

$\left[{ }^{14} \mathrm{C}\right]$-drug solutions $(25 \mathrm{ml})$ were recirculated through loops of proximal jejunum $(15 \mathrm{~cm})$ for three hours. Water movement was monitored using the nonabsorbable marker $\left[{ }^{3} \mathrm{H}\right]-\mathrm{PEG}$ and $\mathrm{pH}$ by pH electrode.

Toxin caused a significant $(p<0.001)$ reversal of the normal acidification to an alkalinisation of the luminal perfusate. Additionally it reduced fluid absorption to one quarter of control values $(p<0.001)$ except for cephalexin where the drug itself produced a secretory effect. This effect was antagonised by toxin and fluid absorption increased towards normal with toxin. Cephalexin absorption, however, although tending to decrease, was not significantly altered. Pyrimethamine absorption remained unaltered despite much reduced solvent drag. The larger analogue, trimethoprim, showed increased absorption $(\mathrm{p}<0.05)$. Solvent drag and $\mathrm{pH}$ both affect the drugs to varying degrees dependent on their physical properties. These results in rat in vivo, particularly the increased weak base absorption, closely resemble changes in active coeliac disease and may serve as an experimental model.

\section{F31 \\ HLA-DR typing in coeliac disease: evidence for genetic heterogeneity}

A ELLIS, C J TAYLOR, M DILLON-REMMY, J C WOODROW, AND R B MCCONNELL (Gastroenterology Unit, Broadgreen Hospital, Liverpool, Department of Child Health and Tropical Child Health, Alder Hey Children's Hospital, Liverpool, Department of Medicine, University of Liverpool, Liverpool) The association between coeliac disease and the histocompatibility antigen HLA-DR3 is well recognised and has been found in all the populations in which it has been studied. An association between coeliac disease and HLA-DR7 has also been reported in some populations but not in others. These differences have been explained by postulating a coeliac disease gene in linkage disequilibrium with DR3 and DR7 in some populations but with DR3 alone in others. We have HLA-DR typed 69 coeliacs as part of a family study and found that $91.3 \%$ were HLA-DR3 and
$33.3 \%$ were DR7 compared with $26.2 \%$ $\left(p=2.0 \times 10^{-19}\right)$ and $29.2 \%(p=0.63)$ in the controls respectively. As a separate study 42 childhood coeliacs, all of whom fulfilled the ESPGAN criteria, were typed: $85.7 \%$ were DR3 $\left(p=4.3 \times 10^{-12}\right)$ and $59.2 \%$ were DR7 $\left(p=4.6 \times 10^{-4}\right)$. When the patients in the family study were analysed according to age at presentation and were combined with the patients from the childhood study, a comparison of the juvenile coeliacs (less than 20 years) and the adult coeliacs (greater than 20 years) revealed no difference in the proportions who were DR3 $\left(X^{2}=0\right)$ but a significant difference in the proportions who were DR7 $\left(X^{2}=9 \cdot 18\right.$, $p=0.0024)$. Thus juvenile coeliacs are genetically different from adult coeliacs. It is noteworthy in this respect that six of the seven studies reporting an association with DR7 are from paediatric centres.

\section{F32}

Soya protein hypersensitivity in coeliac disease: evidence for cell mediated immunity

N MIKE, M HAENEY, AND P ASQUITH (The Alastair Frazer and John Squire Metabolic and Clinical Investigation Unit, Birmingham) Humoral and cell mediated immunity to gluten occur in coeliac disease. Up to $10 \%$ of patients with coeliac disease have a suboptimal response to gluten withdrawal, and this may in part be related to sensitivity to other foods. We have previously shown evidence of humoral immunity to soya protein in nonresponsive coeliac disease.

In this study, cell-mediated immunity to soya has been assessed. Sixty three patients with coeliac disease ( 24 on a normal diet, 27 with a good response to gluten-free diet, and 12 with a suboptimal response) were compared with 20 healthy controls, 16 patients with inflammatory bowel disease, and 27 patients with other upper gastrointestinal diseases. The leucocyte migration inhibition test was used as an in vitro correlate of cell mediated immunity while a heated, ethanol extracted soya bean meal was used as the antigen. There was no significant difference between patients in each group, except those with a suboptimal response to gluten withdrawal, of whom $66 \%$ showed significant inhibition with soya. This group's mean migration inhibition was significantly different from all other groups $(p<0.003)$

This confirms that lymphocytes sensitised to soya protein are present in patients with suboptimally responsive coeliac disease, and suggests that soya protein may be causally implicated in this condition.

F33

Is reaginic (type I) hypersensitivity involved in coeliac disease?

B B SCOTT, ANNE GOODALL, P M STEPHENSON, AND D JENKINS (Departments of Medicine and Pathology, Lincoln County Hospital, Lincoln). The small intestinal mucosal damage in coeliac disease is caused by an abnormal response to gluten. The mechanism of the damage is not known but immunological factors are thought to play an important part. Both cell mediated and humoral responses, which are by no means mutually exclusive, have been incriminated. Type I, reaginic, mechanisms have generally been assumed not to be involved but there is growing evidence that they may be. An ultrastructural study has shown that the initial mucosal changes during the first few hours after gluten challenge are oedema, vascular changes and mast cell degranulation and a recent study has shown an increase in mucosal mast cells in untreated coeliac disease falling to normal on treatment. There is little information on mucosal IgE plasma cells. We have therefore studied $\operatorname{IgE}$ plasma cells, using a modified immunoperoxidase technique, in the small bowel mucosa of 20 controls, 23 untreated coeliacs, 19 treated coeliacs, and seven patients with Crohn's colitis. We used a single batch of IgE antiserum showing no cross-reactivity with $\operatorname{IgA}$.

IgE plasma cell counts were very significantly increased $(p<0.001)$ in untreated coeliacs compared with controls, and fell significantly on treatment. The counts were similar in controls and Crohn's disease. The results taken together with results of the previous studies suggest that reaginic, type I, hypersensitivity may be involved in the pathogenesis of coeliac disease, possibly as an initial step predisposing to other types of immune response.

F34

Chemically defined low fat diet does not improve calorie absorption in the short bowel syndrome

P B MCINTYRE, M FITCHEW, S R WOOD, AND J E LENNARD-JONES (St Mark's Hospital London) A controlled comparison has 
been made of two different types of liquid feeds used in the treatment of the short bowel syndrome. One feed (Ensure, Abbott) consists of whole protein, hydrolysed corn starch and long chain tri-glycerides; the other (Nutranel, Roussel) consists of short chain peptides, low fat (20\%, half as medium chain triglycerides) and oligosaccharides. Feeds were formulated to give an equivalent quantity of nitrogen, sodium, and total volume and were administered as a sip feed to four patients, and by nasogastric tube to two patients. In these patients the remaining length of bowel ranged from $60-150 \mathrm{~cm}$ and ended in a small bowel stoma with fasting effluent losses of $800-20000 \mathrm{~g} / 24$ hours. Two patients were receiving home parenteral feeding, and three required nasogastric supplementation of their diet. Twenty four hour collections of stoma effluent were analysed for total calorie content by bomb calorimetry, wet and dry weight, and sodium and potassium concentration on both diets. Results expressed as mean \pm SEM for Ensure and Nutranel respectively were: calorie absorption $53.8 \% \pm 4.8 \%$ (range $29 \cdot 6-80 \cdot 3$ ) and $54.0 \% \pm 6.4 \%$ (range 18.9-78.9), wet weight $2118 \mathrm{~g} \pm 259$ and $1942 \mathrm{~g} \pm 108$, dry weight $139.9 \mathrm{~g} \pm 14.03$ and $154.7 \mathrm{~g} \pm 17.03$, sodium $94.5 \mathrm{mmol} / \mathrm{l} \pm 3.4$ and $78.8 \mathrm{mmol}$ $1 \pm 7.4$, potassium $10.8 \mathrm{mmol} / 1 \pm 0.32$ and $10 \cdot 7 \mathrm{mmol} / \mathrm{I} \pm 0.98$. There was no significant difference in any parameter measured when analysed by Student's $t$ test for paired samples. These results indicate that patients with the short bowel syndrome may absorb only a small proportion of calories administered, even though given as a liquid feed by slow infusion. No apparent benefit was observed from using a more expensive chemically defined, low fat diet, as compared with a simpler whole protein, fat containing feed.

\section{F35}

How does guar gum improve glucose tolerance in man?

N A BLACKBURN, H JARJI, AND N W READ (Department of Physiology, University of Sheffield, Sheffield) Experiments were carried out in human volunteers to investigate the mechanism by which guar gum improves glucose tolerance. In the first study, the effect of guar gum $(5.8 \% \mathrm{w} / \mathrm{v})$ on glucose tolerance was determined in eight healthy volunteers while gastric emptying was simultaneously measured using a gamma camera. Guar reduced the blood glucose (mean peak increase in blood glucose concentration: control, 3.6 \pm 0.4 $\mathrm{mmol} / 1$; guar $1.6 \pm 0.3 \mathrm{mmol} / \mathrm{l}$; $\mathrm{p}<0.001)$ and plasma insulin response (mean peak insulin concentration: control, $46 \pm 6 \mathrm{mU} / 1$; guar $20 \pm 3 \mathrm{mU} / \mathrm{l} ; \mathrm{p}<0.01$ ) to an oral glucose load, but did not significantly delay gastric emptying, and there was no correlation between individual blood glucose responses and gastric emptying rates $(r<0.22)$. In a separate study, the effect of guar $(0.6 \% \mathrm{w} / \mathrm{v})$ on the jejunal absorption of glucose was assessed in six volunteers by steady state perfusion using a solution containing $135 \mathrm{mM} \mathrm{NaCl}, 30 \mathrm{mM}$ glucose and $6 \mathrm{~g} / \mathrm{l}$ PEG with or without $0.6 \%$ (w/v) guar. Glucose absorption was significantly reduced during perfusion with guar (8.6 \pm 1 vs $13.2 \pm 1.3 \mathrm{mmol} / \mathrm{h} ; 25 \mathrm{~cm}$ small intestine; $\mathrm{p}<0.01$ ), but returned to control values during subsequent perfusion with guar-free solutions. Fluid absorption was also inhibited in the presence of guar $(72 \pm 20 \mathrm{vs}$ $115 \pm 26 \mathrm{ml} / \mathrm{h} ; 25 \mathrm{~cm}$ small intestine; $\mathrm{p}<0.02$ ). We conclude that guar gum can improve glucose tolerance by a mechanism independent of gastric emptying, probably by reducing the rate of small intestinal glucose absorption.

\section{F36}

Effect of acetate and citrate on sodium and water absorption in the human jejunum: implications for oral rehydration solutions

D D K ROLSTON, $K$ J MORIARTY, M J G FARTHING, M J KELLY, M L CLARK, AND A M DAWSON (Department of Gastroenterology, St Bartholomew's Hospital, London) Oral rehydration solutions (ORS) containing glucose and bicarbonate are widely used to correct dehydration and acidosis seen in severe diarrhoeal disease. The few animal studies reported have shown that acetate and citrate enhance intestinal water and electrolyte absorption. It has therefore been suggested that these organic anions be incorporated into ORS for use in man. We report here results of a study of the effect of acetate and citrate on water and electrolyte transport in the human jejunum in vivo. A standard technique was used to compare the effect of isotonic solutions of acetate $(n=5)$ or citrate $(n=6)$ with saline $(n=11)$ on jejunal water and electrolyte movement. $50 \mathrm{mM}$ acetate enhanced net absorption (denoted as +$)$ of water $(+110 \cdot 8 \pm 21.3 \mathrm{vs}$ $+33.5 \pm 16.7 \mathrm{ml} / 30 \mathrm{~cm} / \mathrm{h}, \mathrm{p}<0.005)$ and sodium $(+25.0 \pm 2.0$ vs $+12.5 \pm 2.9 \mathrm{mmol} /$ $30 \mathrm{~cm} / \mathrm{h}, \mathrm{p}<0.02)$, while $5 \mathrm{mM}$ acetate had no effect. Interestingly, the enhancement of water and sodium absorption by $50 \mathrm{mM}$ acetate is of the same magnitude as that earlier shown for $30 \mathrm{mM}$ bicarbonate. Paradoxically, although $5 \mathrm{mM}$ citrate stimulated net absorption of both water $(+61.3 \pm 17.5$ vs $+1.9 \pm 16.2 \mathrm{ml} / 30 \mathrm{~cm} / \mathrm{h}$, $\mathrm{p}<0.05)$ and sodium $(+18.4 \pm 3.4$ vs $6.3 \pm 3.5 \mathrm{mmol} / 30 \mathrm{~cm} / \mathrm{h}, \mathrm{p}<0.025), 50 \mathrm{mM}$ citrate had no singificant effect.

Before extrapolating animal data to therapeutic regimes in man, more information on the optimal concentrations of these organic anions in enhancing water and electrolyte absorption in the human intestine is required.

\section{F37}

Effect of psychological stress on fluid and electrolyte transport in the human jejunum

P WOODMANSEY, T E BATES, AND N W READ (Department of Physiology, University of Sheffield, Sheffield) The effect of controlled psychological stress on jejunal transport of fluid and electrolytes was investigated by steady state intestinal perfusion in five healthy volunteers. Stress was induced by a dichotomous listening test, in which the subject listened to two spoken essays played through each ear of stereo headphones simultaneously, and the stress period was sandwiched between two control periods, during which subjects listened to a mono-recording of a light novel. Stress induced significant increases in objective measurements of pulse, blood pressure, and subjective scores for anxiety, compared with either control period $(p<0.05)$. Stress was also associated with a significant reduction in absorption of water (control $126 \pm 20 \mathrm{ml}$ vs stress $79 \pm 13 \mathrm{ml} / 25$ $\mathrm{cm} / \mathrm{h} ; \mathrm{p}<0.02 ;$ Mean $\pm \mathrm{SEM}$ ) and sodium $(15.4 \pm 2.7$ vs $10.0 \pm 1.7 \mathrm{mM} / 25 \mathrm{~cm} / \mathrm{h}$; $\mathrm{p}<0.05$ ), though these reductions were maintained during the subsequent control period. In a separate series of experiments, listening to the control tape for three consecutive one hour perfusion periods did not cause any significant changes in transport (fluid absorption: $55 \pm 31,78 \pm 26$, $58 \pm 18 \mathrm{ml} / 25 \mathrm{~cm} / \mathrm{h}$ ) or in objective and subjective indices of stress. These results may help to explain the association between functional diarrhoea and high anxiety scores.

\section{F38}

Mechanisms of diarrhoea after morphine withdrawal in tolerant animals 
G WARHURST, G S SMITH, N B HIGGS, AND L A TURNBERG (Department of Medicine, Hope Hospital [University of Manchester School of Medicine], Salford) The characteristic syndrome which occurs after withdrawal from morphine tolerance includes diarrhoea which may be due to a disturbance of control of intestinal transport by endogenous opiates. We have studied this response in vivo and in vitro in rat intestine. Tolerance was induced within 48 hours by injection of a slow release emulsion of morphine hydrochloride (75 $\mathrm{mg} / \mathrm{rat}$ ) and withdrawal was precipitated by naloxone $(10 \mathrm{mg} / \mathrm{kg}, \mathrm{SC})$. Diarrhoea occurred within 10 minutes. Using a single pass perfusion technique under anaesthesia absorption of water in ileal loops was reduced after naloxone withdrawal (control 338 \pm 35 , tolerant $381 \pm 41$, withdrawal $158 \pm 50 \mu \mathrm{l} / \mathrm{g} / 15 \mathrm{~min}, \mathrm{p}<0.01, \mathrm{n}=7$ ). Similar results were observed in the colon. To investigate ion flux responses pieces of rat ileal mucosa stripped of muscle coats were studied in vitro under short circuited conditions. Naloxone withdrawal in tolerant animals provoked a marked reduction in net absorption of $\mathrm{Na}$ and $\mathrm{Cl}$ ( $\mathrm{Na} ; 1.64 \pm 0.6$ compared with $4.86 \pm 0.75$ in control and $5.51 \pm 0.46 \mu \mathrm{Eq} / \mathrm{cm}^{2} / \mathrm{h}$ in tolerant animals: $\mathrm{Cl} ; 0.717 \pm 0.53$ on withdrawal, $3.76 \pm 0.63$ and $4.68 \pm 0.82 \mu \mathrm{Eq} /$ $\mathrm{cm}^{2} / \mathrm{h}$ in control and tolerant animals respectively). Adenylate cyclase activity and prostaglandin $E_{2}$ synthesis and degradation were unchanged in ileal mucosa but prostaglandin $E_{2}$ output in ileal perfusate was increased $2-10$ fold during the first $\mathbf{1 0}$ minutes after naloxone with a fall to unrecordable concentrations after 20 minutes. This release of $\mathrm{PGE}_{2}$ occurred 30 minutes before the ion transport responses.

These data suggest that inhibition of salt and water absorption occurs after morphine withdrawal, supporting a physiological role for endogenous opiates and providing a mechanism for withdrawal diarrhoea.

POSTERS

F39-F82

\section{F39}

Inhibitory effect of peppermint oil on gastrointestinal smooth muscle

B A TAYLOR, D K LUSCOMBE, AND H L DUTHIE (University Department of Surgery, Welsh National School of Medicine and Division of Phamacology, Welsh School of
Pharmacy, UWIST, Cardiff) Recent studies have shown that peppermint oil (PPT) produces symptomatic improvement in patients with irritable bowel syndrome. We have now examined the action of PPT on gastrointestinal smooth muscle, to determine the possible mechanism by which this substance exerts its effect. Guinea pig ileum was suspended in modified Tyrode's solution at ${ }^{\circ} 37^{\circ} \mathrm{C}$ and contractile responses obtained to the cumulative addition of carbachol $\left(10^{-8}-10^{-5} \mathrm{M}\right)$ in the presence of increasing doses of PPT $\left(0.5 \times 10^{-6}-1 \times 10^{-4 v} / \mathrm{v}\right)$. Peppermint oil was found to inhibit muscle contractions, the resultant log concentration-response curves being shifted to the right in a non-parallel fashion. The same phenomenon was observed when histamine $\left(3 \times 10^{-7}-6 \times 10^{-6} \mathrm{M}\right)$, potassium chloride (0.5-20 $\mathrm{mM})$, barium chloride $(0.8-10$ $\mathrm{mM}$ ) and electrical field stimulation were used to contract the ileum. Adrenoceptor involvement was discounted when PPTinduced shifts in carbachol dose-response curves were found to be unaffected by either phentolamine $\left(10^{-6} \mathrm{M}\right)$, or propranolol $\left(10^{-6} \mathrm{M}\right)$. In the apparent absence of a neuronal effect, a possible direct action of PPT on smooth muscle contractility was examined. Using calcium free high potassium Tyrode's solution, log concentration-response curves to calcium chloride $(0.03-30 \mathrm{mM})$ were obtained in the presence of increasing doses of PPT, the resultant curves being shifted to the right in a parallel manner. In addition, PPT inhibited the carbachol-induced contractions of ileum suspended in $\mathrm{Ca}^{2+}$ free Tyrode's solution on the readmission of calcium ions. As these contractions may be attributed to carbachol-induced influx of extracellular $\mathrm{Ca}^{2+}$, it is concluded that PPT exerts its inhibitory effect on gastrointestinal smooth muscle by interference with the mobilisation of calcium ions.

F40

Differential absorption technique to assess sucrase activity in human intestine

D G MAXTON, R BEACH, D NICHOLAS, C NOONE, AND I S MENZIES (Department of Chemical Pathology, St Thomas' Hospital Medical School, London) A disaccharide absorption technique incorporating an unhydrolysable marker allows correction for variables affecting permeation and renal clearance. Using this method, we have studied, in vivo, the action of
Acarbose (Bay g 5421), a powerful alphaglucosidase inhibitor, at varying dosage, on intestinal sucrase activity.

Ten healthy fasted adult volunteers ingested test solutions containing sucrose $20 \mathrm{~g}$, lactose $20 \mathrm{~g}$ and L-rhamnose $1 \mathrm{~g}$ with between 0 and $500 \mathrm{mg}$ Acarbose, in $300 \mathrm{ml}$ water. Lactulose $7 \mathrm{~g}$ was included as an unhydrolysable marker. A complete urine collection was then made for 10 hours, and sugar content estimated by quantitative layer chromatography.

Results, expressed as a ratio of the percentage of ingested sucrose excreted to that of lactulose, showed a consistent rise as the dose of Acarbose was increased. The sucrose/lactulose, excretion ratio approached $1 \cdot 0$, indicating complete inhibition of intestinal sucrose hydrolysis, with $400 \mathrm{mg}$ Acarbose, but lactose hydrolysis, denoted by the lactose/lactulose excretion ratio, was not affected. Varying the dose of sucrose between 10 and $30 \mathrm{~g}$ did not alter the degree of inhibition. Deferring the ingestion of test sugars showed that the action of Acarbose was temporary, $80 \%$ of sucrase activity returning within 60 minutes.

Differential disaccharide absorption provides a quantitative and reproducible assessment of intestinal disaccharidase activity which is independent of monosaccharide absorption.

\section{F41}

Intestinal permeability in acute gastroenteritis of infants and adults

C NOONE AND I S MENZIES (Departments of Chemical Pathology and Paediatrics, St Thomas's Hospital Medical School, London) Lactulose (lacl: MW 342) and L-rhamnose (rham: MW 164) have been incorporated as inert markers of intestinal permeation in a study of absorption in acute gastroenteritis. During the acute illness and after recovery four weeks later 17 adults ingested lactulose $5 \mathrm{~g}$, rham $1 \mathrm{~g}$, D-xyl $5 \mathrm{~g}, 3 \mathrm{mGlc} 2.5 \mathrm{~g}$ in $250 \mathrm{ml}$ water ( 280 $\mathrm{mmol} / \mathrm{l})$ and 14 infants were given lacl 3.5 $\mathrm{g}$, rham $0.5 \mathrm{~g}$, lactose $10 \mathrm{~g}$, D-xyl $0.5 \mathrm{~g}$, $3 \mathrm{mGlc} 0 \cdot 1 \mathrm{~g}$ in $150 \mathrm{ml}$ water $(310 \mathrm{mmol} / \mathrm{l})$. Complete 5 hour urine collections were made, volumes recorded and an aliquot of each preserved for sugar analysis by quantitative layer chromatography.

The infants with acute enteritis (13 rotavirus, one adenovirus) showed an increase in lacl/rham urine excretion ratio (mean 0.41 ; range $0.06-1 \cdot 20$ ) which fell to normal $(0.027 ; 0.003-0.05)$ on recovery. 
The adults (two rotavirus, one astrovirus, arteritis nodosa (three), radiation enteritis two salmonella, one campylobacter, 11 (three), perforated small bowel carcinoma unidentified) had a similar response, with (two), and miscellaneous (two).

high initial lacl/rham ratios $(0 \cdot 167 ; 0.023$ $0.46)$ becoming normal $(0.025 ; 0.008-0.04)$ on recovery. The change in lacl/rham ratio during the acute phase was the result of both decreased rham and increased lacl absorption. Identical changes have been reported in coeliac disease where malabsorption of smaller molecules (D-xyl, mannitol, rham) due to reduced absorptive area is associated with increased permeability to larger molecules (cellobiose, lacl,

${ }^{51} \mathrm{Cr}$-EDTA) because of mucosal damage, both features are characteristic of villous atrophy.

Measurement of intestinal permeability in acute gastroenteritis may be of value for the investigation of delayed clinical recovery and, although the relationship between permeation of sugars and antigen is unknown, of complications such as milk allergy.

\section{F42}

\section{Small bowel perforation}

A B LUMSDEN, J M DIXON, AND J PIRIS (University Departments of Clinical Surgery and Pathology Royal Infirmary, Edinburgh) Perforation of the small bowel is uncommon in the western world. A clinical and histological review has been undertakenfl of 54 patients presenting with small bowel perforation over a 17 year period in Edinburgh.

The ages of patients with this condition ranged from nine to 92 years (mean 58.1 years). All 54 patients had abdominal pain, the duration being greater than 24 hours in 19; 36 patients had vomited before surgery. On examination 44 had signs of peritonitis. Free gas was present in 24 of 50 chest radiographs and gaseous distention of bowel with fluid levels was seen in 26 of 50 abdominal radiographs. Postoperative mortality was $17 \%$; $24 \%$ of patients developed a postoperative complication, including reperforation in six.

The sites of perforation were jejunum 14, Meckels diverticulum four, and ileum 36. A specific aetiology for the perforation was identified in 40 of the 50 jejunoileal perforations (10 non-specific). The causes were: proximal to an obstruction (13) (the obstruction being adhesions (eight); colonic carcinoma (two); gall stone (two); and small bowel volvolus (one)), perforated lymphoma (nine), Crohn's disease (five), infarction (three), poly-
This review has shown that the postoperative morbidity and mortality in patients with this condition is high. Perforation was the first presentation of a more widespread disorder in 13 patients. Increased awareness of this condition and its causes may lead to a decrease in the frequency of postoperative morbidity and mortality.

\section{F43}

Ileocolonic junction - a specialised region showing unique patterns of motor activity

E M M QUIGLEY, S F PHILLIPS, AND B CRANLEY (Gastrointestinal Unit, Mayo Clinic and Foundation, Rochester, Minnesota, USA) Little attention has been paid to motor activity at the junction between small and large intestine. Our aim was to characterise interdigestive motor patterns in this region. Studies were performed in two separate groups of animals. In group A (five dogs) motor activity was recorded from ileocolonic loops using a perfused catheter assembly positioned such that eight side holes, spaced $1 \mathrm{~cm}$ apart, straddled the ileocolonic sphincter while a ninth was $18-20 \mathrm{~cm}$ proximal. In group B (two dogs) intestinal continuity was maintained and motor activity recorded from strain gauge transducers sutured to the serosa at the ileocolonic sphincter, to ileum 5, 10, 20 and $40 \mathrm{~cm}$ proximal and to colon $3 \mathrm{~cm}$ distal to the sphincter. Recordings were performed for six hours after an overnight fast.

Identical motor patterns were recorded in both groups. Sustained tonic pressures $\left(10-70 \mathrm{~cm} \mathrm{H}_{2} \mathrm{O}\right)$ were noted within a 1-2 cm zone corresponding to the anatomical sphincter. Unique, coordinated phasic pressure patterns were recorded over a segment which comprised $10-20 \mathrm{~cm}$ distal ileum, ICS and 3-5 cm proximal colon. Three distinct patterns were recorded: (1) slowly propagated phasic bursts - lasted a mean of 3.5 minutes, recurred on average every 5 minutes and propagated across ICS in both aborad $(81 \%)$ and orad $(19 \%)$ directions at a mean velocity of $3 \mathrm{~cm} / \mathrm{min}$; (2) migrating motor complexes; (3) broad phasic waves - high amplitude (mean 270 $\mathrm{cm} \mathrm{H}_{2} \mathrm{O}$ ) waves occurred, on average every three hours and swept rapidly (mean velocity $12 \mathrm{~cm} / \mathrm{min}$ ) through distal ileum, across ICS and into colon. In summary, we have identified an ileocolonic junctional segment which shows unique, coordinated motor patterns. This motor specialisation may serve to regulate transfer of chyme into the colon.

\section{F44}

Quantitation and antibody activity of polymeric and monomeric serum IgA in coeliac disease

F DUPREY, M LEMAIRE, B DELPECH, AND C MATUCHANSKY (Immunochemistry Laboratory, H Becquerel Center, Rouen; and Gastroenterology Unit, University Hospital, Poitiers, France) Whereas several recent studies have clearly suggested an association between circulating antigliadin antibodies of the IgA class and the mucosal lesion in active coeliac disease (CD), there is no available information on the relative amounts and functional activity of monomeric $\left[(\operatorname{IgA})_{1}\right]$ and dimeric $\left[(\operatorname{IgA})_{2}\right]$ serum $\operatorname{IgA}$ in adult $C D$. Four fractions that contained respectively IgM, $(\operatorname{Ig} A)_{2},(\operatorname{Ig} A)_{1}$ and $\operatorname{IgG}$ were separated by gel filtration on Ultragel ACA 34 in 11 adult patients with active $C D$, eight $C D$ patients on a gluten-free diet (GFD), six patients with non-CD small intestinal diseases and 14 normal subjects. Immunoglobulin concentrations in the four fractions were measured by nephelometry, and their antibody activities against various antigens (hydrolysed gliadin, $\beta$ lactoglobulin, casein) were determined by ELISA. ELISA titres of antigliadin antibodies of $\operatorname{IgA}, \operatorname{IgG}$ and $\operatorname{IgM}$ classes in corresponding unseparated serum were also measured. $(\operatorname{IgA})_{2}$ levels and $(\operatorname{IgA})_{2} /$ $(\operatorname{IgA})_{1}$ ratio were significantly $(\mathrm{p}<0.01)$ increased in patients with active $C D$ (maximal level related to elution peak: $189 \pm 50 \mathrm{mg} / 1$; ratio: $1 \cdot 07 \pm 0 \cdot 31$ respectively), as compared with controls $(15.4 \pm 5.4 \mathrm{mg} / \mathrm{l}$, and $0 \cdot 15 \pm 0.05)$, CD patients on a GFD $(19 \cdot 2 \pm 5 \cdot 1 \mathrm{mg} / \mathrm{l}$, and $0 \cdot 15 \pm 0 \cdot 18$, and subjects with non-coeliac diseases $(32 \pm 7 \cdot 2 \mathrm{mg} / 1$, and $0 \cdot 28 \pm 0 \cdot 16)$. The titres of $(\operatorname{IgA})_{2},(\operatorname{IgA})_{1}$ and $\operatorname{IgG}$ antigliadin antibodies were significantly $(p<0.01)$ higher in patients with active CD than in controls and other patient groups: levels of $(\operatorname{IgA})_{2}$ antibodies were much higher than those of $(\operatorname{IgA})_{1}$ antibodies. Subjects with high titres of antigliadin antibodies of $(\mathrm{IgA})_{2}$ and $\mathrm{IgG}$ classes have increased levels of $(\operatorname{IgA})_{2}$ and $\operatorname{IgG}$ antibodies to $\beta$ lactoglobulin as well. No difference in titres of IgM antigliadin antibodies were observed between the various groups. Strikingly, the IgA antibody activity against gliadin was much higher 
when measured in the $11 \mathrm{~s}$ fraction than in the corresponding unseparated serum.

We conclude that serum $(\operatorname{IgA})_{2}$ and $(\operatorname{IgA})_{2} /(\operatorname{IgA})_{1}$ ratio are significantly increased in patients with active $C D$, and that $\mathrm{IgA}$ antigliadin antibodies are mainly related, in these patients, to the dimeric form of the molecule.

\section{F45}

In vitro toxicity of gluten fraction III on cultured coeliac biopsies shown by an effect on enzyme activities in isolated brush borders

G M WOOD, P D HOWDLE, AND M S LOSOWSKY (Department of Medicine, St James's University Hospital, Leeds) Organ culture of small intestine mucosal biopsies can be used to show gluten sensitivity in vitro. Inhibition by gluten of the increase in brush border enzyme activity during culture has been suggested as a discriminatory finding but this has not been confirmed by other workers. The brush border, however, forms only a small part of the biopsy and thus, in order to clarify the situation brush borders have been isolated from peroral small bowel biopsies cultured for 24 hours in control medium and medium containing Frazer's gluten fraction III (GFIII) at a concentration of $1 \mathrm{mg} / \mathrm{ml}$. Uncultured normal biopsies from 14 controls had higher sucrase, alkaline phosphatase, and aminopeptidase $\mathbf{N}$ activities in the whole homogenate and brush border fraction than biopsies from eight coeliac patients taking a normal diet.

In seven coeliac patients in relapse and six control patients, enzyme activities in the isolated brush borders were similar before and after culture contrary to the activities in the whole homogenate which increased during culture. There was also a significant increase in the enzyme activity in the cellular fraction remaining after isolation of the brush borders.

Enzyme activities in the isolated brush borders were less after culture with GFIII than without in six out of seven coeliac patients. In contrast, in five out of six controls isolated brush border enzyme activities were greater after culture with GFIII than without.

We conclude that by measuring enzyme activity in isolated brush borders it is possible to show in vitro toxicity of GFIII for coeliac mucosa in relapse. These biochemical findings confirm the histological observation of damage to the microvilli by gluten in coeliac biopsies during organ culture.
F46

Cavitation of mesenteric lymph nodes: a possible feature of coeliac disease associated with splenic atrophy

C MATUCHANSKY, R COLIN, G TOUCHARD, J HEMET, P BABIN, C EUGÈNE, P ZEITOUN, AND M A BARBOTEAU (Departments of Gastroenterology and Pathology, University Hospitals of Poitiers, Rouen and Reims; and General Hospital, Poissy, France) It has been suggested that, in coeliac disease (CD), splenic atrophy may be part of a more widespread lymphoreticular dysfunction. The aim of the present study is to describe, in six patients with total or subtotal villous atrophy (TVA) of the small bowel and hyposplenism, a particular lesion of mesenteric lymph nodes - namely 'cavitation' - which has received so far little attention.

In four women and two men, aged 31 to 63 years, who underwent exploratory laparotomy for large abdominal masses (three cases), intestinal obstruction or suspicion of $\mathrm{CD}$-associated lymphoma (three cases), unusual lymph nodal lesions were observed in the jejunal or jejuno-ileal mesentery. They consisted macroscopically of a cystic appearance of strikingly enlarged ( 2 to $8 \mathrm{~cm}$ ) lymph nodes, and histologically of a large central cavity occupied by a protein/lipid-containing material and surrounded by fibrous tissue and remnants of lymph nodal structures. There was no histological evidence of lymphoma, mesenteric panniculitis, or abnormalities of lymphatic channels. Diffuse TVA involving the jejunum or the jejuno-ileum was found in every patient, and was associated with ileal ulcerations in two cases. In all the patients there were anatomical and/or biological (Howell-Jolly bodies) evidence of splenic atrophy, signs of severe malabsorption, and a past history of chronic or childhood diarrhoea. HLA B8 and/or DR3 was present in 4/4 cases, dermatitis herpetiformis in one, and signs of autoimmunity and peripheral neuropathy in two cases. TVA responded to a gluten-free diet (GFD), alone or associated with steroids, in two patients; in one of these, a dramatic regression of lymph node cavitation was noted at a second laparotomy. In the four other cases, intestinal and mesenteric lymph node lesions, and signs of splenic atrophy were resistant to GFD, steroids and/or total parenteral nutrition; two patients died.

We conclude that cavitation of mesenteric lymph nodes is an original feature which may be associated with adult
$\mathrm{CD}$ and splenic atrophy. Intestinal lesions may be responsive or, more often, unresponsive to GFD. We suggest that, in $C D$, cavitation of mesenteric lymph nodes is the expression, beside splenic atrophy, of a severe lymphoreticular dysfunction.

\section{F47}

Defective antigen specific (liver specific protein) suppressor cell function in autoimmune chronic active hepatitis

S VENTO, J E HEGARTY, A L W F EDDLESTON, AND ROGER WILlIAMS (Liver Unit, King's College Hospital, London) Defects in non-antigen-specific suppressor $T$ cell function have been shown in autoimmune chronic active hepatitis (CAH), but it is unclear why this global defect should result in an immune response directed specifically against the liver. The possible pathogenetic role of antibodies to liver specific protein (LSP) in CAH has led us to investigate the function of the specific suppressor $T$ cell population controlling the immune response to LSP in this disease. A newly developed indirect $\mathrm{T}$ lymphocyte migration inhibition system (T-LIF) showed that purified T cells from 26 of 29 patients with autoimmune CAH were sensitised to LSP (mean migration index $(\mathrm{MI})=0.67 \pm \mathrm{SD}$ $0 \cdot 13$ ), compared with only one of 21 with $\mathrm{HBs} A \mathrm{~g}+\mathrm{ve} \mathrm{CAH}(\mathrm{MI}=0.97 \pm 0.1)$ and none of five patients with autoimmune thyroid diseases $(\mathrm{MI}=0.91 \pm 0.04)$. The addition of $T$ cells (ratio 1:9) from normal subjects and patients with $\mathrm{HBs} \mathrm{Ag}+\mathrm{ve}$ $\mathrm{CAH}$ and thyroid diseases reversed this $\mathrm{T}$ cell sensitisation to $\mathrm{LSP},(\mathrm{MI}=0.91 \pm 0.04$, $0.91 \pm 0.08$ and $0.87 \pm 0.04$ respectively), whereas $\mathrm{T}$ cells from other patients with autoimmune $\mathrm{CAH}$ had no such effect. Using human thyroid membranes as the antigen in the T-LIF system, $T$ cell sensitisation was found in all five patients with thyroid diseases $(\mathrm{MI}=0.71 \pm 0.03)$ but only in one with autoimmune $\mathrm{CAH}$, a patient who also had autoimmune thyroid disease. $T$ cells from normal subjects and patients with autoimmune $\mathrm{CAH}$ reversed the sensitisation to thyroid membranes in the five patients with thyroid disease (MI $=0.90$ and $0.89 \pm 0.09$ respectively). The results show a defect in the suppressor $T$ cell subset specifically controlling the immune response to LSP in autoimmune $\mathrm{CAH}$ and emphasise the fundamental difference in the immunoregulatory disturbance in the autoimmune and $\mathrm{HBs} A \mathrm{~g}$ positive forms of the disease. 
F48

Suppressor cell function and HLA B8 DR3 in first degree relatives of patients with autoimmune chronic active hepatitis

K T NOURI-ARIA, P DONALDSON, J E HEGARTY, A L W F EDDLESTON, AND ROGER WILLIAMS (Liver Unit, King's College Hospital, London) Family studies of patients with $\mathrm{CAH}$ have suggested that the inheritance of a gene(s) linked to B8 and/or DR3 is associated with a non-specific increase in immune responsiveness. Defects in nonantigen specific suppressor cell function have been shown in untreated patients with chronic active hepatitis (CAH), although it is not known if this defect is secondary to the disease process or is an inherited primary abnormality of the immune system. In the present study we have examined the relationship between the inheritance of HLA haplotype and suppressor cell function in 20 first degree relatives of four patients with autoimmune CAH.

Suppressor cell function, as assessed by Concanavalin $\mathbf{A}$ activated suppressor cell inhibition of pokeweed mitogen stimulated IgG production, was abnormal (less than mean \% suppression - 2SD of control values) and within the range seen in patients with untreated $\mathrm{CAH}$ in all seven first degree relatives with HLA B8 DR3. In marked contrast, suppressor cell function was abnormal in only two of 13 relatives who were HLA B8 DR3 negative $(p=0.004$; one tail Fisher's exact test $)$ in whom the values were similar to those of control subjects ( $p>0.05$; Wilcoxon's rank sum test).

The results show a strong association between the inheritance of HLA B8 DR3 and a defect in suppressor cell function in relatives of patients with $\mathrm{CAH}$ but that additional genetic or environmental influences are necessary for expression of the disease. Moreover the results suggest that defective suppressor cell function in untreated $\mathrm{CAH}$ occurs as a primary event and is not a secondary development to hepatic cell damage.

\section{F49}

Failure of BCG to eradicate the hepatitis B virus

G M WOOD, P D HOWDLE, AND M S LOSOWSKY (Department of Medicine, St James's University Hospital, Leeds) Two previous uncontrolled reports have suggested that serial injections of bacillus Calmette-
Guerin (BCG) hastens the clearance of hepatitis B viral (HBV) markers from patients with $\mathrm{HBs} \mathrm{Ag}$ positive liver disease. The reactions to the injections were local and apparently well tolerated. A prospective, controlled trial was set up and 19 chronic carriers of $\mathrm{HBV}$ were randomly allocated to control or treatment groups, with stratification according to e antigen status. The treatment group received $0 \cdot 1$ $\mathrm{ml}$ aliquots of Glaxo strain BCG to a total dose of $0.28 \mathrm{mg}$ dry weight of mycobacterium over 20 weeks. The groups were similar in age, known duration of viral carriage and liver histology and follow-up has been for at least six months.

All five $\mathrm{HBeAg}$ positive patients had raised HBV specific DNA polymerase activity, signifying active viral replication, and aspartate transaminases. No sustained falls in either of these were seen in the BCG treated or control groups. The other 14 patients were anti-HBe positive with low levels of DNA polymerase, and with transaminases around the upper limit of normal. Again no consistent changes were observed in either the treated or control patients.

There have been no changes in $\mathrm{HBsAg}$ or $\mathrm{HBeAg}$ status or titre of $\mathrm{HBsAg}$ in treated or control patients, whether $e$ antigen or e antibody positive.

Patients receiving BCG had marked skin reactions with ulcers and scarring in some cases; two patients were compelled to withdraw. These results have failed to confirm a therapeutic effect of BCG in chronic HBV carriers and the cosmetic effects of the injections have been not inconsiderable.

\section{F50}

Hepatitis B core (HBcAg) and e (HBeAg) antigens in the liver detected by immunofluorescence with monoclonal antibodies

M MONDELLI, A ALBERTI, P PONTISSO, $R$ S TEDDER, P CADROBBI, C A BUSACHI, A L W F EDDLESTON, $R$ WILLIAMS, AND G REALDI (Liver Unit, King's College Hospital and Middlesex Hospital, London. Patologia Medica, Universita di Padova, Patologia Medica I, Universita di Bolgna,'Italy)

Current knowledge on the expression of HBeAG in hepatocytes is incomplete because of difficulties in obtaining monospecific antisera. In this study we have therefore examined, by immunofluorescence, the expression of $\mathrm{HBcAg}$ and $\mathrm{HBeAg}$ in liver biopsies from $30 \mathrm{HBsAg}$ chronic carriers using highly specific mono- clonal antibodies. Nuclear HBcAg was detected in 16 of 20 patients positive for $\mathrm{HBeAg}$ and HBV-DNA polymerase in serum. Cytoplasmic $\mathrm{HBcAg}$ was rarely observed, while six patients showed membranous $\mathrm{HBcAg}$ staining. $\mathrm{HBeAg}$ was found both in the nuclei and in the cytoplasm of hepatocytes in 18 patients including all those positive for $\mathrm{HBcAg}$. The percentage of $\mathrm{HBeAg}$ positive cells always exceeded that of $\mathrm{HBcAg}$ containing cells. In three cases with only a few HBcAg-positive hepatocytes, diffuse HBeAg staining was observed. When isolated hepatocytes prepared from eight liver biopsy cores were studied by immunofluorescence after cytocentrifugation on slides, the percentage of $\mathrm{HBeAg}$ positive cells was $42 \cdot 3 \pm 24$ (mean \pm SD) while that of $\mathrm{HBcAg}$ positive cells was $27 \cdot 6 \pm 18$. Cytoplasmic but not membranous $\mathrm{HBeAg}$ was often detected. By electron microscopy, no virus particles were observed in the cytoplasm of hepatocytes in biopsies with abundant $\mathrm{HBeAg}$. Neither $\mathrm{HBcAg}$ nor $\mathrm{HBeAg}$ were found in the liver of 10 anti-HBe positive patients without viral replication nor $10 \mathrm{HBsAg}$ negative patients with various liver diseases. These results provide definite evidence that $\mathrm{HBeAg}$ is expressed both in the nuclei and in the cytoplasm of infected hepatocytes. The observation that in chronic HBsAg carriers with active viral replication the number of $\mathrm{HBeAg}$ positive cells largely exceeds that of $\mathrm{HBcAg}$ containing cells would suggest that assembly of core particles occurs in only a proportion of infected hepatocytes expressing the protein precursor $(\mathrm{HBeAg})$ of the virion nucleocapsid.

F51

Azathioprine in primary biliary cirrhosis: late results of an international trial

E CHRISTENSEN, J NEUBERGER, J CROWE, H POPPER, B PORTMANN, D DONIACH, L RANEK, N TYGSTRUP, AND R WILLIAMS (Division of Hepatology: Rigshospitalet and Hvidovre Hospitals, Copenhagen; Liver Unit, King's College Hospital, Department of Immunology, Middlesex Hospital, London; Mount Sinai Hospital, New York, USA) An international double blind, placebo controlled randomised trial was set up in 1971 to assess the therapeutic benefit of azathioprine, given at a dose of 1 $\mathrm{mg} / \mathrm{kg} /$ day. Two hundred and forty eight patients were entered into the trial until December 1977, of whom 127 received azathioprine. There was no significant 
difference between patients at entry into the trial with respect to age, sex, duration of history, clinical, serological, biochemical, or histological features. These patients have now been followed up to 12 years. During the course of the trial $39 \%$ of those receiving placebo and $44 \%$ of those on azathioprine died. Cumulative survival analysis showed that azathioprine was associated with an improvement in survival, although this difference did not reach statistical significance. These results were similar if patients were analysed for the time of receiving therapy only or for the entire period of observation. Azathioprine was associated with a significant reduction in the degree of incapacity associated with the disease and a reduction in the rise of serum IgG. Separate analyses of subgroups, by sex, age, nationally or histological stage, did not reveal any differences to the overall results. These findings suggest that azathioprine alone has little place in the treatment of primary biliary cirrhosis.

\section{F52}

Effect of water on bile excretion in guinea pigs receiving total parenteral nutrition

S J LABROOY, M V MATH, T S YEOH, AND E JACOB (Department of Medicine II and Pharmacology, Faculty of Medicine, National University of Singapore. Department of Clinical Chemistry, Singapore General Hospital, Singapore) Bile is isosmotic and there is evidence that bile osmolality is directly related to plasma osmolality. The infusion of hyperosmolar total parenteral nutrition (TPN) solutions (amino acids $+10 \%$ glucose) have already been shown to decrease bile flow in rabbits. It has been postulated that this highly concentrated bile may be the the cause of cholestatic hepatitis which is a well recognised complication of TPN. The aim of this study was to confirm the changes in bile excretion with TPN infusion in adult guinea pigs and assess the effect of a simultaneous jejunal infusion of water on this.

Three groups of animals were used. Group A (eight animals) acted as controls, group B (seven animals) were infused with a TPN solution (Trive 1000) at $1 \mathrm{ml} / 100 \mathrm{~g} / \mathrm{h}$ for six hours and, group $C$ (seven animals) were infused with TPN and enterally with water both at $1 \mathrm{ml} / 100 \mathrm{~g} / \mathrm{h}$ for six hours. Trive 1000 has an osmolality of $1440 \mathrm{~m}$ Osm $/ \mathrm{kg}$ water and contains $60 \mathrm{~g} / 1$ amino acid, $45 \mathrm{~g} / 1$ lipid and $100 \mathrm{~g} / \mathrm{l}$ carbohydrate.
Fasted animals were anaesthetised with sodium pentobarbitone injected intraperitoneally. The cystic duct was ligated and bile sampled from the cannulated common bile duct at 30 minute intervals for a period of six hours. Infusion of TPN in group $B$ and $C$ and enteral infusion of water in group $\mathrm{C}$ animals was started immediately after a fasting sample was obtained. In group B the volume of bile decreased progressively (reduction of 44 $\mu \mathrm{l} / \mathrm{min} \pm 0.07 \mathrm{SEM}$ from fasting levels at 6 hours), this being significantly different $(p<0.05)$ from control levels by 60 minutes. Bile osmolality increased significantly $(\mathrm{p}<0.01)$ from 30 minutes, reaching $39.5 \pm 3.0 \mathrm{~m} \mathrm{Osm} / \mathrm{Kg}$ water above fasting levels at six hours. In group $\mathrm{C}$ animals the decrease in bile flow was $31.8 \mu \mathrm{l} / \mathrm{min} \pm 0.06$ SEM at 6 hours. Bile osmolality decreased to $7.4 \mathrm{~m} \mathrm{Osm} / \mathrm{Kg}$ water $\pm 1.6 \mathrm{SEM}$ below fasting levels at 6 hours. This was significantly different from group $B$.

These results show that an enteral infusion of water reduces the effect of a TPN infusion on bile excretion and this may prove useful in preventing cholestasis associated with TPN.

F53

Serological diagnosis and current epidemiology of hydatid disease in England and Wales

M F STALlbaUmer, M J ClaRKSON, J F PRITCHARD, J W BAILEY, AND D L MORRIS (Department of Veterinary Preventive Medicine, University of Liverpool and Department of Surgery, General Hospital, Birmingham) In 1981 the Public Health Laboratory Service set up a centralised service for the serological diagnosis of hydatid disease in England and Wales. The results of the first two years of this service are reported. Two thousand eight hundred and sixty six sera from 2642 patients were tested. All samples were screened with the compliment fixation test (CFT) and latex agglutination test. Positive samples were then examined by enzyme linked immune zorbitent assay (ELIZA) and immunophoresis. Clinical details were obtained by a questionnaire. The serological results have been compared with the clinical or pathological diagnosis and while all serological tests in combination were correct in $82 \%$ of cases the ELIZA test alone was equally active at a dilution of $1 / 100$. Sensitivity of the CFT at $1 / 16$ was $84 \%$ and specificity $37 \%$. The corresponding values for the ELIZA were $94 \%$ and $65 \%$.
Of 148 patients with proven hydatid disease there were 91 new cases. Eighty three of these cases probably originated overseas but of the 65 indigenous cases 33 originated in Powys, Glamorgan, or Herefordshire. Several people, however, appeared to have acquired this disease in urban areas of the West Midlands. While negative serology does not exclude hydatid disease it has an important role in its diagnosis. Previously multiple serological tests have been performed but our results indicate that the ELIZA test alone is likely to be more accurate and further purification of the antigen used in the ELIZA test could further improve results.

\section{F54}

Adhesion of enterotoxigenic and enteroinvasive Escherichia coli to human intestinal epithelial cells

S KNUTTON, D R LLOYD, D C A CANDY, AND A S MCNEISH (Institute of Child Health, University of Birmingham, Francis Road, Edgbaston, Birmingham) Enterotoxigenic (ETEC) and enteroinvasive $E$ coli (EIEC) are two distinct classes of $E$ coli causing diarrhoea in humans. Enterotoxigenic proliferates in the upper small intestine and produce cholera-like symptoms while EIEC invade the mucosa of the ileum and colon and cause a dysentry-like syndrome. In this study we have examined the adhesion of two human ETEC and two EIEC strains to different epithelial surfaces of the gastrointestinal tract. Adhesion was assessed by scanning electron microscopy and phase contrast microscopy respectively after the incubation of human intestinal biopsies or isolated human intestinal epithelial cells with bacteria for 30 minutes at $37^{\circ} \mathrm{C}$ and removing non-adherent bacteria by washing. Enterotoxigenic strains $\mathrm{H} 10407$ (078:H11:CFA/I) and B2C (06:H16:CFA/ II) adhered to human duodenal mucosa and to the brush border surface of isolated duodenal enterocytes (mean of 91 and 80 bacteria adhering to 20 brush borders respectively) but did not adhere to colonic mucosa. In contrast, EIEC strains 469-3 (021:H-) and 444-3 (0?:H4) adhered to colonic mucosa and isolated colonic enterocytes (87 469-3 adhering to 20 brush borders) but not to duodenal mucosa or isolated duodenal enterocytes (5 469-3 adhering to 20 brush borders). A spontaneous mutant of $\mathrm{H} 10407$ lacking CFA/I fimbriae and mutants of 444-3 and 469-3 lacking mannose-resistant haemagglutinins 
did not adhere to either duodenal or colonic enterocytes. These observations show that ETEC and EIEC bind to different brush border receptors and provide further evidence that the interaction of pathogenic bacteria with specific tissue surfaces in the intact host is determined by their adhesive properties.

\section{F55}

High incidence of potentially pathogenic $E$ coli in first attacks of inflammatory bowel disease

I F PINDER, R J DICKINSON, E M COOKE, AND A T R AXON (Gastroenterology Unit, The General Infirmary, Leeds, and Department of Microbiology, The University of Leeds, Leeds) Invasive and adhesive $E$ coli are found more commonly in patients with inflammatory bowel disease than in controls and are even more common in relapse, but as previous studies have been done on patients with chronic inflammatory bowel disease it is not known whether these potentially pathogenic organisms are primary or secondary invaders. We have therefore studied the faecal flora in 28 consecutive patients presenting at a General Hospital with a first attack of clinical colitis. Stool samples were collected and the dominant $E$ coli isolated was serotyped, tested for invasion and adhesion, colonisation factor, pili antigen, haemolysin production, and labile and stable enterotoxin.

$E$ coli with adhesive or invasive properties were found in eight of 28 (29\%) new colitics compared with only one of 40 controls $(3 \%) \mathrm{p}<0.01$. In addition two colitics had toxin producing $E$ coli and one a recognised enteropathogenic serotype in the stool, no toxin producers or recognised pathogens were isolated from the control group. There was no significant difference in haemolysin producers, pili antigen of colonisation factor between groups.

Overall 11 of $28(39 \%)$ colitics harboured $E$ coli with pathogenic features compared with only one of 40 controls (3\%) $\mathrm{p}<0.001$.

Pathogenic $E$ coli may play a primary role in the pathogenesis of some cases of ulcerative colitis.

F56

Screening for colorectal cancer in a factorybased population using Fecatest

F I LEE (Department of Gastroenterology,
Victoria Hospital, Blackpool) The high incidence of colorectal cancer in Western communities and the demonstration that diagnosis at an early stage is associated with improved prognosis have led to the development of screening programmes using faecal occult blood tests. This report concerns the use of Fecatest, a relatively sensitive test in a factory-based population. A total of 2420 workers between 40 and 65 years of age returned kits for testing after suitable dietary restriction. In factory $A$, in which screening was offered as part of an annual medical examination, 989 men agreed to participate, a compliance rate of $45 \%$. In factory $B$, in which screening was offered in their weekly pay packets, 1431 men participated, a compliance rate of $22 \%$. An overall positivity rate of $5.8 \%$ was found. In factory A, the test kits were interpreted in the Medical Department and the positivity rate was $4.6 \%$. In factory B kits were sent by post to the Department of Gastroenterology for testing and the positivity rate was $6.6 \%$. Five cancers were found, two of the rectum, one at the recto-sigmoid junction and one in the transverse colon. Two of these lesions were at Dukes Stage A, one at Stage B and two at Stage $C$. In addition, 25 adenomatous polyps were found in 17 men. In 13, these were characterised as tubular adenomata and in four as tubulovillous adenomata. The mean age at diagnosis in the polyp cases was 52.6 years and in the cancer cases, $\mathbf{5 8 . 8}$ years. Increased specificity is obtained by excluding participants below 46 years of age. The detection rate in the 46-65 year range is approximately 1 in 100 for adenomatous polyps and 1 in 300 for cancer in the population screened. This detection rate is higher than most comparable studies using a less sensitive Guaiac test on older populations.

\section{F57}

Neuropathology of slow transit constipation

D M PRESTON, M G BUTLER, B SMITH, AND J E LENNARD-JONES (St Mark's Hospital, London, and St Bartholomew's Hospital, London) A group of patients can be defined with severe idiopathic constipation who have a normal sized colon but prolonged total intestinal transit time. In the last three years 10 such patients (all women, mean age 28.3 years) have had subtotal colectomy because of failure of medical treatment. The resected colons were examined using a special silverstaining technique on frozen section. Of 10 patients, three showed evidence of severe myenteric plexus damage. Six showed less severe abnormalities and one was within normal limits. The changes in the severe cases consisted of complete loss of the argyrophil plexus with a marked increase in Schwann cells indicating that extrinsic damage to the plexus had occurred. Some non-argyrophil cells remained and conventional paraffin sections were unremarkable. The plexus damage was most marked distally except in two cases where the transverse colon was worst affected. The changes are different from those seen following abuse of anthraquinone-type laxatives when the plexus shows swelling of the nerve cells, clubbed axonal processes, no Schwannosis and maximum damage in the ascending colon. In some cases there was also evidence of laxative induced damage, but melanosis coli was not prominent.

All patients had colonic motility studies performed before operation with the introduction of intraluminal Bisacodyl in an attempt to test the integrity of the myenteric plexus. Six patients showed a peristaltic response to Bisacodyl, though in some this was short lived, and four showed no response. The four who failed to respond all had plexus abnormalities but there was no definite correlation between colonic activity in response to Bisacodyl and the degree of myenteric plexus damage.

\section{F58}

lleal bypass enhances colorectal carcinogenesis in the rat but to a lesser degree than ileal resection

J B RAINEY, $\mathbf{P}$ W DAVIES, AND $R \quad C \quad \mathbf{N}$ WILliamson (University Department of Surgery, Bristol Royal Infirmary, Bristol) As ileal resection and ileal bypass are commonly performed in man and might stimulate colonic hyperplasia, their cocarcinogenic potential was explored in male Sprague-Dawley rats $(n=135)$. One week after $33 \%$ distal small bowel resection, $33 \%$ distal small bowel bypass or distal ileal transection (control), animals received a six week course of azoxymethane (total dose $90 \mathrm{mg} / \mathrm{kg}$ ip). Findings in rats killed at 20 and 25 weeks were similar: bypass produced a higher yield of colorectal tumours $(4.0 \pm 0.6$ per rat: mean \pm sem) than controls $(2 \cdot 4 \pm 0 \cdot 4$ : $\mathrm{p}<0.05)$, but resection caused maximal enhancement $(5 \cdot 2 \pm 0 \cdot 5: p<0 \cdot 01)$. In rats killed at 30 weeks, however, tumour yields 
were almost identical $(4 \cdot 8,4 \cdot 7,4 \cdot 8)$, with $9.5 \%$ (14 of 147) of ulcerative colitis Overall, resection increased colonic and 8.8\% (12 of 137) of Crohn's disease tumour yield by $51 \%(\mathrm{p}<0.02)$ and bypass patients $(\mathrm{p}<0.01)$. These results indicate increased the yield by $40 \%(p<0.05)$. Both that intensive investigation of the familial operations produced similar increases in nature and the genetics of isolated colonic crypt cell production rate (CCPR) as polyps may be more rewarding than measured stathmokinetically in residual continuing genetic studies of established functioning small bowel (109-200\%: $\mathrm{p}<0.01)$ and in colorectum $(8-100 \%$ : $\mathrm{p}<0.05)$ at 20 weeks. At 30 weeks these adaptive effects persisted, but there was an overall increase in CCPR (compared with 20 -week values) of $71 \%$ in small bowel and $36 \%$ in colorectum $(p<0.01)$.

Loss of functioning ileum enhances experimental colorectal carcinogenesis principally by reducing the latent period for tumour development. Resection has a greater effect than bypass probably by producing earlier hyperplasia, though later adaptive effects are similar. The generalised increase in CCPR found throughout the bowel at 30 weeks may represent the continuing hyperplastic effect of azoxymethane.

\section{F59}

Family history of colorectal cancer in patients with isolated colonic adenomatous polyps

ELSPETH M ALSTEAD AND R B MCCONNELL (Royal Liverpool Hospital, Liverpool) Hereditary factors are undoubtedly important in colorectal cancer. In addition to the well recognised familial syndromes, there have been many studies showing a positive family history in about $20 \%$ of sporadic cases of the disease. Present evidence strongly suggests that many colorectal cancers develop in pre-existing adenomatous polyps. Although one study of a large Utah kindred showed an increased incidence of adenomatous polyps in the third generation of a family with a high incidence of colorectal cancer, suggesting dominant inheritance of polyps, there have been no studies of the families of large numbers of unrelated polyp patients.

The family history of 102 unrelated patients with symptomatic isolated adenomas of the colon and rectum has been studied and compared with that in three control groups. A positive history of colorectal cancer was obtained in the parents, sibs, aunts, or uncles of $19.3 \%$ (20 of 102) of patients with adenomas compared with $7.7 \%$ (eight of 102) of age and sex matched control patients with no gastrointestinal symptoms $(p<0.02)$, and colorectal cancer. As colonic adenomas autopsies in old people, there may be
ause certain genetic and other features which characterise those with malignant potential.

\section{F60}

Cigarette smoking, blood pressure, and

S N GYDE, P PRIOR, K TAYLOR, AND R N ALLAN (Gastroenterology Unit, The General Hospital, Birmingham) Recent work suggests that patients with ulcerative colitis smoke less than the general population. Certainly in a recent mortality study of patients with ulcerative colitis we found a significant deficit of deaths in the cardiovascular system and from cancer of the lung in men. We therefore studied a consecutive series of 103 patients with ulcerative colitis using matched controls drawn from the workforce of a local factory. Patients and controls were assessed for age, sex, and social class. A careful history was taken of tobacco and alcohol consumption. Height, weight, and blood pressure were recorded and fasting blood samples taken for measurement of total serum cholesterol, HDL cholesterol, serum triglycerides, and apolipoprotein $\mathbf{A}$ and B. After matching for age, sex, and social class, patients with ulcerative colitis smoked significantly less than controls $\left(\chi_{(2)}^{2}=7.01, p<0.05\right.$, men, $n=43$ cases and controls; $\chi_{(2)}^{2}=10.39, p<0.01$, women, $\mathrm{n}=31$ cases and controls). The proportion of patients with ulcerative colitis who had never started smoking was higher than that in the control group. Ulcerative colitis patients had significantly lower systolic and diastolic blood pressures than controls $(p \leqslant 0.01)$. There was no significant difference in the lipid measurements between ulcerative colitis cases and controls. We conclude there is a real association between non-smoking and ulcerative colitis. The relationship is not explained by individuals stopping smoking after developing colitis as there was a significant difference between the two groups in respect of those individuals who never started smoking. The blood pressure changes occur predominantly in patients with extensive colitis or those treated by colectomy, suggesting that sodium depletion may be important in aetiology.

\section{F61} ulcerative colitis
Sexual function after intersphincteric suture in inflammatory bowel disease

R J LEICESTER, JEAN K RITCHIE, JANE WADSWORTH, J P S THOMSON, AND P R HAWLEY (St Mark's Hospital, London) Intersphincteric excision of the rectum for inflammatory bowel disease was introduced with the aim of avoiding postoperative sexual dysfunction. When combined with primary perineal suture, this technique should decrease morbidity from delayed perineal wound healing.

Ninety eight patients (50 men, 48 women, mean age 42.9 years) underwent intersphincteric rectal excision with primary perineal suture for inflammatory bowel disease ( 79 colitis, 19 Crohn's). Sixty three patients aged 60 years or less at the time of study were alive and living in the United Kingdom; 48 (23 men, 25 women) attended for interview and in 41 of these their partner was also interviewed in an attempt to exclude psychological aspects of the presence of a stoma.

One male patient $(4.3 \%)$ suffered permanent sexual impairment due to sympathetic nerve damage (ejaculation). No patient exhibited signs of parasympathetic nerve damage (nervi erigentes). Nineteen $(46 \%)$ patients felt that their sexual activity was inhibited by the stoma, but only five $(24 \%)$ of their partners agreed. Primary healing of the perineal wound was successful in half of the cases and in $69 \%$ the wound healed within three months of operation.

It is suggested that this combination of operative techniques significantly decreases morbidity from rectal excision compared with more extensive procedures and should be more widely adopted.

\section{F62}

Poorly absorbed prednisolone retention enema gives good therapeutic results in distal colitis

P B MCINTYRE, F A MACRAE, L BERGHOUSE, J ENGLISH, AND J E LENNARD-JONES ( $t$ Mark's Hospital, London) Plasma prednisolone levels were measured by radioimmunoassay at intervals after excision of the rectum and primary perineal 
retention enemas containing prednisolone $20 \mathrm{mg}$ as the metasulphabenzoate (MSB) and the prednisolone-21-phosphate esters (P-21-P) in each of three patients with distal ulcerative colitis. The maximum plasma levels of prednisolone in the three patients after MSB were 32, 16, and 2 $\mathrm{ng} / \mathrm{ml}$, compared with 235,109 , and 100 $\mathrm{ng} / \mathrm{ml}$ after the P-21-P and the areas under the curve after MSB were $107 \cdot 25,45 \cdot 0$, and $11.0 \mathrm{ng} / \mathrm{ml} / \mathrm{h}$, compared with 1051.0 , 406.75, and $341.0 \mathrm{ng} / \mathrm{ml} / \mathrm{h}$ after P-21-P, confirming previous observations that MSB is poorly absorbed compared with P-21-P. A double blind controlled therapeutic trial of these two enemas given nightly for a two week period was therefore undertaken in 40 patients with active distal colitis. The two groups were comparable for age, sex, extent of disease, and severity of symptoms. Two patients in the P-21-P group did not complete the trial. Symptomatic results after treatment in the P-21-P and MSB groups showed no significant differences and were respectively: symptom free, five and two; improved, nine and 13; no change, three and five; worse, one and none. Bowel frequency decreased to a similar extent in both groups: P-21-P, initial $4.9 \pm 1.4$, final $2 \cdot 6 \pm 2 \cdot 5$; MSB, initial $4 \cdot 5 \pm 2 \cdot 4$, final $2 \cdot 7 \pm 1 \cdot 1$. Sigmoidoscopic improvement occurred in 10 of 18 and 14 of 20 patients in the P-21-P and MSB groups respectively. Both enemas were tolerated equally well by patients. It appears that the poorly absorbed MSB enema gives as good therapeutic result as P-21-P, but is theoretically advantageous because of reduced prednisolone absorption and plasma levels.

\section{F63}

Clostridium difficile enterotoxin: amino acid composition and bacterial location

J KETLEY, T J MITCHELL, S C REDMOND, J STEPHEN, D C A CANDY, AND D W BURDON Department of Microbiology, Institute of Child Health, University of Birmingham, General Hospital, Birmingham) Cdifficile enterotoxin (toxin A) has now been purified by a reproducible, high yielding, two step physicochemical procedure consisting of preparative electrophoresis and ion exchange chromatography. The toxin was pure by serological and immunological criteria.

Its amino acid composition has been determined to be: Asp (5), Thre (2), Ser (5), Glu (8), Pro (12), Gly (29), Ala (9), Cys (0), Val (3), Met (1), Ileu (3), Leu (3),
Tyr (2), Phe (2), His (2), Lys (2), Arg (4), where figures in parentheses represent molar ratios.

Monopreciptin rabbit antisera to this preparation and fluorescently labelled sheep anti-rabbit sera have been used to examine organisms growing in culture to determine whether toxin appears early in the growth cycle in a cell associated form, as it is only released (as is the cytotoxin that is, toxin B) into the supernatant in maximum yield at 96 hours from inoculation. The evidence is that it is present in/on the cells long before toxin appears in the culture medium but it is not readily extractable by ultrasonication of the organisms. These results strongly suggest that toxin $A$ is a surface component of $C$ difficile; this may have important implications in the pathogenesis of disease caused by this organism.

\section{F64}

Cellulose metabolism in the human

J KELLEHER, M P WALTERS, T R SRINIVASAN, G HART, J M FINDLAY, AND M S LOWOSWKY (Department of Medicine, St James's Hopital, Leeds, and Department of Gastroenterology, The Royal Infirmary, Bradford) Cellulose is a common dietary fibre constituent but little is known about its metabolism or digestion in man. Using ${ }^{14} \mathrm{C}$-labelled cellulose we have studied its digestion/metabolism in 10 normal subjects (six elderly, $>65$ years of age, and four younger subjects) without history or symptoms of gastrointestinal disease.

A standard breakfast containing $500 \mathrm{mg}$ cellulose together with $5 \mu \mathrm{Ci}$ of ${ }^{14} \mathrm{C}$ cellulose was administered to the fasting subjects. Complete faecal collections for seven, days and frequent expired air samples were collected and analysed for ${ }^{14} \mathrm{C}$. The mean cumulative faecal excretion of ${ }^{14} \mathrm{C}$ was $57 \cdot 2 \pm 13.3 \%$ of the oral dose, this was lower in the elderly compared with the younger subjects but not significantly so. A proportion (range $2 \cdot 6-14 \%$ ) of the faecal ${ }^{14} \mathrm{C}$ was water soluble and presumably represents cellulose degradation products.

The cumulative excretion of expired air ${ }^{14} \mathrm{C}-\mathrm{O}_{2}$ varied from $7 \cdot 6-32 \cdot 2 \%$ of the oral dose and was significantly higher $(t=2.63$, $\mathrm{p}<0.05)$ in the elderly $(22.2 \pm 7.5 \%$ than in the younger subjects $(10 \cdot 5 \pm 1 \cdot 7 \%) .{ }^{14} \mathrm{C}-\mathrm{O}_{2}$ appeared early in the expired air and could be detected at 30 minutes, with an initial sharp peak at 1.55 hours followed by a later and much broader peak between 10-30 hours. The later peak contained the major fraction $(89.9 \%)$ of the expired air ${ }^{14} \mathrm{C}-\mathrm{O}_{2}$.

Oral cellulose is digested in the human gastrointestinal tract and approximately $60 \%$ is excreted in the faeces. Up to $30 \%$ of ingested cellulose is metabolised and can be detected in expired air.

\section{F65}

Second look at ursodeoxycholic acid (UDCA): high efficacy for partial but low efficacy for complete gall-stone dissolution, and a high rate of acquired stone opacification

D GLEESON, D C RUPPIN, G M MURPHY, AND R H Dowling (Gastroenterology Unit, Department of Medicine, Guy's Hospital Medical School, London) Previous studies from our unit and elsewhere indicate that UDCA has a comparable efficacy to chenodeoxycholic acid in dissolving gall stones, but is virtually free from side effects. Our most recent analysis in 130 patients with radiolucent stones in 'functioning' gall bladders, treated with approximately $10 \mathrm{mg} / \mathrm{kg} /$ day for up to five years or to treatment withdrawal, is less encouraging. Of the 119 completing $<6$ months (87 women, 32 men), $82(69 \%)$ had stones $<15 \mathrm{~mm}$ in diameter, $26(22 \%)$ were obese $(>130 \%$ IBW), and six $(5 \%)$ had floating stones. Confirmed complete gall stone dissolution (CGSD) occurred in 20, all with stones $\leqslant 15 \mathrm{~mm}$; 52 stopped treatment: unrelated death (three), default (six), severe biliary pain (eight), acquired non-functioning gall bladder (NFGB) (11), and radiological non-response (RNR) (24). The remaining 47 continue UDCA, 31 with partial gall stone dissolution (PGSD), and 16 with as yet no change in stone size or number. Life table analyses show minimum (including, in the denominator, treatment failures because of pain, NFGB, and RNR, but excluding those dying or defaulting), cumulative CGSD rates on $13.1 \%$ at one year, $19.0 \%$ at two years, and $20.3 \%$ at three years with $8.5 \pm$ SEM $0.6 \mathrm{mg}$ UDCA $\mathrm{kg} / \mathrm{day}$. Maximum cumulative efficacy (in stones $<15 \mathrm{~mm}$, accepting either PGSD or CGSD, and excluding those stopping for any reason other than RNR) was $70.4 \%$ at one year, $77.4 \%$ at two years, and $77.4 \%$ at three years. Of 41 patients showing PGSD at six months, only 11 went on to CGSD, the cumulative rate being $34 \%$ over the subsequent 30 months by life table analysis. Nineteen patients developed GS opacification equivalent to rates of $11.2 \%$ at one 
year, $17 \cdot 2 \%$ at two years, and $24.1 \%$ at three years. Despite this, of 10 patients continuing treatment, one achieved CGSD and one PGSD.

Despite high partial dissolution rates, the efficacy of UDCA in producing complete gall-stone dissolution is low and the acquired stone opacification rate high.

\section{F66}

Protective effects of exogenous secretin on ceruletide induced acute pancreatitis in the rat

I G RENNER, J $R$ WISNER JR, AND $H$ RINDERKNECHT (INTRODUCED BY A P DOUGLAS) (USC School of Medicine and VA Medical Center, Los Angeles, California, USA) Clinical and biochemical changes consistent with acute pancreatitis (AP) have been observed by us in three patients given large intravenous (iv) doses of cholecystokinin (CCK) without secretin during endoscopic cannulation and collection of pure pancreatic juice. We have never observed a similar situation when secretin was given concomitantly with CCK. Cerultide given iv in $5 \mu \mathrm{g} / \mathrm{kg} / \mathrm{h}$ doses consistently produces $A P$ in rats. We therefore decided to investigate whether secretin might confer a protective effect on ceruletide induced AP in rats.

In one group of unconscious rats given constant iv infusions of ceruletide $(5 \mu \mathrm{g} / \mathrm{kg} /$ h) for six hours, moderate AP was observed at three hours and florid AP by six hours. Biochemical serum markers of AP tended to parallel the severity of the pancreatic damage. In $50 \%$ of the rats, mesenteric fat necrosis was present and free peritoneal fluid containing massive rises of trypsinogen and amylase were noted in most animals. Intravenous secretin in high dose $(5 \mathrm{CU} / \mathrm{kg} / \mathrm{h})$ given simultaneously with ceruletide produced a striking macroscopic, microscopic and biochemical protective effect on ceruletide induced AP. High resolution light microscopy and electron microscopy showed a marked cellular disorganisation of the acini of animals treated with ceruletide alone. By contrast, there was a striking apical redirection of zymogen granules in acini of the animals treated with secretin. The results of this study suggest that high dose iv secretin may exert a beneficial effect on AP.
F67

Secretin re-establishes pancreatic secretion in rats with ceruletide induced acute pancreatitis

I G RENNER, J R WISNER JR, AND B C LAVIGNE (INTRODUCED BY A P DOUGLAS) (USC School of Medicine, Los Angeles, California, USA) We have shown in rats that continuous intravenous (iv) infusion of high dose secretin $(5 \mathrm{CU} / \mathrm{kg} / \mathrm{h})$ concomitant with infusion of high dose ceruletide $(5 \mu \mathrm{g} / \mathrm{kg} / \mathrm{h})$ confers a striking biochemical and histological protection against development of ceruletide induced acute pancreatitis (AP). In this study we show in unconscious rats with an indwelling pancreatic duct cannula that two hour iv infusions of cerultide at $5 \mu \mathrm{g} / \mathrm{kg} / \mathrm{h}$ results in $75 \%$ reductions in pure pancreatic juice (PPJ) flow and total protein content with further decreases to $5 \%$ of initial values over a subsequent four hour period. In animals infused with ceruletide for two hours and with high dose secretin (5 $\mathrm{CU} / \mathrm{kg} / \mathrm{h}$ ) for a subsequent four hours, PPJ volumes were restored to pre-ceruletide infusion levels and PPJ total protein content was significantly raised four fold compared with animals not infused with secretin. Light microscopy of the pancreas in ceruletide only infused animals revealed contracted acinar lumens, a basolateral migration of zymogen granules, and marked interstitial oedema. In contrast, the pancreas of rats treated with secretin revealed widely patent acinar lumens, apical orientation of zymogen granules, and a significant decrease in interstitial oedema.

These results suggest that iv secretin serves to ameliorate AP in the rat and this effect may be linked to secretin induced re-establishment of PPJ flow and protein content.

\section{F68}

Plastic pH electrodes suitable for use at endoscopy

M L LUCAS AND J M RAWLINGS (Institute of Physiology, University of Glasgow, Glasgow) A recent development in ion selective electrodes has been the synthesis of lipid soluble ligands. When incorporated into polyvinylchloride (PVC), these provide plastic ion sensors similar to the valinomycin based potassium ion electrode. Recent developments have made plastic $\mathrm{pH}$ electrodes feasible since the introduction of OCPH and dodecylamine for micro-electrodes.

Dodecylamine is a pH sensitive ligand which can be successfully incorporated into PVC. These PVC films can be cast over the end of tubing to provide catheter $\mathrm{pH}$ electrodes. Such electrodes have a slope factor of $58 \mathrm{mV}$ per $\mathrm{pH}$ unit, close to the ideal response. They also have a low resistance of $10 \mathrm{M} \Omega$ making them suitable for unshielded use with routine laboratory pH meters of sufficiently high input impedance. Linearity is apparent between the $\mathrm{pH}$ range 5 to 8 , although a diminished response is present outside this range. Dilution, interfering inorganic cation and anion effects are minimal. Lipophilic anions interfere with the response such that reliable electrodes show no response in common laboratory buffers such as phthalate.

Their successful production as catheter electrodes of diameter $2 \mathrm{~mm}$ or less makes them suitable for delivery by endoscope allowing transendoscopic $\mathrm{pH}$ measurements or as free floating intraluminal $\mathrm{pH}$ electrodes, if their response range is appropriate for proposed investigations.

Preliminary results at endoscopy show that duodenal luminal and mucosal surface $\mathrm{pH}$ can be measured and that the values obtained from the plastic electrodes are similar to those obtained from glass electrodes delivered by endoscope. Their use in forward viewing endoscopes allows direct $\mathrm{pH}$ measurements to be taken under visual inspection.

\section{F69}

International classification for endoscopic retrograde pancreatography (ERP) in chronic pancreatitis

A T R AXON, M CLASSEN, P B COTtON, M CREMER, P C FREENY, AND W LEES (Pancreatic Inflammatory Disease - International Workshop, King's College, Cambridge) There is no generally agreed terminology or classification for ERP appearances in chronic pancreatitis, most authors have used variations of a classification described by Kasugai et el 1974, but the significance of certain changes described is disputed and the concept of 'minimal change' pancreatitis controversial, some considering this pathological others equivocal or normal. The confusion has arisen as a result of imprecise terminology and the use of different gradings of severity. This lack of uniformity has made it difficult to compare ERP results in 
different centres and with other measurable parameters of pancreatic disease. An International Group experienced in pancreatogram reporting recently met to devise a terminology and classification of ERP changes in chronic pancreatitis. A new terminology based on morphological radiographic appearances was agreed together with a classification describing the severity and localisation of pancreatogram changes and was tested successfully for interobserver error. Pancreatograms in chronic pancreatitis are graded as normal or equivocal or as showing mild, moderate, or marked changes of chronic pancreatitis, either diffuse or local. An authoritative statement was made giving the minimum ERP criteria needed for a diagnosis of chronic pancreatitis. It is hoped that the use of this terminology and classification will help communication between different centres, serve as a basis for prospective and comparative studies and, after testing for interobserver error in different centres, may be used in computer systems.

\section{F70}

Modified sham feeding: an alternative to the insulin test?

A C ATHOW, A T SEWERNIAK, T P BARTON, M R LEWIN, AND C G CLARK (Surgical Unit, University College London, The Rayne Institute, London) A simple technique of modified sham feeding (MSF) has been developed and compared with the insulin test. Twenty healthy and 16 preoperative duodenal ulcer (DU) patients chewed, enjoyed and spat out toasted cheese sandwiches for 15 minutes after an hours basal collection. Fifteen minute samples were collected for one and a half hours and acid output calculated. Each subject also had an insulin test $(0.2 \mathrm{w} / \mathrm{k} \mathrm{bw})$. The secretory response to MSF was rapid, peaking within 45 minutes in $95 \%$ of subjects and returned to basal levels in 90 minutes. A reproducible peak acid output to MSF ( $\mathrm{PAO}_{\text {sh }}$ ) was shown in five healthy subjects. Also, in these, timing was shown to significantly affect $\mathbf{P A O}_{\text {sh }}$. At lunchtime (12-2.00 p.m.) median (range) $\mathrm{PAO}_{\text {sh }}$ was $8.8(4.3-36.7)$ compared with 6.3 (3.1$28.2) \mathrm{mmol} / \mathrm{h}$ in the morning (10-11 a.m.) $(\mathrm{p}<0.01)$. As with the insulin test, $\mathrm{PAO}_{\text {sh }}$ in DU patients $17.68(6.92-39.84)$ was significantly higher than in controls 10.68 $(3 \cdot 58-33.7) \mathrm{mmol} / \mathrm{h}(\mathrm{p}<0 \cdot 01)$. The gastric secretory response to MSF was less than to insulin $\mathrm{PAO}_{\mathrm{sh}}: \mathrm{PAO}_{\mathrm{I}}=60 \%$. There were, however, no stressful side effects to MSF. Finally both tests were used to evaluate residual vagal innervation in 20 postvagotomy patients; 10 routinely at three to six months, six with recurrent ulcers and four with dyspepsia. Using traditional criteria and four more recent criteria, the responses to MSF and the insulin test corresponded in $85 \%$ of cases. We conclude that MSF stimulates a sufficiently powerful response to be useful as a gastric secretion test and moreover avoids the stressful side effects and inhibitory period of insulin hypoglycaemia. The results suggest that MSF maybe as efficient a discriminant of residual vagal innervation as the insulin test.

\section{F71}

Mucolytic properties of gastric juice from duodenal ulcer patients

R WARD, J P PEARSON, A ALLEN, AND C W VENABLES (Departments of Physiological Sciences and Surgery, The Medical School, The University, Newcastle upon Tyne) Gastric mucus is important in the defence of the mucosa against gastric acid and pepsin. At the same time, luminal pepsin has been shown to erode the adherent mucus, producing degraded glycoprotein in the lumen. Here we describe a method for assessing the mucus degrading potential of gastric juice by measuring the fall in viscosity of mucous glycoprotein incubated with gastric juice in a Contraves Low Shear Viscometer.

The viscosity of pure gastric mucous glycoprotein fell rapidly when incubated with juice from duodenal ulcer patients. The fall was $\mathrm{pH}$ dependent, with substantial mucolytic activity occurring over the range $\mathrm{pH} 2$ to $\mathrm{pH} 5$. In contrast, the $\mathrm{pH}$ profiles for haemoglobin proteolysis by the same juices were noticeably narrower, with minimal detectable proteolysis above $\mathrm{pH} 3$.

Analysis of glycoprotein by Sepharose 2B gel filtration showed the fall in viscosity to be associated with an increase in the proportion of lower molecular weight pepsin degraded glycoprotein.

Our results show that gastric juice from duodenal ulcer patients degrades gastric mucus in vitro at $\mathrm{pH} 2$ to $\mathrm{pH} 5$. This mucolysis occurs over a substantially higher $\mathrm{pH}$ range than would be predicted from pepsin activity measured with standard protein substrates. This suggests that the mucolytic activity or pepsin in vivo can occur at higher values of $\mathrm{pH}$ than previously supposed. Changes in such activity might be a factor in the aetiology of duodenal ulceration.

\section{F72}

Does the acetyl linkage in acetylsalicyclic acid (ASA) contribute to the gastric mucosal damaging effect of this drug?

B J Z DANESH, L M NELSON, R J MORGAN, C ORJIOKE, C DOCHERTY, AND R I RUSSELL (Gastroenterology Unit, Royal Infirmary, Glasgow) The acetyl group in ASA (aspirin) is considered a noxious factor contributing to the gastrointestinal side effects of this drug. Choline magnesium trisalicyclate (CMT), a non-acetylated salicyclate, has been found to be an equally effective analgesic and considered to have fewer adverse side effects than ASA. We have compared the absorption of these drugs and their acute effect, with and without the potentiating influence of taurodeoxycholic acid (TDC), on gastric mucosal haemorrhage in rats $(n=120)$.

Test solutions were administered to five groups of fasting rats $(n=24)$ by peroral intubation of the stomach. The gastric mucosa was examined after four hours and mucosal injury assessed by a lesion scoring system. The incidence and severity (median lesion scores with quartiles) of bleeding lesions were $83 \%$ and 13 (7:20) respectively for ASA (128 $\mathrm{mg} / \mathrm{kg})$ compared with $17 \%$ and $0(0: 0)$ for CMT $(128 \mathrm{mg} / \mathrm{kg})(\mathrm{p}<0.001$ and $\mathrm{p}<0.001)$. The effect of TDC ( $5 \mathrm{mM})$ was to increase mucosal damage to $100 \%$ and $29(20: 34)$ for ASA compared with $30 \%$ and $0(0: 4)$ for CMT $(p<0.001$ and $p<0.001)$.

Tail blood samples taken four hours after the ingestion of these drugs, showed no significant differences in salicyclate levels - median values $\mathbf{1 . 4}$ for ASA and 1.5 $\mathrm{mmol} / \mathrm{l}$ for CMT.

We conclude that non-acetylated salicyclate (CMT) produces significantly less gastric mucosal injury than acetylated salicyclate (aspirin) in rats, despite a similar salicyclate absorption. CMT may thus be a safer drug than aspirin for therapeutic use in man.

\section{F73}

Intragastric bacterial overgrowth during treatment with poorly absorbable antacids

H-J HAGEL, R L MÜLLER, G GREIM, H RUPPIN, W GRÄF, AND W DOMSCHKE (Department of Medicine and Institute of Environmental Hygienics and Preventive Medicine, 
University Erlangen, $F R G$ ) Intragastric bacterial overgrowth during treatment with poorly absorbable antacids. Stockbrügger et al have recently shown that the reduction of gastric acid by cimetidine creates an intragastric milieu similar to that in chronic atrophic gastritis associated with gastric bacterial overgrowth, increased counts of nitrate reducing bacteria and enhanced gastric nitrite concentrations (Gut 1982; 23: 1048).

The present investigation was conducted in eight healthy volunteers. Subjects were treated - in randomised sequence - for each of 28 days either with aluminium hydroxide + magnesium hydroxide $(3 \times 10$ g/day, po), aluminium phosphate $(3 \times 11$ g/day, po), or placebo (three times/day, po). The day before onset of treatment and on the last day during each treatment period, gastric juice was collected by continuous aspiration using a sterile tube. Collections of basal gastric acid lasted 60 minutes followed by aspiration over 120 minutes during pentagastrin stimulation $(1.5 \mu \mathrm{g} / \mathrm{kg} \mathrm{bw})$ for determination of BAO and PAO.

No change of BAO, PAO, total bacterial counts, nitrite reducing bacteria, and nitrite concentrations occurred after the placebo period. In none of the subjects was PAO decreased by treatment with antacids. BAO was only modestly reduced by aluminium phosphate in three out of eight volunteers and almost no change in bacterial counts was obtained. In contrast, BAO was profoundly reduced in four and moderately in four subjects during oral aluminium hydroxide and magnesium hydroxide. The fall in BAO was associated with an enormous increase in the total number of bacteria (mean $1.4 \times 10^{6}$ to $\left.4.8 \times 10^{6} / \mathrm{ml}\right)$ and of nitrite reducing bacteria (mean $0.009 \times 10^{6}$ to $0.5 \times 10^{6} / \mathrm{ml}$ ) $(p<0.05)$. The decline in BAO was accompanied - in any case - by an increase in gastric nitrite concentration.

We conclude from these results that total bacterial counts, nitrate reducing bacteria, and nitrite concentration in gastric juice will rise during effective oral antacid therapy and that gastric bacterial overgrowth is mainly associated with the rise in gastric $\mathrm{pH}$ and not with the choice of gastric antisecretory or antacid treatment.

\section{F74}

Omeprazole in duodenal ulcer disease: tolerance, acid inhibition, and endoscopic healing
M J DALY, A L HOWE, J J MISIEWICZ, I F TROTMAN, J A WILSON, K G WORMSLEY, R E POUNDER, B SHARMA, J SPENCER, AND J H BARON (Astra Clinical Research Unit, Edinburgh; Central Middlesex Hospital, London; Ninewells Hospital, Dundee; Royal Free Hospital, London; Royal Postgraduate Medical School and St Charles Hospital, London) Omeprazole inhibits gastric acid secretion by interacting with the enzyme $\mathrm{H}^{+}, \mathrm{K}^{+} \mathrm{ATPase}$, the postulated proton pump of the parietal cell. We have investigated the effect of different doses of omeprazole $(20,30,40$, or $60 \mathrm{mg})$ given once daily for 28 days to 40 patients with duodenal ulcer. Endoscopy and pentagastrin stimulated peak acid output (PAO) were performed before and after treatment.

Endoscopic healing was seen in 38 of the 40 patients $(95 \%)$ completing the study. Healing rate were similar in each dose: $8 / 9$ on $20 \mathrm{mg}, 12 / 12$ on $30 \mathrm{mg}, 7 / 8$ on $40 \mathrm{mg}$, and $11 / 11$ on $60 \mathrm{mg}$ omeprazole daily. Complete relief of pain was reported by $84 \%$ of patients after one week and by $100 \%$ of patients after four weeks. The percentage inhibition of PAO measured 24 hours after the last dose was $57,94,94$, and $81 \%$ respectively with $20,30,40$, and 60 $\mathrm{mg}$ omeprazole $(n=25)$. One week after stopping treatment PAO was not conistently different from the pretreatment value $(n=10)$. One patient was lost to follow up. Two patients had transient diarrhoea during the treatment. No serious adverse events or clinically significant changes in laboratory values were observed. Omeprazole is very effective in reducing gastric acid secretion and in healing duodenal ulcer. Large comparative clinical trials are needed to assess its therapeutic potential.

F75

Results of a two year maintenance study in gastric ulcer disease

A G MORGAN, W A F MCADAM, C PACSOO, AND A DARNBOROUGH (Endoscopy Unit, Airedale General Hospital, Steeton, Keighley, West Yorkshire) One hundred patients with a benign gastric ulcer were randomly allocated to either cimetidine or caved $S$ therapy. Once ulcer healing was confirmed endoscopically, they were entered into a two year maintenance study. An asymptomatic ulcer recurrence was looked for after six months' treatment, and all patients were endoscoped if they had dyspeptic' symptoms that lasted for more than three to four days.

Forty one patients were treated with cimetidine, $400 \mathrm{mg}$ at night, and 34 patients with caved $\mathrm{S}$, two tablets twice daily. During the first year $9.8 \%$ of the cimetidine group and $14.3 \%$ of the caved S group had an ulcer recurrence. In the second year this rose to $14.3 \%$ (cimetidine) and $18.5 \%$ (caved $\mathrm{S}$ ). Both drugs were thus equally effective in delaying ulcer recurrence.

All patients were then observed for a further four months after stopping maintenance therapy. Of the cimetidine group $30.4 \%(7 / 32)$ and $9.1 \%$ of the caved $S$ group $(2 / 22)$ had an endoscopically proved ulcer recurrence. The rapid ulcer recurrence following cimetidine therapy found in this study, is similar to that seen in duodenal ulcer disease.

\section{F76}

Postmarketing surveillance of cimetidine safety: a twelve month morbidity report

D G COLIN JONES, M J S LANGMAN, D H LAWSON, AND M P VESSEY (Queen Alexandra Hospital, Portsmouth; Queen's Medical Centre, Nottingham; Royal Infirmary, Glagow; and Radcliffe Infirmary, Oxford) We have examined pattern of morbidity in an initial twelve month follow up period in 9928 cimetidine takers and 9351 general controls, $98.9 \%$ of takers and $97.7 \%$ of controls being successfully followed. Recipients attended hospital or were admitted more often than controls (attendances: recipients 39\%, controls $21 \%$; admissions: $18 \%$ and $8 \%$ respectively), both for gastrointestinal and non-gastrointestinal disease. Nineteen recipients had ulcer perforation (three gastric, 16 duodenal) during the year, as did one control; timing was unrelated to duration, or intensity of treatment. Pancreatitis and hepatitis were also more common in patients, but no clear causal relationships emerged; thus 27 takers and three controls had acute pancreatitis but pancreatitis antedated treatment in seven takers and 15 had known predisposing disease. There were also more diagnoses of lung, lymphoid, oesophageal, gastric, large intestinal, and pancreatic cancer in recipients, but relationships were generally unsuspicious. Thus for lung cancer the great majority of recipient diagnoses were made within a year of initial treatment.

Other excesses were usually explainable for example, pulmonary disease (by 
heavier smoking) and locomotor disorders (by treatment of drug induced dyspepia), although we did find more gynaecomastia in takers than controls. Major undetected risks of cimetidine treatment have not been uncovered by this survey.

\section{F77}

Combination of $\mathbf{H}_{2}$-receptor antagonist with anticholinergic agent

T GLEDHILL, J A BILLINGS, S P GRAY, AND R H HUNT (Department of Biochemistry and Gastroenterology, Royal Naval Hospital Haslar, Gosport, Hants, and McMaster University, Hamilton, Ontario, Canada) Gastric secretion may be inhibited by anticholinergic agents and histamine $\mathrm{H}_{2}$ receptor antagonists although individual responses to these agents varies. The aim of our study was to assess whether combination of an anticholinergic agent with an $\mathrm{H}_{2}$-receptor antagonist could improve inhibition of acid output (AO) and pepsin output (PO). We compared the effect of no treatment (NT), cimetidine $1 \mathrm{~g} /$ day (C), atropine $4.8 \mathrm{mg} /$ day (A), and $\mathrm{C}$ combined with A (CT) on 24 hours intragastric acidity $\left(\mathrm{H}^{+}\right)$, nocturnal $\mathrm{AO}$, and nocturnal $P O$ in seven duodenal ulcer patients chosen because of a poor clinical response to $C$. Each patient was studied over four identical 24 hour periods receiving either NT, C, A, or CT. Hourly samples of gastric juice were taken via a nasogastric tube for $\mathrm{pH}$ estimation. From 01.00 continuous aspiration was used to collect volume of secretion. Every hour two $5 \mathrm{ml}$ samples were taken, one for titration to $\mathrm{pH} 7$ to estimate $\mathrm{AO}$ and a second for estimation of peptic activity by the Method of Gray and Billings (Clin Chem 1983; 29: 447). Pepsin output was then calculated.

Nocturnal AO \pm SD $(\mathrm{mmol} / \mathrm{h})$ was $6.3 \pm 3.9$ on NT, $3.3 \pm 1.9$ on $C, 2.9 \pm 1.5$ on $A$, and $1.3 \pm 1.3$ on $C T(p<0.05$ cf $C)$. Nocturnal $\mathrm{PO} \pm \mathrm{SD}(\mathrm{IU} / \mathrm{h})$ was $3 \cdot 1 \pm 4 \cdot 2$ on NT, $3.8 \pm 3.6$ on $C, 1.5 \pm 1.1$ on $A$, and $1.0 \pm 1 \cdot 1$ on CT $(p<0.01$ cf $C)$. Mean 24 hour $\mathrm{H}^{+} \pm \mathrm{SD}(\mathrm{mmol} / \mathrm{l})$ was $34.5 \pm 6 \cdot 1$ on NT, $23.8 \pm 7.5$ on $C, 26.8 \pm 9.4$ on $A$, and $9.5 \pm 9.0$ on CT (p<0.05 cf C).

Our results confirm that $\mathrm{C}$ may increase nocturnal $\mathrm{PO}$ and that combination of an anticholinergic agent with an $\mathrm{H}_{2}$-receptor antagonist provide greater reduction in mean 24 hour $\mathrm{H}^{+}$, nocturnal $\mathrm{AO}$, and nocturnal PO than either drug alone.
F78

Towards an optimum drug regimen for bedtime maintenance treatment of duodenal ulcer

J CHAMBERS, D PRYCE, AND T C NORTHFIELD (Norman Tanner Gastroenterology Unit, St James' Hospital, and Department of Medicine, St George's Hospital Medical School, London) Maintenance treatment with a bedtime dose of ranitidine or cimetidine reduces the relapse rate of duodenal ulcer, but the optimal drug regimen is not known. We have therefore carried out two randomised dose:response studies in 13 patients with endoscopically proven duodenal ulcer (DU) in symptomatic remission, measuring intragastric $\mathrm{pH}$ and acid output hourly overnight. In study 1 , the conventional bedtime dose of cimetidine $(400 \mathrm{mg}$ ) was compared in six DU patients with $200 \mathrm{mg}, 800 \mathrm{mg}$, and with placebo. In study 2 , it was compared in seven different $D U$ patients with ranitidine $75 \mathrm{mg}, 150 \mathrm{mg}$, and $300 \mathrm{mg}$, and with placebo. In study 1 , cimetidine $400 \mathrm{mg}$ inhibited gastric acid output by $93 \pm 2 \%$, by comparison with placebo. This inhibition was greater than for cimetidine $200 \mathrm{mg}$ $(54 \pm 11 \%, \mathrm{p}<0.05)$ but similar to cimetidine $800 \mathrm{mg}(94 \pm 2 \%)$. Intragastric $\mathrm{pH}$ was $>4$ for $64 \pm 13 \%$ and $94 \pm 6 \%$ of samples with cimetidine $400 \mathrm{mg}$ and $800 \mathrm{mg}$ respectively (NS), compared with $3 \pm 3 \%$ of samples with placebo $(p<0 \cdot 01)$. In study 2 acid inhibition with cimetidine $400 \mathrm{mg}$ at bedtime was $70 \pm 10 \%$, and this tended to be lower than for all three doses of ranitidine $(87 \pm 3 \%, 85 \pm 7 \%$, and $89 \pm 3 \%$ respectively; NS), and for the same dose in study 1. Intragastric $\mathrm{pH}$ was $>4$ for $39 \pm 15 \%$ of samples with cimetidine 400 mg, compared with $86 \pm 9 \%$ and $90 \pm 7 \%$ with ranitidine $150 \mathrm{mg}$ and $300 \mathrm{mg}$ respectively $(p<0.05)$. We conclude that the optimum bedtime dose of cimetidine is $400 \mathrm{mg}$, and of ranitidine $75 \mathrm{mg}$ or less, if efficacy in preventing DU relapse depends on suppressing overnight acid secretion: that a higher dose of cimetidine may be necessary if efficacy depends on maintaining intragastric $\mathrm{pH}$ at a level that will inactivate pepsin overnight; and that the conventional bedtime dose of ranitidine (150 mg) is more effective than the conventional dose of cimetidine $(400 \mathrm{mg})$ in maintaining intragastric $\mathrm{pH}$.

\section{F79}

Twenty four hour ambulatory monitoring of gastric pH
B KAPUR, P J HOWLETT, N G KENYON, $M$ J LUNT, J MILLS, R H SMALLWOOD, A J WILSON, AND $K$ D BARDHAN (District General Hospital, Rotherham; Royal Hallamshire Hospital, Sheffield; Smith, Kline and French, Welwyn Garden City, Herts) A method has been developed for continuous 24 hour ambulatory monitoring of gastric pH, permitting physiological and pharmacological studies. A combined pH and reference electrode ( $3 \mathrm{~mm}$ diameter) is connected via a cable to a Medilog cassette recorder. The system, limited by the electrode, has a response time of approximately one second, with a resolution of $0 \cdot 1$ pH unit. A good correlation with simultaneous aspirate sampling was obtained both in vitro $(\mathrm{r}=0.99, \mathrm{p}<0.001)$ and in vivo $(\mathrm{r}=0.72, \mathrm{p}<0.001)$, discrepancies being due to differences in physical conditions.

The recordings are transferred to digital computer for subsequent analysis. The main index used in data analysis is the percentage time spent within predetermined $\mathrm{pH}$ bands. Measures of rhythmicity and rate of change have also been examined. Nocturnal, postmeal, and intermeal data can be separately analysed.

In 16 studies from eight normal volunteers, the percentage of 24 hours spent at pH bands $<1 \cdot 2,1 \cdot 2-1 \cdot 5,>1 \cdot 5-2$, $>2-3,>3-4,>4( \pm \mathrm{SE})$ was $43.5 \pm 4 \cdot 5$, $23 \cdot 3 \pm 2 \cdot 5,12 \cdot 3 \pm 1 \cdot 3,9 \cdot 1 \pm 1 \cdot 0,4 \cdot 1 \pm 0 \cdot 6$, $7 \cdot 6 \pm 1.7$ respectively. The repeat studies show good reproducibility. In five of eight volunteers spontaneous hypochlorhydria ( $\mathrm{pH}>4.0)$ was observed at night and in all but one this was reproducible.

\section{F80}

Natural history of endoscopic oesophageal sclerotherapy complications

J D R ROSE AND P M SMITH (Department of Gastroenterology, Llandough Hospital, Penarth) The complications of sclerotherapy have been studied endoscopically in 65 patients, who underwent 526 follow up endoscopies, including 328 further injection sessions. In the first five days after sclerotherapy, superficial ulceration was seen in $24 \%$ of endoscopies. Linear and deeper ulceration reached a maximum at six to 10 days, occurring in $28 \%$. From 11-15 days $44 \%$ showed some form of ulceration, but by 16-20 days half were healing. By 26-30 days linear and deeper ulceration occurred in only $10 \%$ and superficial ulceration in only $1 \%$. Ulcers bled in four patients between nine and 13 days after sclerotherapy and another perforated 
on the eleventh. Granulation tissue formation was followed by late oesophagogastric junction ulceration in two patients four and eight months after their last injection.

Strictures occurred after multiple injections (three to nine, mean 4.75 ) in 14 patients but resolved spontaneously in half. Two strictures were present for over a month before resolving. Five patients needed to be dilated once; the others required two and four dilatations respectively.

After a single sclerotherapy session deep ulcers, haemorrhage, and perforation can occur, most frequently about $\mathbf{1 0}$ days later, but the majority of ulcers heal within 30 days. Strictures only occur after multiple injections and frequently resolve spontaneously.

\section{F81}

\section{Seasonal incidence of oesophagitis}

M C HOLBROOK AND J B ELDER (University Department of Surgery, The Royal Infirmary, Manchester) To evaluate our workload we have used a CBM microcomputer and a Compsoft DMS program to directly store and analyse the findings in 6300 consecutive gastroscopies performed under Valium with the flexible gastroscope in the years 1978 to 1983.

A total of four instruments were used by 32 different endoscopists over the period under study. Physicians performed more gastroscopies than surgeons in the ratio of $1 \cdot 4: 1$. The sex ratio of the patients gastroscoped was $55 \%$ men and $45 \%$ women. The method of analysis revealed a startling biannual incidence of oesophagitis with peaks in March and September, and a threefold drop in incidence in the months of July and August $(p<0.01)$ which remained when the figures were corrected for the different numbers of gastroscopies performed each month. The variation in the monthly incidence of oesophagitis was more marked in men than women. The well described seasonal variation in duodenal ulceration was confirmed. Over the entire series a total of 55 different endoscopic diagnoses were recorded.

This study has shown the ease with which the system described can be used to store and analyse gastroscopy data, and has revealed a previously unreported variation in the incidence of oesophagitis that has obvious implications for the timing of short term studies of oesophageal and gastric function.

\section{F82}

Endoscopic colostomy, gastrostomy, and anastomosis

C P SWAIN, T N MILls, JULIA DARK, T C NORTHFIELD, AND P R SALMON (Departments of Gastroenterology and Medical Physics, University College Hospital, and Norman Tanner Gastroenterology Unit, St James' Hospital, London) Experimental studies were undertaken to develop endoscopic methods for forming colostomy and gastrostomy without laparotomy. Parallel studies were undertaken to establish a methodology for endoscopic anastomosis. In the anaesthetised dog colostomy and gastrostomy were formed under endoscopic control. The endoscope is positioned in the air distended viscus against the anterior abdominal wall so that the light is seen shining through and the tip can be palpated to ensure that there are no organs intervening between the chosen site of stoma formation and the abdominal wall. A wire is passed via the endoscopic biopsy channel through the viscus and the abdominal wall into the hands of an assistant. The endoscope is removed and a plastic introducer and catheter are attached to the guide wire and pulled through the abdominal wall until the dilated distal end of the catheter pulls the viscus against the abdominal wall. A rubber grommet is sewn over the catheter against the skin exerting gentle pressure. The orifice heals around the catheter into an enterocutaneous stoma. Feasibility studies of endoscopic anastomosis were carried out at laparotomy. A fenestrated button was designed to fit over an endoscope tip without impairing its function. Under endoscopic control, a wire is passed through one viscus into its partner, is seized by a snare and pulled through the biopsy channel. By means of this wire a button is drawn into tight apposition with the button on the endoscope tip. The buttons are left joined, the endoscope removed. The tissue crushed between the buttons atrophies, the buttons drop into the gut leaving an enteroenterostomy. Endoscopic anastomosis with catheter was also studied. These experimental studies show that colostomy and gastrostomy can be formed by endoscopic means without laparotomy and that endoscopic anastomosis appears feasible at certain anatomical sites.

\section{BILIARY}

F83-F88

F83

Biliary secretion of alkaline phosphatase

(AP) in man: dependency on the bile acid (BA) secretion and detergency of BA pool

P LORIA, M PONZ DE LEON, F ZIRONI, M BERTOLOTTI, D MENOZZI, AND N CARULLI (Istituto di Clinica Medica I, Università di Modena, Italy) It has been shown that changes of bile acid (BA) pool composition induce quantitative changes of biliary lipid secretion and it has been suggested that alkaline phosphatase (AP) secretion into bile is dependent on BA secretion. In this study we investigated the effect of acute infusion of five different BAs with different detergent capacity: deoxycholic (DCA), chenodeoxycholic (CDCA), cholic (CA), ursodeoxycholic (UDCA) and ursocholic (UCA) on AP activity secretion into bile.

Alkaline phosphatase activity in bile was determined as a part of a more complete study on biliary lipid secretion in patients with T-tube before (depletion) and after intraduodenal infusion (replacement of the endogenous pool) with individual BAs. Alkaline phosphatase activity was determined on hourly collected bile samples during the depletion (five hours) and during the replacement period (five hours), by automated technique. Three infusions were performed with DCA, three with CDCA, four with CA, four with UDCA and two with UCA. One to two hours after the starting of the infusion BA pool became predominately $(80-90 \%)$ constituted by the infused BA. Biliary AP activity increased in an exponential manner to reach a peak value one to two hours after the beginning of the infusion. Thereafter the activity declined to reach the values of the depletion period. Peak activity values of the ratio FA/BA secretion (mU/umol) were respectively: $106 \pm 52$ for DCA, $44 \pm 18$ for CDCA, $13 \pm 5 \cdot 2$ for CA, $1.49 \pm 0 \cdot 8$ for UDCA and $0.12 \pm 0.02$ for $U C A$; respective value of the depletion period was: $7 \cdot 26 \pm 10 \cdot 2$. The difference was statistically significant $(p<0.01)$ among all different BAs except between DCA and CDCA $(p<0.05)$. Highest value of AP activity was correspondent to the highest value of $\mathrm{BA}$ secretion but afterwards the two parameters were not parallel.

Our study suggests that AP secretion into bile is related to $\mathrm{BA}$ secretion and to the detergency of the BA pool. 
F84

Is 'intrahepatic cholestasis in sickle haemoglobinopathies' typical cholestasis?

S I TERRY AND G R SERJEANT (Department of Medicine and MRC Laboratories, University of the West Indies, Kingston, Jamaica) The syndrome of intrahepatic cholestasis in sickle cell disease is well recognised but poorly understood. To clarify the mechanisms, studies of maximal bile canalicular transport (Tm) and hepatic storage (S) of bromsulphthalein (BSP) at different infusion rates have been performed. Other cholestatic conditions generally reveal a reduced $T m$ with $S$ being normal or slightly reduced.

Six patients with homozygous sickle cell (SS) disease were studied during an episode of acute cholestasis. There were four men and two women with age (range: $16-42$ years), weight $(40-65 \mathrm{~kg})$, total serum bilirubin $(415-723 \mu \mathrm{mol} / \mathrm{l})$ of which $55 \pm 18 \%$ was direct-reacting, SGOT (28245 IU/I), and alkaline phosphatase (106$234 \mathrm{IU} / \mathrm{l}$ ). Haemoglobin (mean $\pm \mathrm{SD}$ : $7 \cdot 8 \pm 1 \cdot 0 \mathrm{~g} / \mathrm{dl})$ and reticulocyte count $(11 \pm 6 \%)$ did not differ from steady state values. Bile pigment was seen on liver biopsy in all patients.

The results of BSP infusion during the acute episode were calculated and related to body weight. The Tm was $1 \cdot 2 \pm 0.5$ $\mathrm{mg} / \mathrm{mg} \% / 10 \mathrm{~kg}$ which did not differ from that in 11 Jamaicans with SS disease in the steady state $(1 \cdot 3 \pm 0 \cdot 3)$ or from four normal Jamaican controls $(1 \cdot 4 \pm 0 \cdot 2)$. Values for $S$ were markedly reduced $(0.2 \pm 0.34 \mathrm{mg} /$ $\mathrm{mg} \% / 10 \mathrm{~kg}$ ) compared to the two control groups $(0 \cdot 3 \pm 5 \cdot 5)$ and $(14 \cdot 8 \pm 4 \cdot 6$ respectively.

The pattern or results is thus different from that seen in other cholestatic conditions and suggests that cholestasis in SS disease may not reflect a primary failure in biliary transport but a defect in hepatocellular function with decreased uptake or increased release of BSP (or direct-reacting bilirubin) back into the blood steam. The association of increased direct-reacting bilirubin with increased hepatocellular enzymes is compatible with the latter hypothesis.

\section{F85}

Deleterious effects of jaundice in pancreatoduodenectomy for cancer

M J COOPER, A P CORFIELD, AND R C N WILlIAMSON (University Department of Surgery, Bristol Royal Infirmary, Bristol)
As originally described radical resection of periampullary carcinoma involved pancreatoduodenectomy after a preliminary internal biliary decompression. The greater convenience of the one-stage resection now generally practised might be balanced by the risks of undertaking a major resectional and reconstructive procedure in patients with prolonged obstructive jaundice. The effect of hepatic function on operative results was therefore assessed in 54 patients receiving pancreatoduodenectomy for cancer in Bristol between 1971-82. There were 30 men and 24 women with a mean age of 63 years (range 35-83 years). Carcinomas were sited in the pancreas $(n=25)$, ampulla $(17)$, bile duct (10) and duodenum (two). Onestage resection was performed in 35 icteric patients, six of whom survived a second operation for haemorrhage or anastomotic leak and 17 of whom died within 30 days. Among six non-icteric patients with onestage resection there were no postoperative deaths but one reoperation for anastomatic leak. Two-stage resection was performed in 13 icteric patients with two deaths $(15 \%)$ and one reoperation for a T-tube leak. In the absence of jaundice pancreatoduodenectomy had a lower hospital mortality rate $(11 \%$ vs $49 \%: p<0.01)$ and a slightly lower reoperation rate ( $11 \%$ vs $18 \%$ : NS). Any increased risk in performing two operations rather than one for resectable periampullary cancer is apparently outweighed by the advantage of restoring normal hepatic function before pancreatoduodenectomy; median survival (17 months) being similar in each group.

F86

Gall-stone pathogenesis: physicochemical factors which control the nucleation of cholesterol by compounds in gall stones

B W A WILLIAMSON AND $M$ TRAINER (INTRODUCED BY D C CARTER) (University Department of Surgery, Royal Infirmary, Glasgow) The rate of formation of cholesterol crystals in bile, although faster in gall-stone patients than in controls, is unrelated to the degree of cholesterol supersaturation implying that other factors are involved. The purpose of this study is to establish that one such factor is nucleation of cholesterol crystals by other compounds found in gall stones and, in addition, to determine the physicochemical criteria which influence this process.

The growth rate of cholesterol crystals from purified biliary lipid solutions was significantly faster in the presence of added crystals: $1640 \mu \mathrm{g} / 24 \mathrm{~h}$ with added calcium bilirubinate, $1440 \mu \mathrm{g} / 24 \mathrm{~h}$ with added hydroxyapatite and $1120 \mu \mathrm{g} / 24 \mathrm{~h}$ with added calcium carbonate, than in unseeded controls $(800 \mu \mathrm{g} / 24 \mathrm{~h}) \mathrm{n}=5 ; \mathrm{p}<0.05$. More than $80 \%$ of the observed growth, however, occurred in the first 20 minutes after seeding. The occurrence of seeding was dependent on the degree of cholesterol supersaturation (CSI range 0.80-1.27). The magnitude of seeding was increased $\times 5$ by changes in the bile salt/lecithin ratio from $1: 1$ to $9: 1$; and increased $\times 2$ by changes in the degree of mixing of the seed crystals with the lipid solution. Seeding was not influenced by $\mathrm{pH}$ changes nor by the seed crystal size or mass.

It is concluded that the process of crystal seeding may be pertinent to the initial stages of gall stone formation but that this process may only take place within a closely defined physicochemical microenvironment in bile.

\section{F87}

Prevention of nocturnal interruption of the enterohepatic circulation by taking bedtime bile acid

A LANZINI, D FACCHINETTI, AND $T$ C NORTHFIELD (Department of Medicine, St George's Hospital Medical School, London) The enterohepatic circulation (EHC) of bile acids (BA) is interrupted overnight, as the BA pool is stored in the gall bladder during fasting. As a result, hepatic BA secretion rate falls and hepatic bile becomes supersaturated with cholesterol even in health. The aim of this study was to test the hypothesis that this interruption of the EHC would be prevented by bedtime BA administration, thus providing an explanation for the previous finding that bedtime BA administration has a significantly greater effect on cholesterol saturation index of gall bladder bile than does mealtime administration. It has been previously shown that mealtime BA administration does not alter BA secretion rate. We measured hepatic BA secretion rate in six gall-stone patients before and during treatment with ursodeoxycholic acid (UDCA) $750 \mathrm{mg}$ at bedtime given for one month. Continuous intravenous infusion of ICG was given as a hepatic bile marker, and PEG was given as a non-absorbable duodenal perfusion marker. Duplicate studies in two patients showed good reproducibility. Before UDCA, mean hepatic BA secretion rate 
$(\mu \mathrm{mol} / \mathrm{kg} / \mathrm{h}$; mean $\pm \mathrm{SEM})$ fell overnight from $16 \pm 5$ (first hour after evening meal) to $5 \pm 1$ (twelfth hour). During UDCA, mean BA secretion rates $(n=4)$ during the five hours before the bedtime dose were similar to the pretreatment values (12 vs $10 ; 17$ vs $15 ; 12$ vs $15 ; 13$ vs 11). During the five hours after the bedtime dose there was a significant increase in mean BA secretion rates for all four subjects ( 16 vs $7, \mathrm{p}<0.02$; 9 vs $3, \mathrm{p}<0.05 ; 13$ vs $7, \mathrm{p}<0.005 ; 13$ vs 6 , $\mathrm{p}<0.02)$. We conclude that bedtime UDCA is effective in preventing nocturnal interruption of the EHC of $\mathrm{BA}$; and that this provides an explanation for the finding that bedtime administration is more effective than mealtime administration of the same total daily dose of bile acids.

\section{F88}

British gall-stone study group (BGSG) postdissolution trial: interim report on overall recurrence rates and discrepancies between ultrasonography (US) and oral cholecystography (OCG)

D GLEESON, D C RUPPIN, AND R H DOWLING; AND THE BRITISH GALL STONE STUDY GROUP (Gastroenterology Unit, Department of Medicine, Guy's Hospital and Medical School, London) The BGSG trial is designed to compare the efficacy of lowdose ursodeoxycholic acid $3 \mathrm{mg} / \mathrm{kg} / \mathrm{d}$, placebo (double-blind), and diet (high fibre, low refined carbohydrate), in preventing recurrence in patients with confirmed gall-stone dissolution (2 OCGs \pm 1 US), followed up for two to five years with six monthly USs and yearly OCGs (unless symptoms or ultrasound had suggested early recurrence). As the treatment code remains unbroken, this report deals only with overall recurrence rates, independent of treatment. To date, 58 patients have entered the trial and of these, 45 have been followed for one year, and 29 for two years or until recurrence.

Recurrence was diagnosed in 12 patients - by one abnormal OCG in 10, and by two abnormal USs in two (with acquired iodine sensitivity). By life table analysis, cumulative recurrence rates were $17 \%$ at one year, and $33 \%$ at two years. None of these patients had biliary colic.

Discrepancies between OCG and US: (i) Number of occasions: from 128 US examinations, stones were detected on 25 occasions, and of these, 18 had accompanying OCGs which confirmed stones in only seven; 16 had subsequent USs which were normal in seven.
Conversely of 71 OCGs carried out, 11 showed recurrence and of these, four accompanying USs showed no stones. (ii) Number of patients: of 49 patients studied by US, recurrent stones were detected in 14. 13 of these had OCGs which showed stones in only seven, while 11 have had one or more subsequent USs which showed stones in nine and no stones in seven. Of 43 patients studied by OCG, however, recurrence was diagnosed in 10 , all of whom had an associated US which was non-confirmatory in four.

It is concluded, therefore, that there is major inter-technique and intra-technique variation in detecting recurrence after confirmed gall-stone dissolution, and that surgical 'proof' of diagnostic accuracy is needed for both OCG and US in detecting small stones.

\section{OESOPHAGUS}

F89-F96

F89

Optimal length of cardiomyotomy for achalasia

J H WYLLIE AND D A W EDWARDS (Academic Unit of Surgery, Whittington Hospital, London) When dysphagia persists or recurs after cardiomyotomy for achalasia, the cause is nearly always either a peptic or a ring stricture. In 106 cardiomyotomised patients referred because of dysphagia a peptic stricture was found in 60 , a ring stricture in 27 , and in 19 dysphagia was associated with a large mucosal herniation through the myotomy. It was postulated that postoperative dysphagia might be reduced by confining myotomy to the sphincter segment; avoiding extension on to the stomach where the hiatus might be damaged with a risk of inducing reflux, and avoiding a long cut on the oesophagus with its risk of mucosal herniation.

In 30 patients the length of the sphincter was measured radiologically before operation. The median length was $20 \mathrm{~mm}$, no case exceeding $25 \mathrm{~mm}$. No myotomies less than $50 \mathrm{~mm}$ long have been made over a period of three years in a consecutive series of 29 cases. The mean length of cut was $35.9 \mathrm{~mm}$ (SD $7.3 \mathrm{~mm}$, range $20-47$ $\mathrm{mm})$. In 28 cases the result were gratifying, with cessation of regurgitation, and residual dysphagia confined to an occasional sensation of sticking when eating dry food. This could always be rectified by drinking. In no case could reflux be shown radiologically on mean follow up of 14 months. But one patient continued to eat very slowly, and to regurgitate. He had a myotomy $20 \mathrm{~mm}$ long, the shortest made; after two years we decided that the top of the sphincter had not been divided. Reoperation extended the myotomy proximally with immediate relief of dysphagia.

Myotomy confined to the sphincter gives satisfactory results provided the entire sphincter has been divided.

\section{F90}

Does the upper oesophagus play a part in preventing reflux oesophagitis?

M H EDWARDS (Department of Surgery, Friarage Hospital, Northallerton, $N$ Yorks) The lower oesophagus has been extensively studied in patients with reflux oesophagitis. Measurement of clearance of acid from the lower oesophagus by $\mathrm{pH}$ monitoring has led to the concept of a defective oesophageal pump playing part in reflux oesophagitis. Little attention has been paid to the role of the upper oesophagus as part of an oesophageal pump in normal and reflux states.

Manometric studies were performed using a perfused system which monitored pressures at the top, middle, and bottom of the oesophagus in four groups of patients with either no oesophageal symptoms $(n=11)$, symptoms of reflux only $(n=10)$, oesophagitis $(n=7)$, or dilated peptic strictures $(n=7)$. Peristaltic waves were recorded after wet swallows using a tube perfusion rate of $10 \mathrm{ml}$ water per minute.

In the upper half of the oesophagus, the amplitude and speeds of conduction of the peristaltic waves were significantly lower in patients with oesophagitis or stricture than in those with reflux symptoms only or no symptoms. Also the ratios of conduction speeds in the upper half of the oesophagus to the conduction speeds in the lower half of the oesophagus were significantly lower, the more serious was the severity of the oesophageal reflux disease.

The findings suggest an impairment of the oesophageal pump in the upper half of the oesophagus in reflux patients. This may be causative.

\section{F91}

\section{Hyperdynamic oesophagus}

B FLESHLER AND E ACHKAR (Department of Gastroenterology, Cleveland Clinic 
Foundation, Cleveland, Ohio, USA) The advent of low compliance, high fidelity pressure recording systems has uncovered a previously unrecognised disorder of oesophageal motility called variously the 'nutcracker' or 'supersqueezer' or, by us, the 'hyperdynamic' oesophagus. Over a three year period, 28 patients were studied. Twenty two were women; the ages ranged from 32-71 years. Chest pain, present in 23 patients, was the most usual cause for study. The pain was retrosternal, occurred intermittently, was often severe, and was not necessarily related to swallowing. Intermittent, non-progressive dysphagia was present in 19 patients. In 25 patients barium radiologic examination of the oesophagus revealed no abnormality; in two some tertiary contractions were reported. Upper endoscopy was normal in 16 of 22 patients who had this procedure; mild oesophagitis was present in four of a few 'spastic' contractions in two. Manometric study revealed peristalsis in all cases with normal lower and upper oesophageal sphincter function. The predominant abnormality was increased amplitude of contractions with some contractions, especially in the lower third, of long duration.

Contraction pressures $(\mathrm{mmHg})$ (mean $\pm \mathrm{SD} ; \mathrm{p}<0.001$ for each comparison): upper third, hyperdynamic $70 \cdot 2 \pm 31 \cdot 4$, normal $48 \cdot 2 \pm 21 \cdot 2$; middle third, $148 \cdot 7 \pm 65 \cdot 2,72 \cdot 5 \pm 31 \cdot 7$; lower third, $219 \cdot 9 \pm 85 \cdot 6,79 \cdot 9 \pm 41 \cdot 05$.

The hyperdynamic oesophagus is a primary disorder of the oesophagus characterised by chest pain with or without dysphagia. The diagnostic hallmark of the syndrome is the finding, by oesophageal manometry, of contraction waves of increased amplitude and, at times, of long duration with preserved peristaltic progression and normal sphincter function.

\section{F92}

Does ranitidine prevent recurrence of reflux oesophagitis?

H R KOELZ, R BIRCHLER, Y CAPITAINE, G DELMORE, H F FEHR, G MÜNST, I FUMAGALLI, J GEHRIG, J J GONVERS, F HALTER, B HAMMER, L KAYASSEH, E KOBLER, G MILLER, S PELLONI, S REALINI, M VOIROL, AND A L BLUM (Gastrointestinal Unit, Inselspital, Bern, Switzerland) Little is known about recurrence rate and efficacy of prophylactic medical treatment of reflux oesophagitis. Thus, we performed a multicentre study in 69 patients with erosive-ulcerative oesophagitis which had healed under open ranitidine treatment (150 or $300 \mathrm{mg}$ bd for six to 24 weeks). Patients with peptic stricture were excluded. Prophylactic treatment was double blind and consisted of ranitidine ( $R 150 \mathrm{mg}$ nocte) or placebo (P) for six months or until recurrent oesophagitis was shown by endoscopy. The patients were endoscoped as soon as symptoms reappeared and/or after six months. Four patients in each group did not complete the study. The two groups with the remaining patients, 28 under $R$, and 33 under $P$, had similar sex ratio, age, duration of history of reflux of symptoms, severity of previous oesophageal lesions, previous dose of ranitidine, and duration of treatment for healing. Four asymptomatic patient under $R$ and seven under $P$ were not willing to undergo endoscopy at the end of the study. Recurrent oesophagitis was diagnosed in $10 / 28(36 \%)$ under $R$, and $14 / 33(42 \%)$ under $P$ (NS). Under $R$ oesophageal lesions at the time of recurrence were, as compared with previous oesophagitis, identical in four, less severe in six, and more severe in one. Under $P$ they were identical in seven, less severe in six, and more severe in one. Recurrent symptoms predicted oesophagitis in $9 / 12$ patients under $\mathrm{R}$ and $10 / 13$ under $\mathrm{P}$. In summary, erosive-ulcerative oesophagitis after healing with ranitidine recurred in more than one third of the patients within six months. Prophylactic ranitidine treatment was not effective in preventing recurrence.

\section{$\mathrm{F} 93$}

Gastro-oesophageal refiux (GOR) in patients with oesophagitis or a columnar lined (Barretts) oesophagus

D FLOOK AND C J STODDARD (University Department of Surgery, University of Liver pool, Liverpool) Barretts oesophagus is an acquired condition, present in $10 \%$ of patients with significant gastro-oesophageal reflux (GOR) and predisposes to the development of oesophageal adenocarcinoma. The reason why some, but not all, patients with GOR develop a Barretts oesophagus is obscure; but the extent of identifiable reflux may be a factor.

We have performed 24 hour intraoesophageal pH measurements and standard acid reflux tests (SART) and measured the lower oesophageal sphincter pressure (LOSP) by conventional techniques in three groups of patients. Group $(n=12)$ control subjects with no GOR symptoms, group $2(n=22)$ patients with GOR oesophagitis and a squamous lined oesophagus, and group $3(n=13)$ patients with a Barretts oesophagus.

Values were obtained in each group for the time within the 24 hour monitoring period during which intraoesophageal $\mathrm{pH}$ was $<4$, the number of reflux episodes on SART and LOSP and the results compared by the Mann Whitney $U$ test. Group 3 (Barretts) patients had longer periods of $\mathrm{pH}<4(\mathrm{p}=0.05)$, more reflux episodes on SART $(p<0.005)$, and lower LOSPs $(p<0.01)$, than patients in group 2 . Group 2 patients also differed significantly from those in group 1 on all three tests $(p<0 \cdot 01)$.

Barretts oesophagus is found in those patients with GOR who have unusually abnormal results on standard investigation.

F94

Barrett oesophagus: incidence of adenocarcinoma during long term follow up

A J CAMERon, B J OTT, AND W S PAYNe (INTRODUCED BY S F PHILLIPS) (Mayo Clinic, Rochester, Minnesota, USA) Barrett oesophagus (columnar lined oesophagus) is associated with adenocarcinoma of the oesophagus, but the risk of a patient with Barrett oesophagus subsequently developing adenocarcinoma has not been determined.

We therefore reviewed records of patients with a diagnosis of Barrett oesophagus from 1961 to 1979 . Cases were included if the endoscopist or pathologist found the junction between squamous and columnar mucosa to be $7 \mathrm{~cm}$ or more above the stomach, above the lower one third of the oesophagus, or $32 \mathrm{~cm}$ or less from the incisor teeth. Oesophageal biopsy proof of columnar mucosa was also required.

One hundred and twenty cases of Barrett oesophagus met these criteria. Eighteen $(15 \%)$ had adenocarcinoma at the time of initial Barrett diagnosis. Ninety eight per cent of the remaining 104 patients were traced in 1982-1983. Twenty five had died at mean age 73 years, one from metastatic adenocarcinoma of the oesophagus, two from complications after diaphragmatic hernia repair, and two after oesophageal haemorrhage. The other 20 patients died of unrelated causes. Seventy seven patients were alive with mean follow up of 8.5 years. One had multicentre oesophageal adenocarcinoma resected and is well five years later. The two patients developing adenocarcinoma did so six and 10 years after initial Barrett diagnosis. 
Patients with a Barrett oesophagus may have an adenocarcinoma at the time of initial presentation; but if they do not, the risk of subsequent development of this malignancy was only one per 441 patientyears of follow up.

\section{F95}

Safe outpatient dilatation of benign cesophageal strictures

M LEE, M M RAVENSCROFT, J R B GREEN, AND C H J SWAN (Department of Gastroenterology, City General Hospital, Stokeon-Trent) Three hundred and fifty five dilatations were performed on 97 patients presenting with benign oesophageal strictures between May 1976 and April 1983.

After anaesthetising the pharynx with Xylocaine spray and giving intravenous diazepam, Eder-Puestow (309 dilatations) or Celestin (46 dilatations) dilators were passed over a guide wire negotiated through the stricture using a flexible endoscope. Radiological screening was required on only four occasions to achieve safe guide wire placement and routine practice did not include chest radiography or restriction of oral intake after dilatation.

The majority of cases (79) were managed entirely as outpatient. Of the remaining 18 , seven were referred while in hospital, but subsequently treated as outpatient, and eight were admitted overnight because of frailty or social circumstances. Three patients bled significantly and were kept in for observation but each settled uneventfully. There were no other complications in the series and in particular, no evidence of perforation. We conclude that this method of oesophageal dilation is safe for outpatient use.

\section{F96}

Effects of bougie dilatation on oesophageal stricture size

J R BENNETT, D R SUTTON, J F PRICE, AND J F DYET (Hull Royal Infirmary, Hull) There is no quantitative information about the effect on stricture diameter of dilatation by bougies of different size and different design.

Initial studies in 32 patients with benign peptic oesophageal strictures showed that the stricture diameter could be equally well estimated using an endoscopic measuring device or a measured stream of barium radiologically. The largest opaque ball which would pass through the stricture was within two millimetres of the barium stream in 39 of 53 measurements, but on 11 occasions a ball more than $2 \mathrm{~cm}$ larger than the stream would pass, possibly indicating greater rigidity of these strictures.

After dilatations by Celestin, or EderPuestow bougies, or by prototype dilators, diameter on the seventh postdilatation day was almost always greater than on the first day (mean increase $1.3 \mathrm{~mm}$ ). The postdilatation diameter was $1-11 \mathrm{~mm}$ smaller than the maximum bougie passed, an indication of 'rebound' or elasticity. 'Rigid' strictures (with greater ball/stream differences) showed less difference between bougie size and ball diameter ('rebound').

This technique for measuring stricture diameter is a useful advance and indicates that it may be possible to categorise strictures in order to predict their likely response to dilatation.

\section{COLON CANCER}

F97-F104

\section{F97}

Expression of plasminogen activators in premalignant conditions of the colon

R ELLIOTT, $R$ W STEPHENS, AND W $F$ DOE (Department of Medicine and Clinical Science, John Curtin School of Medicine Research, Australian National University, Canberra, Australia) Two distinct plasminogen activating enzymes (HPA) can be identified on the basis of MW and function. The $66000 \mathrm{MW}$ type (HPA 66) found in endothelial cells, is mainly fibrinolytic while the $52000 \mathrm{MW}$ enzyme (HPA52) which is also fibrinolytic, is principally involved in tissue injury events, remodelling and cancer invasiveness. The purpose of this study was to determine the pattern of HPA expression in colonic conditions known to predispose to malignancy and to explore the potential of HPA52 expression in colonic tissue as a predictor of malignant change. The HPA types present in colorectal biopsies from normal mucosa, isolated adenomatous polyps, polyposis coli polyps, ulcerative colitis and frank carcinoma were separated by electrophoresis in polyacrylamide gels. A fibrin/agarose gel overlay was used to detect sites of enzyme activity as lytic bands. HPA66 was found in all the samples studied. HPA52 expression was seen in all 16 colon cancer specimens. None of the histologically normal mucosa from the same resected colons showed HPA52 activity. Three of five adenomatous polyps and eight of 10 polyps from a polyposis coli specimen showed HPA52 activity. All 10 biopsies of involved ulcerative colitis tissue showed HPA52 activity while histologically normal mucosa from ulcerative colitis patients showed only HPA66 activity. Biopsies from seven normal subjects expressed only the HPA66 enzyme. The finding of HPA52 expression in premalignant conditions of the colon, as well as in frank carcinoma, supports the hypothesis that expression of this enzyme may be an early correlate of the development of malignancy.

\section{F98}

Histochemical changes in colonic mucosubstances during carcinogenesis

o J TRAYNOR AND C B WOOD (Royal Postgraduate Medical School, Hammersmith Hospital, London) Histochemical and biochemical studies have shown that changes in the composition of mucosubstances occur in and around colonic carcinomas. Our aim was to determine how early and how widespread are the changes in colonic mucosubstances during experimental colonic carcinogenesis.

Seventy five Sprague Dawley rats were given weekly subcutaneous injections (20 $\mathrm{mg} / \mathrm{kg}$ ) of 1,2 dimethylhydrazine (DMH) for 16 weeks and 25 rats acted as controls. Groups of six treated rats plus two controls were killed at two week intervals from four to 16 weeks and then at four week intervals until tumours developed (28-36 weeks). Specimens of colonic mucosa were fixed in formaldehyde and stained by the high iron diamine-alcian blue method.

In the control rats goblet cells were abundant at all crypt levels and on the mucosal surface. Sulphated mucins (brown-black staining) predominated but small amounts of sialomucins (blue staining) were detected in places. In DMH treated rats there was a gradual but progressive aberration from normal. At four to eight weeks the goblet cells in the basal crypt regions were partly depleted of mucins and there was a shift from predominance of sulphomucins to coexistence of sulphomucins and sialomucins. A reduction in the number of goblet cells followed, at first, on the mucosal surface and later in the upper $1 / 3$ of the crypts, and was accompanied by gradual sialomucin predominance. By 28-36 weeks the 
mucosal surface was grossly irregular and devoid of goblet cells and the basal cells contained almost exclusively sialomucins.

We conclude that widespread changes occur in the goblet cells of the rat during colonic carcinogenesis and coincide with changes in the nature of the colonic mucosubstances.

\section{F99}

Histochemical demonstration of faecal sulphatase activity

J M RHODES, R R BLACK, R GALLIMORE, AND A SAVAGE (Departments of Medicine and Histopathology, Selly Oak Hospital, Birmingham) Active ulcerative colitis (UC) is associated with an unexplained reduction in colonic sulphomucins. As sulphation of mucins affects their physical properties and resistance to enzymatic degradation this may be pathogenically important by allowing penetration of the colonic mucosa by toxins or allergens. We have been investigating the possibility that the reduction in colonic sulphomucins may be due to faecal sulphatase activity.

Bacteria-free faecal filtrates were prepared from normal $(n=6)$, active UC $(n=6)$ and active Crohn's disease (CD) $(n=6)$ patients by homogenising faecal samples in $0.2 \mathrm{M}$ trisacetate buffer pH6.5 followed by centrifugation and filtration of supernatants through $0.22 \mu \mathrm{m}$ filters. The filtrates represented a 5-fold dilution of the original faecal samples. $5 \mu \mathrm{m}$ paraffin sections of rectal biopsies from patients with inactive UC $(n=6)$, inactive $C D$ $(n=6)$ and irritable bowel syndrome (controls) $(n=6)$ were mounted and then incubated in the faecal extracts (or buffer alone as control) for 24 hours at $37^{\circ} \mathrm{C}$. Sections were then washed, stained with high iron diamine (HID) (sulphomucins black) and alcian blue (AB) pH 2.5 (sialomucins blue) and graded blindly for staining intensity.

Sulphomucin (HID+ve) staining was markedly reduced by prior incubation in $5 / 6$ normal faecal extracts, $3 / 6$ UC extracts and 6/6 CD extracts. All but one of the desulphating faecal extracts also caused reduced sialomucin (AB) staining. One UC extract reproducibly and selectively abolished sulphomucin (HID) staining, converting all $\mathrm{HID}+\mathrm{ve}$ goblet cells to strong sialomucin (AB) staining in all of 30 normal, $U C$ and $C D$ biopsies tested. Addition of thimerasyl $0 \cdot 1 \mathrm{mg} / \mathrm{ml}$ to the faecal extracts completely inhibited desulphation while addition of sodium azide $0.3 \mathrm{mg} / \mathrm{ml}$ had no effect.

The conclusions are (i) normal faeces can desulphate rectal sulphomucins, probably enzymatically, and such desulphation is likely to be continually occurring in vivo; (ii) no difference in susceptibility to desulphation has been shown between normal, UC and CD rectal mucosa; (iii) all sulphomucin containing (HID+ve) goblet cells also contain siaolmucin, a fact which alters the interpretation of previous histochemical studies.

\section{F100}

Depression of interleukin-2 production by lamina propria lymphocytes in colon cancer

P G HOGAN, A J HAPEL, H WARREN, AND W F DOE (Department of Medicine and Clinical Science, John Curtin School of Medical Research, Australian National University, Canberra, Australia) Natural killer (NK) cells appear to be important in defence against neoplasia. They are characterised by their ability to kill tumour cells and by their dependence on the lymphokine interleukin 2 (IL-2) for their growth. Natural killer activity in peripheral blood is depressed in cancer patients. To test whether mucosal NK activity in colon cancer was also depressed and to determine whether the mechanism was diminised IL-2 production, lamina propria lymphocytes (LPL) were harvested by enzymatic disaggregation of mucosa resected for colon cancer and for nonmalignant conditions. When NK cells were assayed by release of ${ }^{51} \mathrm{Cr}$ labelled $\mathrm{K} 562$ cells, no activity was detectable in freshly isolated LPL from nine colon cancer specimens and only very low levels were assayed in six samples. In all 15 specimens, however, NK activity was inducible by culture of LPL in IL-2 containing medium. To test whether there was a deficiency in IL-2 production by LPL in colon cancer, LPL were stimulated with supramitogenic concentrations of PHA and the supernatants assayed for IL-2 in a proliferative assay using an IL-2 responsive cell line. Normal IL-2 production was found in LPL populations from all five benign mucosa, from two Duke's stage A and two Duke's stage B cancer specimens. LPL from four Duke's B and all five Dukes's C specimens failed to generate IL-2 even though these LPL populations were responsive to exogenous IL-2. Depression of IL-2 production was not due to alterations in the proportion of helper and suppressor cells as these were similar for LPL from all specimens.

These data suggest that NK cell activity is diminished or absent in invasive colon cancer mucosa, possibly because of depression of IL-2 production by LPL.

\section{F101}

Detection of gastrointestinal cancer in community centres by clinician, nurse, occult bloods and computer analysis

F T DE DOMBAL, J S WENHAM, J M BROWN, M PARKIN, K J A MILOSZEWSKI, AND G R GILES (University of Leeds, Leeds) Gastrointestinal cancer survival rates are poor, possibly due to diagnostic delay - ranging up to one year in many cases. Hospital studies have indicated that a structured case history, obtained by a non-medically qualified person and analysed by computer, might aid diagnosis, reduce delay, and thereby improve survival.

In order to assess if benefit could be obtained by earlier diagnosis in general practice, an unselected group of 468 patients (aged over 40 presenting with 'new' GI symptoms of over two weeks duration) were referred to special 'screening' clinics in five health centres. A structured interview was obtained from each patient by a nursing sister. The patient was examined by a clinician; and samples obtained for faecal occult blood (FOB) studies. The clinic data were analysed both by computer and by experienced clinician. If any mode was suspicious for cancer, appropriate investigations were arranged. All patients were followed up for a mean of over two years.

Of the 468 patients, 27 were found to have cancer, (and six to have benign colonic polyps). Of the 27 cancer patients, 26 were classified as 'suspicious' in the clinics, and referred for further investigation. The median delay between presentation and diagnosis was 31 days. Clinical analysis of the data obtained in the screening clinic detected 17 cancer patients, with 125 'false positive' referrals (half of whom on investigation had other disorders, warranting treatment, detected). Computer analysis of the nurse's data (plus FOB results) detected 23 cancer patient (and would have resulted in 85 'false positive' referrals).

It is concluded that structured interview, plus computer analysis, (plus FOB testing) is an effective means of detecting cancer (and other disease) in general practice. The effect on survival, however, may not be 
great. All patients with upper GI cancer died within one year, as did three patients with colorectal cancer.

\section{F102}

Clinical review of 87 cases of primary anal malignancy

P C PYPER AND T G PARKS (Department of Surgery, The Queen's University of Belfast, Belfast) Malignancy arising in the anal region is a rare condition and 87 cases presenting over a 23 year period have been studied. Treatment trends and factors leading to reduced survival have been emphasised.

Histology confirmed the presence of squamous carcinoma (anal canal 21, anal margin 12), cloacogenic carcinoma (35), melanoma (14) and basal cell carcinoma (five). Squamous carcinomas presented with bleeding $(23 / 33)$, pain $(19 / 33)$ or a mass (17/33). Fourteen died from their disease within five years but this does not include nine patients with short follow up, three of whom have recurrences. Patients with large (4 cm diameter), nonkeratinising tumours or involvement of inguinal nodes had reduced survival.

Cloacogenic carcinomas presented with bleeding (27/35), pain (20/35), altered bowel habit $(10 / 35)$ or a mass $(4 / 35)$. Twenty four patients had abdominoperineal excision while the rest had wide excision or no definitive treatment. Twenty patients died from their disease in less than five years and those with involved nodes had reduced survival. Fourteen cases of melanoma were studied. Survival was limited with 10 patients dying within one year.

The treatment recommended for cloacogenic carcinomas and squamous carcinomas of the anal canal is abdominoperineal excision. It is often feasible to treat squamous carcinomas of the anal verge and basal cell carcinomas by wide local excision. Patients with melanoma have poor survival whether radical surgery is undertaken or not.

\section{F103}

Adverse features of obstructing colorectal carcinoma

H C UMPLEBY J B BRISTOL, AND R C N williamson (University Department of Surgery, Bristol Royal Infirmary, Bristol) Factors contributing to the poor prognosis of acutely obstructing carcinomas of the large intestine were reviewed in 124 patients presenting over a six year period. The incidence was $19 \%$ of all patients with colorectal carcinoma $(n=646)$. Obstruction was complicated by perforation in 22 $(17 \%)$. Overall five-year survival rates were the same for perforated and nonperforated cases $(18 \%)$ ). Curative resection was feasible in 67 patients $(54 \%)$ with a five-year survival of $33 \%$. Sixty-seven per cent of tumour were Dukes' ' $C$ ' or ' $D$ '. There was a higher proportion of rectal tumours in perforated obstruction than non-perforated obstruction ( $36 \%$ vs $10 \%$ ). Rectal tumours had the poorest five-year survival and right colon tumours the best (5\% vs $36 \%$ ). Defunctioning colostomies were performed in 32 of the 67 patients (48\%) undergoing curative resection and were later closed in 20 , but there were six postoperative deaths; four from anastomotic dehiscence and faecal peritonitis. Overall diagnostic delay occurred in 11 cases $(9 \%)$, ranging from six weeks to two years (median eight months), and five of these were incurable at presentation. Reasons for diagnostic delay included inadequately investigated anaemia (five) and previous false-negative barium studies (four).

Acute obstructing colorectal carcinoma presents at an advanced stage in most patients but some improvement in survival may result from full investigation of unexplained anaemia and careful surgical technique.

\section{F104}

Five-year survival of 1115 patients with colorectal cancer

M J STOWER AND J D HARDCASTLE (Department of Surgery, University Hospital, Nottingham) A retrospective study of all the patients with colorectal cancer admitted to one hospital during the years 1970-1977 was undertaken. Analysis, including life table analysis was performed using SPSS subprogrammes.

One thousand, one hundred and fifteen patients were admitted with colorectal cancer; $51.9 \%$ were men and the mean age was $67.24( \pm 0.34$ SEM $)$ years. The primary was situated in the rectum in $44.2 \%$ of the patients. The Dukes' staging of all the tumours was: Stage A $6.0 \%$, stage B $37.0 \%$ and stage C $57.0 \%$. Liver metastases were present in $28.9 \%$ of the patients.

The minimum follow up period was five years, at which time $17.7 \%$ of the patients were alive, $69.0 \%$ had died of colorectal cancer, 9.0\% had died from other causes, and $4.3 \%$ were lost to follow up.

The overall cumulative five-year survival was $29.9 \%$ and the five-year survival of Dukes' stage A was $82.1 \%$, stage B $53.6 \%$ and stage $\mathrm{C} 12 \cdot 8 \%$.

Of the patients, $21.5 \%$ died during their first admission, and of these $61.7 \%$ had been admitted as an emergency; $70.4 \%$ were over 70 years old. These deaths also included $9.7 \%$ of the patients with Dukes' stage A lesions.

The poor survival figures are probably because of late presentation of many of the patients, who were often elderly and were admitted as an emergency.

\section{INTESTINAL MOTILITY}

F105-F112

\section{F105}

Proctometrogram: does it have a role in the evaluation of adults with chronic constipation?

D M PRESTON, P R H BARNES, AND J E LENNARD-JONES (St Mark's Hospital, City Road, London) The elastic properties of the lower rectum have been measured in 32 adults with chronic constiption. A proctometrogram was obtained by inflating a thin walled rubber balloon with water at a constant rate $(150 \mathrm{ml} / \mathrm{min})$ via an infusion pump. Pressure inside the balloon was measured using a separate miniature recording balloon connected to a pressure transducer. Bench testing showed the balloon made no contribution to any pressure rise during inflation between 30 and $2000 \mathrm{ml}$.

Three groups of patients were studied. Ten had idiopathic megacolon and 12 idiopathic constipation (IC) with a normal barium enema but increased gut transit time. Ten other patients with both normal barium enema and gut transit time were regarded as having the irritable bowel syndrome (IBS). These were compared with control subjects. The patients with megacolon had a much greater capacity and a flat curve with little pressure change. The patients with IBS had a steep curve with higher pressures than normals and tolerated a smaller maximum volume. The values for patients with IC approximated to the controls. For example, after inflation to $180 \mathrm{cc}$ rectal pressures were: controls 39.4 $\mathrm{cm} \mathrm{H}_{2} \mathrm{O} \pm 6 \cdot 5$ (SEM), megacolon 19.6 $\pm 3 \cdot 0$ $(p<0.01)$, IBS 81.5 $\pm 4.7(p<0.01)$ and IC 
44.8 \pm 3.5 (NS). All groups studied experi- F107

enced pain when the intrarectal pressure Motility of the ileocolonic region in healthy rose above $90 \mathrm{~cm} \mathrm{H}_{2} \mathrm{O}$. These results man

suggest that the proctometrogram may be a useful test to help differentiate patients with megacolon from other groups who complain of chronic constipation. Patients with normal rectal size and gut transit time (IBS) were less tolerant of rectal distension and this may reflect excess muscular activity. Rectal elasticity in patients with IC appears to be normal.

\section{F106}

Artificial colon

C A EDWARDS, B I DUERDEN, AND N W READ (Departments of Physiology and Medical Microbiology, University of Sheffield, Western Bank, Sheffield) Investigation of the metabolic function of the colon has been hampered by difficulties of access to the proximal colon. We therefore developed an in vitro model of the proximal colon consisting of a continuous anaerobic culture of faecal bacteria $(20-40 \mathrm{~g}$ fresh human faeces) in $300 \mathrm{ml}$ of medium, mimicking ileostomy effluent. Thirteen millilitres of fresh medium was pumped into the culture every hour to replace the excess culture pumped out. The $\mathrm{pH}$ was maintained constant by means of a pH stat unit controlling an infusion of sodium bicarbonate. Measurements of $\mathrm{pH}, \mathrm{Eh}$, osmolarity, production of volatile fatty acid (VFA) and ammonia were recorded daily and a daily semi-quantitative aerobic and anaerobic culture of bacteria was carried out. A steady state was usually reached after five to seven days and maintained for up to 25 days. At pH 5 the total VFA production $(12 \cdot 2 \pm 3 \cdot 1 \mathrm{mmol} / \mathrm{d}$ mean $\pm \mathrm{SEM}$ ) was less than at $\mathrm{pH} 7$ $(31.6 \pm 2.4 \mathrm{mmol} / \mathrm{d})$ or $\mathrm{pH} 6(31.1 \pm 1.8$ $\mathrm{mmol} / \mathrm{d} ; \mathrm{p}<0 \cdot 01)$. A greater proportion of the VFA was in the form of propionic acid at pH 6 (propionic $49 \pm 2 \%$, acetic $46 \pm 2 \%$ ) compared with pH 7, (propionic acid $28 \pm 3 \%$, acetic acid $71 \pm 3 \%$; $p<0.001$ ), though there was no difference in total VFA concentration. Increasing the carbohydrate in the medium increased total VFA production by $24.5 \pm 0.5 \mathrm{mmol} / \mathrm{d}$ $(p<0.01)$ in three cultures and removing the carbohydrate input decreased the VFA output in every case. Treatment with clindamycin reduced or eliminated the anaerobic bacteria and reduced the total VFA production by $16.8 \pm 3.1 \mathrm{mmol} / \mathrm{d}$ and the proprionic acid by $10 \cdot 7 \pm 2 \cdot 2 \mathrm{mmol} / \mathrm{d}$.
E M M QUIGLEY, T J BORODY, M WIENBECK, A C HADDAD, $R$ L TUCKER, AND S F PHILLIPS (Gastrointestinal Unit, Mayo Clinic and Foundation, Rochester, Minnesota, USA) Motility of the ileocolonic region of man has received scant attention. Dynamic descriptions of its contractile patterns including that of the ileocolonic sphincter (ICS) are unavailable. Our aim was to define fasting motility in terminal ileum, ICS and proximal colon.

A manometric assembly (total OD 0.7 $\mathrm{cm}$ ) of 11 perfused side hole catheters (ID $0.78 \mathrm{~mm}$ ) was introduced orally and positioned under fluoroscopic control. Six side holes at $1.5 \mathrm{~cm}$ intervals between 5 and $12.5 \mathrm{~cm}$ from the end were placed so as to straddle the ICS. Other sensors were at 0 , $17.5,22.5,32.5$ and $57.5 \mathrm{~cm}$. Pressure recordings were obtained for 5-9 hours from 15 fasting healthy volunteers.

Positioning of side holes was confirmed and monitored continuously by measuring the maximum frequency of phasic contractions $(6-7 / \mathrm{min}$ caecum, $8-9 / \mathrm{min}$ terminal ileum) and by fluoroscopy after each study. Patterns of motility differed from those of jejunum and proximal ileum. Most contractile activity lacked any apparent organisation (phase 2-like). Organised activity included: (1) Rare migrating motor complexes (MMCs); (2) Local MMC-like fronts of variable duration which commenced within the distal $30-40 \mathrm{~cm}$ of ileum and which were propagated aborally over distances of 5-10 cm; (3) Isolated high pressure contractions which began within $20 \mathrm{~cm}$ of the ICS and propagated rapidly (mean $68 \mathrm{~cm} / \mathrm{min}$ ). The MMC local MMClike fronts and high pressure waves crossed the ICS frequently and could be recognised in caecal records. Discrete tonic rises of pressure were not universal at the ICS and were usually of small magnitude (up to 20 $\mathrm{cm} \mathrm{H}_{2} \mathrm{O}$ ). These first dynamic observations show the ileocaecal region of healthy man to be unique; the motility should reflect the regions functional specialistion.

\section{F108}

Relationships between gastric emptying, intestinal transit and absorption after proctocolectomy with and without ileal resection

D E NEAL, M J BARKER, R F G J KING, AND N S WILLIAMS (INTRODUCED BY D JOHNSTON)
(University Department of Surgery, The General Infirmary, Leeds) Recent evidence suggests that the distal ileum may influence gastric emptying and small bowel transit, and by inference absorption. Alterations in these parameters may thus explain the high ileostomy output often seen in patients who have had quite modest ileal resections (IR) during proctocolectomy (PC). We therefore simultaneously measured gastric emptying, small intestinal transit and absorption of a standard meal in patients $(n=7)$ following PC and IR (69 \pm SE $6.4 \mathrm{~cm}$ excised) and in similar patients after $\mathrm{PC}$ alone $(\mathrm{n}=9)$. In all patients the remaining small bowel was normal.

Each patient received a solid meal of known composition labelled with ${ }^{99} \mathrm{Tc}$ DPTA. Gastric emptying rate (GE T⿱亠䒑 $)$ was measured by gamma camera and intestinal transit (SBT) by the time to recover $50 \%$ of the marker (corrected for GE T $\frac{1}{2}$ ). Concentrations of fat, carbohydrate, nitrogen, and electrolytes in the effluent were measured and corrected for marker recovered. The excretion of each, and hence absorption, was thus expressed as a percentage of that ingested.

Fat $(18 \pm 5 \%)$ and $\mathrm{N}_{2}$ excretion $(64 \pm 18 \%)$ after PC and IR were significantly greater than $\mathrm{PC}$ alone: fat $7 \pm 2 \%$; $\mathrm{N}_{2} 24 \pm 5 \%, p<0.05$. Gastric emptying rate, $106 \pm 25$ mins, SBT, $219 \pm 63$ mins after PC and IR were not, however, significantly different to PC alone, $89 \pm 30$ mins; $264 \pm 33$ mins.

Thus, modest resection of the distal ileum during PC results in malabsorption of fat and nitrogen but this cannot be explained by rapid gastric emptying or intestinal transit.

\section{F109}

What is enterogastrone?

M R LUCEY, P KWASOWSKI, J A H WASS, P D FAIRCLOUGH, AND L H REES (Department of Gastroenterolgy and Chemical Endrinology, St Bartholomew's Hospital, London; Department of Biochemistry, University of Surrey, Guildford, Surrey) Intraduodenal infusion of isotonic solutions of fat, but not protein or carbohydrate, inhibits gastric acid secretion in man. It is postulated that this effect is mediated by release of circulating hormones termed enterogastrones. GIP and somatostatin are candidates to be enterogastrones. We have studied the 
effect on plasma GIP and somatostatin of during a similar period at rest. The number intraduodenal infusion of nutrients in six and duration of MMCs were compared. fasting healthy male volunteers. Each In the resting group there were a total of subject received four separate 30 minute 20 MMCs during the study period with a infusions, at least one week apart, of median duration of 100 minutes (range isotonic solutions containing 100 calories of $66-144$ minutes). In the exercise group four (a) carbohydrate, (b) protein, or (c) fat and of the 10 subjects had no MMCs during the (d) a control solution of saline. Plasma GIP walk, the remainder had a total of ten with and somatostatin were measured by radio- a median duration of 150 minutes (range immunoassay. Plasma GIP rose markedly 75-240 minutes), significantly longer after carbohydrate basal $506 \pm 50 \mathrm{pg} / \mathrm{ml}, \quad(\mathrm{u}=42, \mathrm{p}=0.01)$ than that of the controls. peak $1480 \pm 120 \mathrm{pg} / \mathrm{ml}(\mathrm{p}<0.001)$ and In this study fasting jejunal activity was protein, peak $1200 \pm 190 \mathrm{pg} / \mathrm{ml}(\mathrm{p}<0.001)$ either abolished or significantly decreased but only moderately after fat, peak during continuous exercise thus showing $790 \pm 240(p<0.01)$. The rise in plasma the modification of gastrointestinal motility somatostatin was slight after carbohydrate by physical activity.

basal $30 \pm 3 \mathrm{pg} / \mathrm{ml}$, peak $46 \pm 16 \mathrm{pg} / \mathrm{ml}$ $(p<0 \cdot 05)$, greater after protein, peak $57 \pm 9$ $\mathrm{pg} / \mathrm{ml}(\mathrm{p}<0.05)$ and greatest after fat, peak $101 \pm 11 \mathrm{pg} / \mathrm{ml}(\mathrm{p}<0.001)$. Neither plasma GIP nor somatostatin rose during the control infusion.

We conclude that while fat is the least potent intraduodenal nutrient stimulus of M S YOULE AND N W READ (Department of plasma GIP release it is the most potent Physiology, University of Sheffield, stimulus of plasma somatostatin release. Sheffield) Diseases of the colon such as These data are consistent with the constipation and ulcerative colitis may be hypothesis that somatostatin rather than associated with upper gastrointestinal GIP circulates as an enterogastrone.

\section{F110}

Does exercise affect small bowel motility in man?

D F EVANS, G E FOSTER, AND J D HARDCASTLE (Department of Surgery, University Hospital, Nottingham) Little is known of the affects of physical activity on the migrating motor complex (MMC) of the small intestine because of difficulties of with the deflated probe in the rectum and recording from the ambulant subject. the ventilator switched on, but disconThere is evidence that psychological stress nected from the probe. Rectal distension inhibits the cycling of the MMC, in this caused significant delays in gastric study the effects of physical stress have emptying ( $t \frac{1}{2}$ distension $=89 \pm 10 v$ s control been examined.

$76 \pm 8 \mathrm{~min}, \mathrm{p}<0.001 ;$ mean $\pm \mathrm{SEM})$, and

Twenty fasted subjects swallowed a small bowel transit time (distention pressure sensitive radiotelemetry capsule $260 \pm 18$ vs control $216 \pm 24 \mathrm{~min}, \mathrm{p}<0 \cdot 001$; tethered in the proximal jejunum, mean \pm SEM). The effects on gastric pressures were recorded using a portable emptying were prevented by prior adminirecording system previously described. stration of $300 \mathrm{mg}$ ranitidine ( $\mathrm{t} \frac{1}{2}$ distension Jejunal motility patterns were examined in $53 \pm 7$; control $=60 \pm 11 \mathrm{~min}$ ), though the 10 subjects undertaking a brisk four hour treatment had no significant effect on small walk along a 12 mile course and in ten bowel transit (distension $303 \pm 22$ min; control $215 \pm 15, \mathrm{p}<0 \cdot 01)$. This study shows that intermittent painless rectal distension may delay small bowel transit and gastric emptying though the latter may be secondary to an increase in acid secretion.

\section{F112}

Development of fasting small intestinal motility in the human neonate

E WOZNIAK, T R FENTON, AND P J MILLA (Institute of Child Health, London) The ability of the human fetal and neonatal gut to move its luminal contents in the last trimester of gestation is well known, yet precise knowledge regarding the nature of intestinal motor activity in the human neonate is fragmentary.

Using constantly perfused naso-jejunal catheters we have studied fasting small intestinal motility in the human neonate. Eight premature infants born between 26 and 30 weeks gestation (mean 28 $\pm 0 \cdot 7$ SEM) were studied longitudinally between 26 and 36 weeks gestation. In the fasting state three stages of development were seen: (1) 26-30 (mean 28.5 \pm 0.7 ) weeks: disorganised random contractions; (2) 30 33 (mean $31 \cdot 2 \pm 0.3$ ) weeks: repetitive regular groups of contractions, (the fetal complex); (3) 33-36 (mean 34.5 $\pm 0 \cdot 8$ ) weeks: cyclical rhythmic $11 \mathrm{cpm}$ activity, (the migrating motor complex (MMC) pattern). It was striking that the onset of the ability to suck was coincident with the appearance of the MMC pattern. In three full term infants a well established cyclical MMC pattern was seen with easily discerned phase I and II activity. Phase III activity occurred at mean intervals of $44 \pm 12$ minutes, moved at a velocity of $3.05 \pm 0.9 \mathrm{~cm} / \mathrm{minute}$ and lasted for $10.9 \pm 3$ minutes.

Our studies show for the first time, a pattern of development of small intestinal motility which is in accord with previous human aminographic studies. It follows a similar pattern but a different time course, to studies in the experimental animal. The onset of sucking coincident with the appearance of the MMC pattern suggest that development of motility is closely related to neurological maturation. 